University of Louisville

ThinkIR: The University of Louisville's Institutional Repository

Electronic Theses and Dissertations

$12-2017$

\title{
An examination of school leaders' preferences for teacher applicant characteristics.
}

Byron Keith Davis

University of Louisville

Follow this and additional works at: https://ir.library.louisville.edu/etd

Part of the Education Commons

\section{Recommended Citation}

Davis, Byron Keith, "An examination of school leaders' preferences for teacher applicant characteristics." (2017). Electronic Theses and Dissertations. Paper 2873.

https://doi.org/10.18297/etd/2873

This Doctoral Dissertation is brought to you for free and open access by ThinkIR: The University of Louisville's Institutional Repository. It has been accepted for inclusion in Electronic Theses and Dissertations by an authorized administrator of ThinkIR: The University of Louisville's Institutional Repository. This title appears here courtesy of the author, who has retained all other copyrights. For more information, please contact thinkir@louisville.edu. 


\title{
AN EXAMINATION OF SCHOOL LEADERS' PREFERENCES FOR TEACHER APPLICANT CHARACTERISTICS
}

\author{
By \\ Byron Keith Davis \\ B.S., Western Kentucky University, 1990 \\ M.A.Ed., Western Kentucky University, 1991
}

\author{
A Dissertation \\ Submitted to the Faculty of the \\ College of Education and Human Development of the \\ University of Louisville \\ in Partial Fulfillment of the Requirements \\ for the Degree of \\ Doctor of Education in \\ Educational Leadership and Organizational Development
}

Educational Leadership, Evaluation, and Organizational Development University of Louisville

Louisville, Kentucky 
Copyright 2017 by Byron Keith Davis

All rights reserved 

AN EXAMINATION OF SCHOOL LEADERS' PREFERENCES FOR TEACHER APPLICANT CHARACTERISTICS

\author{
By \\ Byron Keith Davis \\ B.S., Western Kentucky University, 1990 \\ M.A.Ed., Western Kentucky University, 1991
}

A Dissertation Approved on

November 20, 2017

by the following Dissertation Committee:

\begin{tabular}{c}
\hline $\begin{array}{c}\text { Dissertation Director } \\
\text { W. Kyle Ingle }\end{array}$ \\
\hline Harrie Buecker \\
\hline Namok Choi \\
\hline Blake Haselton
\end{tabular}

Amy Lingo 


\section{DEDICATION}

To my wife, Kellie, for her encouragement and patience and to Braydn and Jude for keeping her company.

To my sons, William and Daniel, who are the best of me, but far better.

To my mother, Judy Spurgeon, my first and greatest supporter.

To my uncle, Morris Ingram, for being an example.

To my best friend Tim Janes, my constant fellow on life's journey. 


\section{ACKNOWLEDGEMENTS}

The fact that this dissertation is complete is due to the tremendous encouragement and support of a whole host of individuals that have provided assistance, favors, and a good solid push every so often. First, Dr. Kyle Ingle, my Chair. I first met him at a Churchill Downs event when I was considering making another run at completing the doctorate. His intelligence, manner, and perspective set me at ease. In the intervening years, I've also seen his more demanding and persistent side, which was exactly what I needed. He is a scholar and a fine human being. The man responsible for my meeting Dr. Ingle was a long-time mentor, Dr. Blake Haselton. Dr. Haselton has been encouraging and inspiring me since I was a young administrator, and he was the man I went to see when considering a return to University of Louisville. His collegial nature and wisdom have made a tremendous difference in my career prior to this endeavor, and his advice during this process has been invaluable. Dr. Namok Choi came to speak to our class one evening. She was obviously very accomplished, and agreed to be my methodologist. In what was probably far too many meetings for her taste, she used gentle prodding, encouragement, and a very subtle sense of humor to help me through the technical aspect of this work, and provided keen insight into the world of academia. Dr. Harrie Buecker has been a long-time

friend and fellow superintendent. She was always willing to listen and encourage 
when I felt like there was no way I would ever possibly finish. Finally, I only recently met Dr. Amy Lingo through partnership work between my district and U of L, but from the very first meeting, I was completely impressed with her enthusiasm and willingness to make things happen.

There were many people along the way that have played a part in forming me as a professional. First, there was my mother, my first teacher, who read to me, loved me, and treated me like an intelligent human being even as a young child. There was my $7^{\text {th }}$ grade teacher, Mr. Baron, who was the first to encourage me in leadership. There was Mrs. Wilma Gumm, my $9^{\text {th }}$ grade English teacher, who made a positive off-hand comment about an insight I expressed that has stuck with me all these years. There is Dr. Nancy Minix from WKU, who saw a teacher and leader in me that I did not even know existed. Mr. Larry Watkins, my first principal, gave a 22 year old kid tremendous opportunities for growth and development. Mr. John Rowland, who hired me to be his assistant principal, who taught me that you could be a decent human being and maintain high standards. Michael Eberbaugh, my predecessor as superintendent, gave me chances, trusted me with incredible responsibility, and taught me much about management and motivation. A number of Board members, particularly my friend Sammy Allen, gave a young guy a chance to make one of the largest school districts in the state a better place for kids and stuck by me through thick and thin. My colleagues in Bullitt County Schools have been incredible in shaping me as a leader through their dedication, intelligence, and tremendous work ethic. I have been very fortunate to work with some of the very best of people, who have tolerated and 
mitigated some of my bad ideas, improved and brought to life some of my good ones, have been patient with me when I was impatient with the process, and in general kept us moving forward.

Finally, I must acknowledge the support and sacrifice of my family, especially my wife and all our children. There have been many weekends spent buried in research and writing. I have missed a few things I needed to attend, I've been distracted when I should have been attentive, and I've be short-fused when faced with hard deadlines and pressures at work. Through it all, my family has been understanding and encouraging. Many times, making them proud was what made me keep putting one foot in front of the other. 


\begin{abstract}
AN EXAMINATION OF SCHOOL LEADERS' PREFERENCES FOR TEACHER APPLICANT CHARACTERISTICS
\end{abstract}

\author{
Byron Keith Davis
}

November 20, 2017

Teachers are important to student achievement. The selection of teachers in most schools in the United States is the responsibility of the principal. This study examined preferences of school leaders for teacher applicant characteristics. An exploratory factor analysis of the results $(\mathrm{N}=209)$ of the Preferred Teacher Applicant Characteristics Survey (PTACS) determined four underlying dimension of the PTACS instrument: personal characteristics, professional characteristics, ancillary characteristics, and demographic characteristics. These became the dependent variable in a series of linear multiple regression analyses to examine the relationship between a school's characteristics - poverty, school performance category, average teacher experience, and the school leader's age, gender, current role and years in current role - and a school leader' preferences for teacher applicant characteristics. Study results indicated a significant positive change in a school leader's preference for personal teacher applicant characteristics for female school leaders as compared to male school leaders. 


\section{TABLE OF CONTENTS}

PAGE

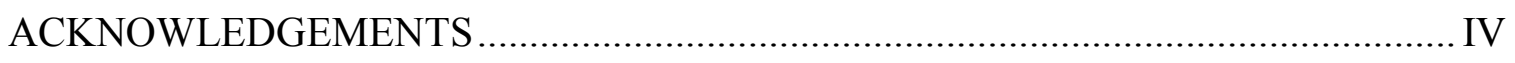

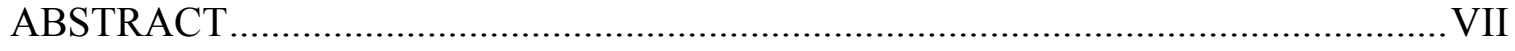

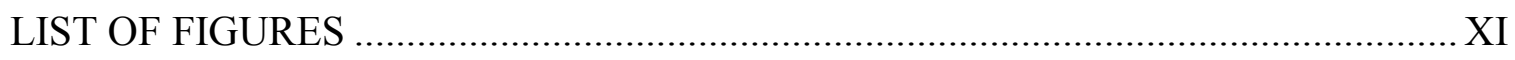

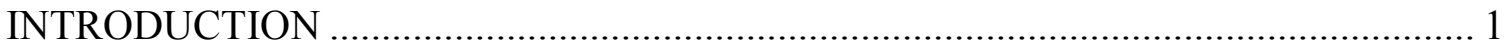

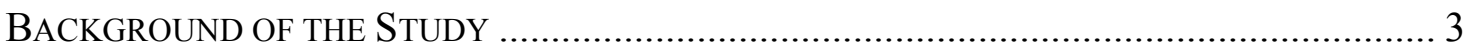

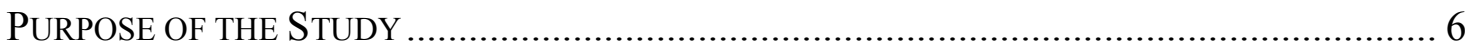

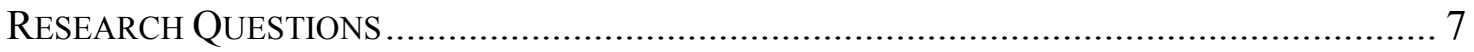

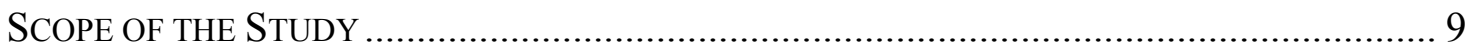

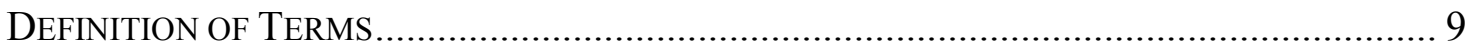

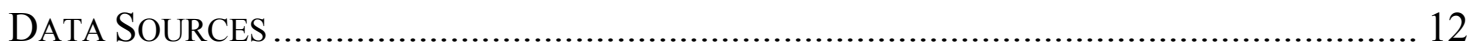

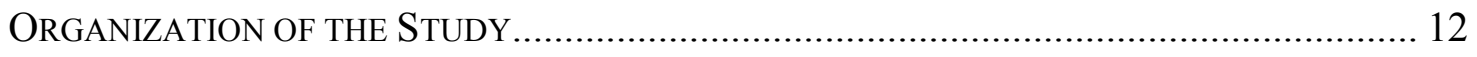

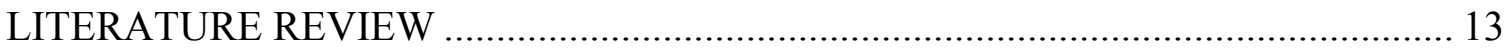

RESEARCH QUESTIONS................................................................................ 14

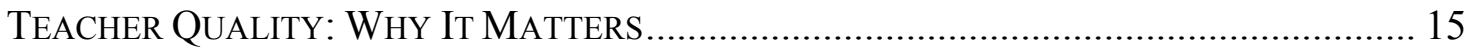

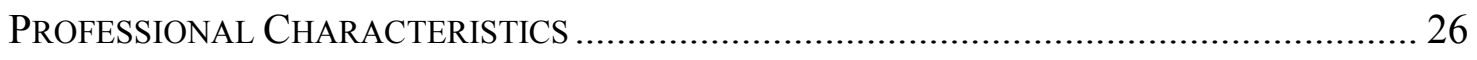

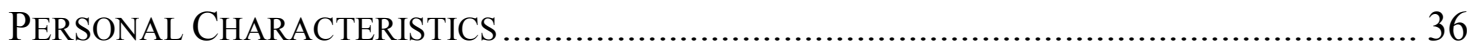

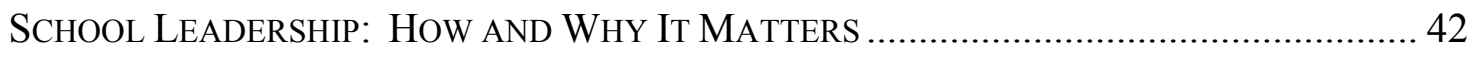




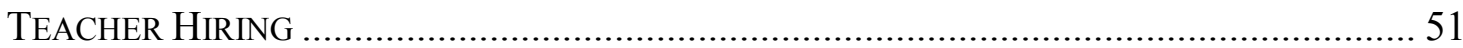

PrinciPal Preferences of TEACHER Characteristics IN HiRING............................ 59

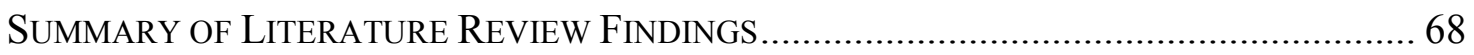

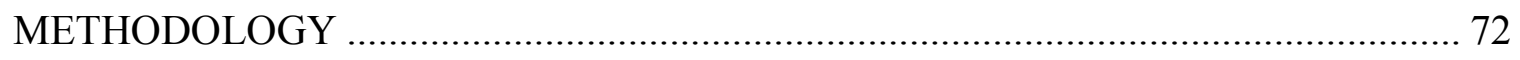

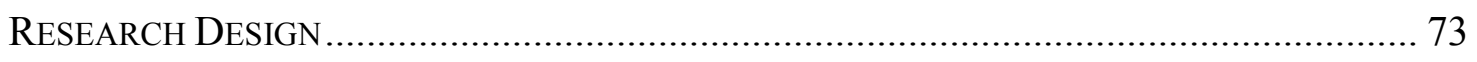

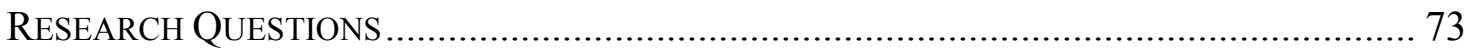

Conceptual Framework: School Leader Perceptions ANd HiRing ...................... 74

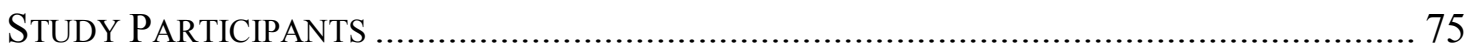

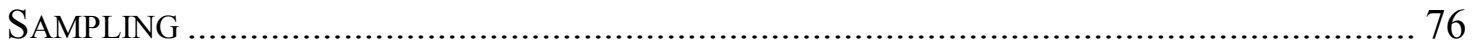

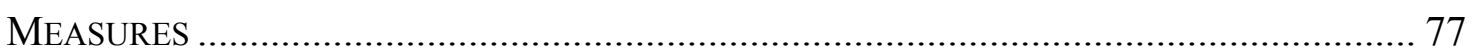

Preferred Teacher Applicant Characteristics Survey (PTACS) ................................ 77

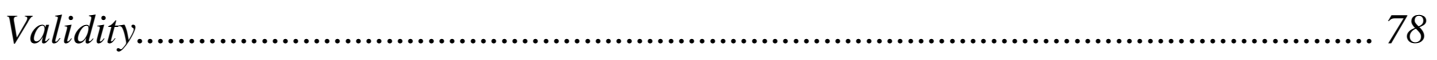

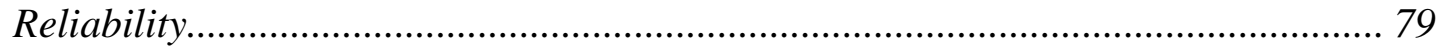

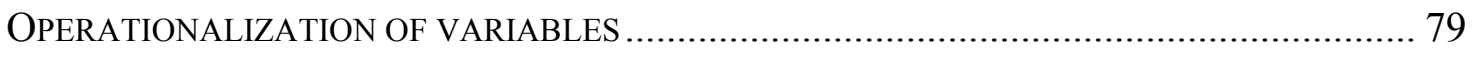

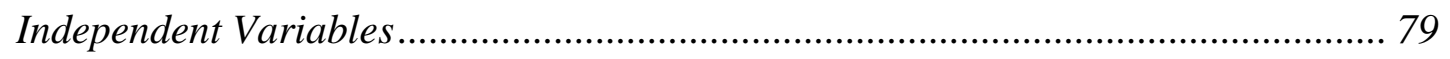

Dependent Variable ……………………........................................................... 81

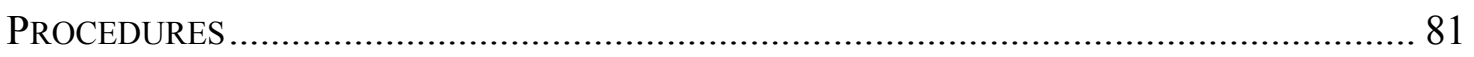

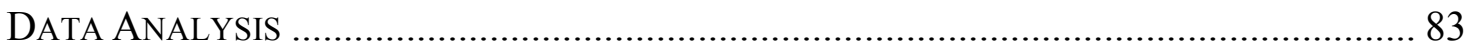

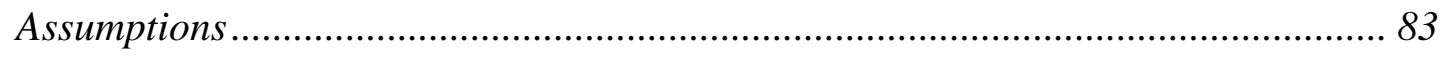

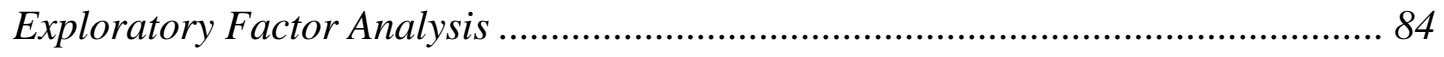

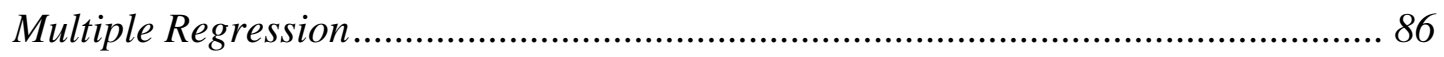

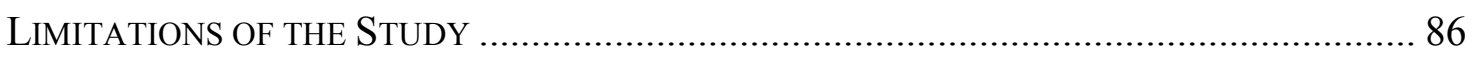

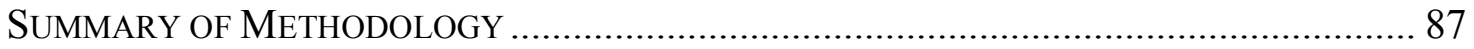




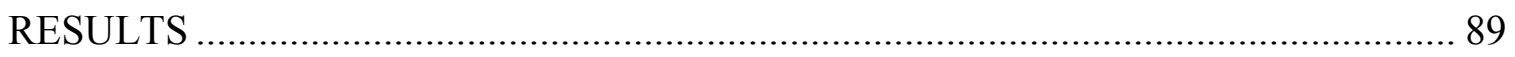

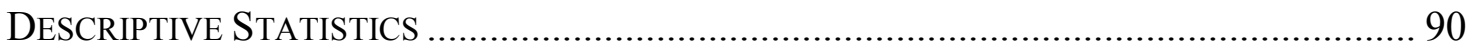

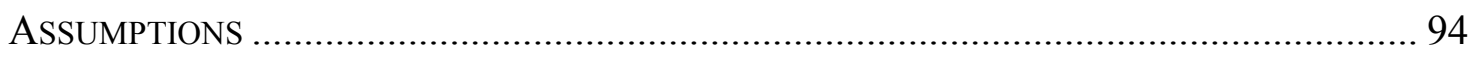

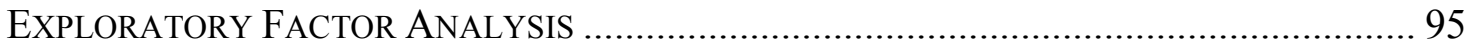

Factor Structure of Preferred Applicant Characteristics.......................................... 96

Reliability Analysis of Constructed Dependent Variables ..................................... 100

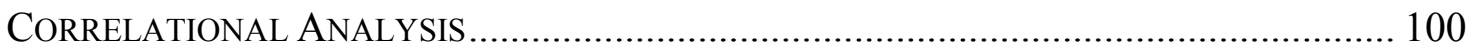

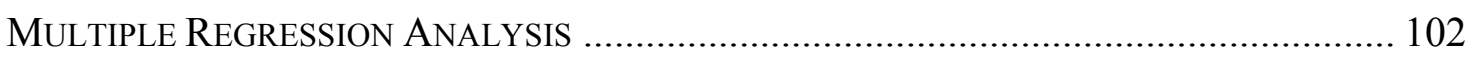

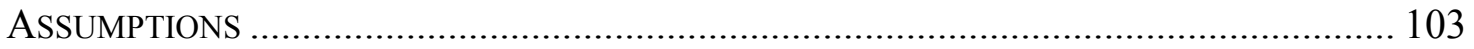

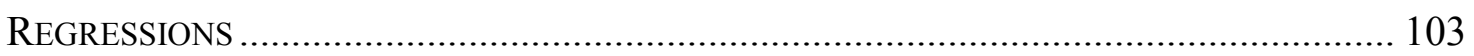

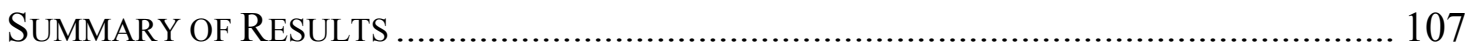

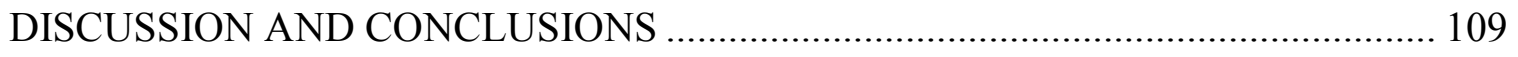

CONCEPTUAL FRAMEWORK AND LIMITATIONS ..................................................... 112

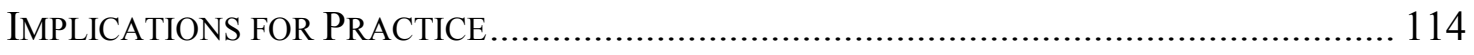

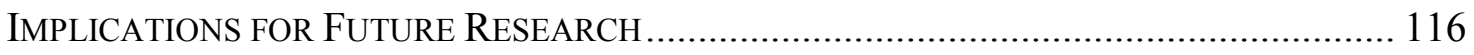

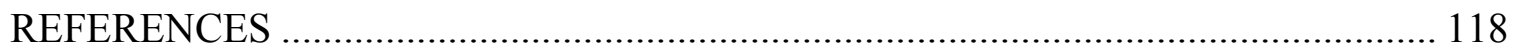

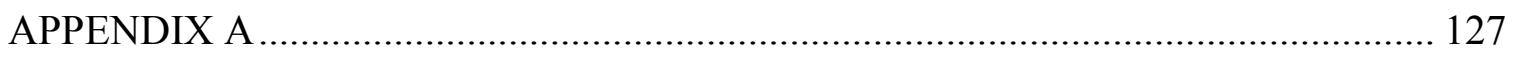

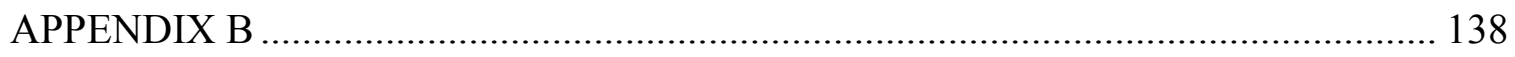

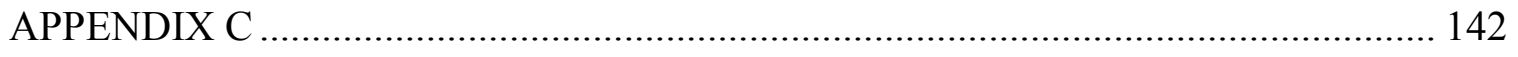

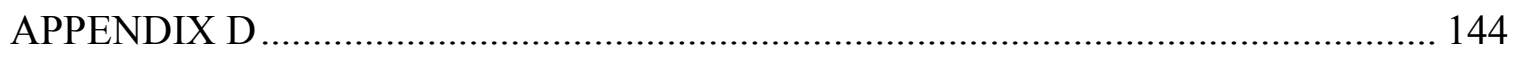

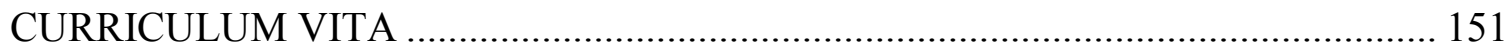




\section{LIST OF FIGURES}

Figure 1. Conceptual Framework for School Factors and

Preferred Teacher Characteristics ................................................................ 75

Figure 2. Age distribution of PTACS respondents...................................................... 92 


\section{CHAPTER I}

\section{INTRODUCTION}

A single fact animates much of the work of educational leaders in today's environment of high stakes accountability: teachers matter to student achievement. Having a good teacher in a classroom can positively impact student outcomes; not just during the time the student is under the tutelage of a particular teacher, but in subsequent grades and beyond (Chamberlain, 2013; Chetty, Friedman, \& Rockoff, 2014). The weighty questions for educational leaders are what makes a good teacher and how can one attract and retain more of them in their schools?

In 2015, the US Congress passed and President Barack Obama signed into law the Every Student Succeeds Act (ESSA). This law replaced the 2001 No Child Left Behind Act (NCLB), and was widely viewed as the result of backlash against federal overreach in educational policy (Usdan, 2016). One of the major features of NCLB was to require every teacher in core academic subjects to be "highly qualified," defined as having at least a bachelor's degree, passing a subject matter test in their instructional area, and obtaining required state certification (Association for Supervision and Curriculum Development, 2015). The law was also very prescriptive regarding professional development offerings and later, through waiver proposals submitted by the states, on teacher evaluation systems. ESSA rolled back many of the state requirements related to teacher quality, leaving it to state legislatures and state education agencies to manage 
teacher quality, professional development, and evaluation. ESSA retains much of the same testing and reporting requirements as NCLB, so the pressure to ensure that students are taught by highly effective teachers in order for students to perform well remains vital. This fact makes it necessary to understand why teacher quality is important; specifically what characteristics make up a high quality teacher, and how to recognize those characteristics when making hiring decisions.

Student achievement can mean many different things other than the results from the regimen of annual testing that is required in U.S. K-12 educational systems. Students in K-12 need teachers who have the knowledge and expertise to deliver academic content, but who also are able to present that content in such a way that students actually learn and retain it (Darling-Hammond 2000; Harris \& Sass, 2014; Monk 1994). It is not enough to be an expert in a particular academic subject. A teacher must be able to manage the classroom environment, design lessons that engage students' interest, make content connections to other disciplines and the wider world, work in teams of other teachers to develop curriculum, analyze assessment data, engage in ongoing formative assessment while delivering instruction, design and deliver instructional modifications for students with disabilities, attend to the need for additional rigor for the highest achieving students, communicate with parents, engage with the wider community, complete all the mundane - but necessary - management tasks, and get his or her students to the cafeteria precisely on time. The best teachers also inspire their students, take a personal interest in their lives, display a friendly sternness, and set a good example as both a person and a life-long learner. Finding individuals to accomplish all these things, keep on doing them 
year after year with a high level of enthusiasm, and do so within budgetary constraints is the task of school leaders, both at the district and school level.

\section{Background of the Study}

The results of myriad studies seem to have laid to rest the question of whether teachers matter to student achievement in the affirmative (Aaronson \& Sander, 2007; Harris \& Sass, 2014; Konstantopoulos, 2011; Rivkin, Hanushek, \& Kain, 2005; Sass, Hannaway, $\mathrm{Xu}$, Figlio, \& Feng, 2012). If this is true, then among the many other questions that arise from this conclusion, we must ask how we ensure that we select the most effective teachers to staff our nation's classrooms. To answer this question, it is important to have an understanding of a number of other issues. First, how do we know that one teacher is more effective in increasing student achievement? This begs another obvious question of how we define student achievement. There are many objections to the use of standardized test scores to define student outcomes, but most studies have settled on this measure as one that is widely available and generally accepted by practitioners and the public, though standardized test scores are imperfect measures. While this is the reality, teachers bring much more to the education of their students than simply preparing them for standardized tests, and this is largely unmeasurable using the administrative data that is widely available and convenient in the sense that it can be expressed numerically. In a recent qualitative study of honors students, Siegle, Rubenstein, and Mitchell (2014) found that students valued teachers who took a personal interest in them and instilled a sense of empowerment and connection. While this likely does not influence performance on standardized tests, these tests simply cannot measure intangible lessons teachers may teach, such as grit, curiosity, 
risk-taking, and higher-level thinking - all of which may contribute heavily to future student success. Within this conversation, it should be mentioned that there are factors other than the teacher which have an effect on student achievement and how these factors interact. From the earliest investigations, researchers have found that family, community, and peer group effects contribute to student performance on standardized tests (Coleman et al., 1966; Pokropek, \& Sikora, 2015).

Second, I examined what teacher personal and professional characteristics appear to be important in raising student achievement. Studies are mixed, and the correlations are relatively weak, but there is some consistency regarding the finding that experience as a teacher matters - and in several studies that was the only independent variable that made a significant difference (Clotfelter, Ladd, \& Vigdor, 2007; Jepsen, 2005). Other researchers, including Andrew, Cobb, \& Giampietro (2005), Hanushek (1971), and Harris and Rutledge (2010), note that teacher verbal ability or general intelligence are important factors in increasing student achievement. Siegle, Rubenstein, and Mitchell (2014) found that social ability and intellectual dexterity were important factors in motivating students toward higher performance. Hanushek (1971), though, nicely sums up the state of research on the characteristics that make an effective teacher all these years later by noting that the standard set of variables widely available on teachers and classrooms are insufficient to explain a large part of teaching and learning.

Another area that illuminates the topic of increasing student achievement is the effect that school leaders have in this area, and what factors of leadership appear to make a difference in raising student achievement levels. Most of the existing research points to the positive relationship between instructional leadership and student achievement 
(Horng, Klasik, \& Loeb, 2010; Karadag, Bektas, Cogaltay \& Yalcin, 2015; Robinson, Lloyd, \& Rowe, 2008). Grissom (2011) found that principals - especially in disadvantaged schools - have a significant role in reducing teacher attrition. Finally, in a contrary finding to that related to teacher characteristics, Dhuey and Smith (2014) found no significant relationship between principal and student achievement.

If it is true that one of the major influences of school leadership on student achievement is the selection of high quality teachers - defined as teachers who increase student achievement - it requires an explanation of the processes by which school leaders actually select teachers. At the district level, the most important role is attracting teacher candidates for possible selection (Balter \& Duncombe, 2008; Lee, 2005), but in the prevailing decentralized hiring system, districts also perform an important screening role (Liu and Johnson, 2006; Young and Delli, 2002). At the school level, there appears to be little ability during the interview process to identify those characteristics that will lead to increased student achievement, and most of the hiring decisions are made based on organizational fit (Ballou, 1996; Broadley \& Broadley, 2004).

At the moment of making selection decisions, it seems clear that school leaders weigh numerous factors. The process is highly subjective and at this stage; a great deal of personal and professional judgement comes to bear on the process. After considering credentials, undergraduate GPAs, certifications, and all the other objective facts before them, a decision must be made and this decision can have wide ranging implications on the school, the colleagues of the teacher selected, the students, and the community. This impact can be one that is felt for many years in ways that are impossible to predict. For a decision of such import, what are the factors at play? To state it another way, what 
personal and professional characteristics are important to school leaders when deciding which teaching candidate to employ? There has been some important and illuminating research conducted regarding principal preferences of particular teacher characteristics (Engel, 2008; Engel, 2013; Harris, Rutledge, Ingle, \& Thompson, 2010; Liu, Liu, Stronge, \& Xu, 2016; Rutledge, Harris, \& Ingle, 2010) To summarize the extant research, school and district context has considerable influence on school leaders' preferred characteristics, and that the process can be highly subjective, though there are some common themes identified in the literature. This study sought to add to this literature by further examining school leaders' preferences regarding teacher personal and professional characteristics in the context of suburban and rural school districts in a largely rural state.

\section{Purpose of the Study}

In this quantitative study, I sought to determine the qualities and characteristics valued by school leaders in suburban and rural school districts when hiring teachers, and whether those valued characteristics varied based on the demographics of the school or background of the school leader. This study extends the mixed method research conducted in a large and medium sized urban school districts (Engel, 2008; Engel, 2013; Harris, Rutledge, Ingle, \& Thompson, 2010; Rutledge, Harris, \& Ingle, 2010). I used survey data collected from principals and assistant principals in suburban and rural districts in a largely rural state in the southeastern U.S. I sought to advance the knowledge in the field by adding data from a different context to the research on school leaders' preferences regarding teacher qualities and characteristics. By conducting this research, I intended to determine if the perception of important teacher qualities and 
characteristics based on school performance or poverty vary in the same manner in a suburban or rural setting as they do in a large urban setting. If so, the findings would necessitate further research into the appropriateness of such distinctions, and this research may inform and assist school leaders in making teacher selections that will best advance student academic achievement. In order to extend the research further, I sought to add demographic characteristics to determine if school factors or school leader backgrounds have any relationship to school leader preferences for particular teacher qualities and characteristics.

\section{Research Questions}

In this study, I answered the following research questions:

- What are the underlying dimensions on the Preferred Teacher Applicant Characteristics Survey (PTACS)?

- Is there a relationship between a school's characteristics (poverty, school performance category, average teacher experience, and the school leader's age, gender, current role, and years in current role) and a school leaders' preferences for teacher applicant characteristics?

There are a variety of reasons that specific teacher applicant characteristics may appeal to school leaders differently depending on their individual and school contexts. Though this is an exploratory study in the context of suburban and rural schools, the literature provided a sound theoretical framework on which to develop the hypotheses. The specific analysis on how demographic characteristics of a school leader or the school context in which that leader works have not been fully explored and form the foundation of this study. For example, it is possible that suburban school leaders in high wealth 
schools prefer a teacher who appears to be more collegial with the school community, where a school leader in a lower wealth school may prefer a teacher applicant who focuses on raising achievement scores. Similarly, a school leader working in a high school may be more interested in a teacher applicant's level of content knowledge than a school leader working at the elementary level. As a final example, a school leader in a school with higher teacher turnover may be more interested in a candidate who exhibits strong caring traits in hopes that the teacher stays in what may be a more difficult environment.

To examine whether these relationships exist and the strength of any such relationships, once the underlying dimensions were identified and named, I examined:

1. The relationship between a school's characteristics (poverty, school performance category, average teacher experience, and the school leader's age, gender, current role, and years in current role) and the school leader's preferences for teacher candidate's personal characteristics.

2. The relationship between a school's characteristics (poverty, school performance category, average teacher experience, and the school leader's age, gender, current role, and years in current role) and the school leader's preferences for teacher candidate's professional characteristics.

3. The relationship between a school's characteristics (poverty, school performance category, average teacher experience, and the school leader's age, gender, current role, and years in current role) and the school leader's preferences for teacher candidate's ancillary characteristics. 
4. The relationship between a school's characteristics (poverty, school performance category, average teacher experience, and the school leader's age, gender, current role, and years in current role) and the school leader's preferences for teacher candidate's demographic characteristics.

\section{Scope of the Study}

This study used survey data collected from principals and assistant principals of 12 suburban and rural school districts that surround two large urban school districts in Kentucky. The districts surveyed are significantly less diverse than the urban districts

they surround, as well as being significantly smaller, ranging in size from 650 to 14,000 students.

The surveys were administered in the summer of 2017, collecting cross-sectional data for that point in time only. This was done purposefully in order to capture school leaders' preferences at a time of the year in which they were likely be in the midst of the hiring process for the upcoming school year and thereby may have considered this survey and any post-survey discussion as relevant to their current duties and less of an imposition on their valuable time. The survey data contained a number of demographic questions, but there were no items published that linked individual respondents, their schools, or districts to their preferences.

\section{Definition of Terms}

Since researchers and educators bring their own background knowledge to ascribe nuance to the meaning of certain terms, it is critical that clear definitions be provided in the context of this study. These terms are defined below. 
Certification: A license granted by a state agency that allows an individual to be a teacher in that state's public elementary and secondary schools. The certificate is granted after fulfillment of various requirements including securing of a bachelor's degree in an approved program and achieving an acceptable score on certain tests or examinations.

Classroom Environment: The set of circumstances created by classroom teachers through their interactions with their students that influence student learning, including the physical structure of the class, decoration, level of organization, mode and method of interacting with students and between students, and academic and behavioral focus. Classroom Practices: A teacher's method of organizing and delivering instructional content.

Credentials: Diplomas, certificates, licenses, endorsements, or other evidence of a teacher's professional attainment.

Efficacy: The power to produce a desired result or effect.

Enthusiasm: Strong excitement about something; a strong feeling of active interest in something that one likes or enjoys.

Hiring Preferences: The expression of the greater desire, by an individual charged with making employment decisions, for a particular characteristic over an alternate characteristic.

Hiring Process: The method by which an organization, in this case a school district or a school, selects and employs teachers.

Leadership: The actions and attitude of an individual that leads to positive organizational outcomes. 
Personal Characteristics: Traits or behaviors - either innate or learned - possessed by an individual which are applicable across any number of settings or roles and existing regardless of professional preparation or training.

Poverty Rate: The percentage of students attending a school who qualify for free or reduced priced meals under guidelines set by the USDA National School Lunch Program Professional Characteristics: Traits or behaviors an individual displays or employs in completing an individual's professional responsibilities.

Recruitment: The method by which organizations attract applicants for employment for positions within that organization.

School Leaders: Individuals, such as principals and assistant principals, who are charged with the management and operation of an elementary or secondary school.

School Performance Level: In Kentucky, schools are rated as Need Improvement, Proficient, or Distinguished according to the state school accountability system, with Distinguished being the highest performance designation.

Student Achievement: A student's knowledge and preparedness for future endeavors. Subjective Rating: Performance evaluation of teacher performance composed of nonfactual indicators.

Teacher: An employee of an educational institution whose job is to deliver curriculum to students through classroom instruction.

Teacher Characteristics: A personal or professional trait or property that serves to distinguish one teacher from another.

Teacher Effectiveness: The ability of a teacher to increase a student's knowledge and preparedness for future endeavors. 
Teacher Evaluation: The method by which a teacher is measured and categorized according to predetermined preferred outcomes.

Teacher Selection: The method whereby a hiring authority decides among a variety of candidates for a teaching position when employing a teacher.

\section{Data Sources}

Survey data for this study were obtained from principals and assistant principals in the 12 rural and suburban school districts surrounding two urban districts in Kentucky. The number of possible respondents was approximately 300 , once all school district superintendents provided permission to collect data. The data were collected during the summer of 2017.

\section{Organization of the Study}

Chapter 1 includes the introduction, purpose, statement of research questions and attendant hypotheses, scope of the study, definition of terms, data sources, and a description of the organizational structure of the study. Chapter 2 reviews the existing literature that pertains to the teacher characteristics and the relative importance of those characteristics to individuals who select teachers for employment. Chapter 3 explains the research methodology, the data collection protocol, and procedures for analysis. Chapter 4 is a presentation of the findings from that analysis and a discussion of the results of the study. Chapter 5 concludes the study with a summary of major findings, possible implications for practice, and recommendations for future research. 


\section{CHAPTER II}

\section{LITERATURE REVIEW}

The story of American education is filled with peaks and valleys. Even before the adoption of the US Constitution, American leaders understood the need for public education in a growing nation. The Ordinance of 1785 proposed by Thomas Jefferson, made specific provision for setting aside one 640 acre tract of land in each township to benefit public education (Carleton, 2002). The same founding father, in a letter to Charles Yancy (Jefferson, 1816), noted his commitment to educating the nation's citizens by stating "If a nation expects to be ignorant and free, in a state of civilization, it expects what never was and never will be" (p. 4). The National Commission on Excellence in Education's publication of A Nation at Risk (United States, 1983) was highly critical of US public education, including teacher quality and preparation. This publication became a rallying cry for reformers, and was at least indirectly responsible for many of the subsequent efforts to address these concerns.

Even given the substantial reforms and increased expenditures, public confidence in public education continues its incremental decline from 58\% in 1972 to $30 \%$ in 2016 (Norman, 2016). This is evidenced by proponents of charter and private schools, including former Florida governor and presidential candidate Jeb Bush (2014), along with persistent low achievement scores among too many children from minority and poor

families (Bohrnstedt, Kitmitto, Ogut, Sherman, \& Chan, 2015). Despite policy efforts to 
strengthen charters and private schools, the job of educating the next generation of US children remains primarily that of public schools, the administrators who lead them, and the teachers who teach in them. Changing expectations of teachers and varying demographic characteristics of the schools in our communities make selecting the "best" teachers one of the most important tasks of school leadership - specifically the principal.

There have been many studies attempting to quantify the attributes of what it means to be an effective teacher, and still others that extend these investigation into what defines the qualities of effective teachers. In terms of individual principal decisionmaking and hiring decisions, how much of that research is brought to bear? Do principals consider the research, do they focus on attributes easiest to see, or do they go with their instincts after the interviews are concluded? Does the location, demographics, or the aggregate performance level of the school have any effect on these decisions? Researchers (Engel, 2008; Engel, 2013; Liu, Liu, Stonge, \& Xu, 2016; Harris, Rutledge, Ingle, \& Thompson, 2010; Rutledge, Harris, \& Ingle, 2010) have sought to shed light on these questions, but further research is needed, concentrating on principals in less urban areas who may have differing pressures and considerations based on their districts' relative size and level of local political pressures.

\section{Research Questions}

There are two research questions in this study. The first research question is to determine the underlying dimensions of the Preferred Teacher Applicant Characteristics Survey (PTACS) instrument. The second research questions was to examine the relationship between a school's characteristics (poverty, school performance category, 
average teacher experience, and the school leader's age, gender, current role, and years in current role) and a school leaders' preferences for teacher applicant characteristics?

To frame this study, I reviewed the literature around a number of critical areas surrounding principals' preferences for teacher characteristics in hiring. I began with a review of teacher quality and why it matters in our schools and followed this with a discussion of the characteristics and relative levels of these characteristics' importance in the effectiveness of teachers, both professional characteristics and personal characteristics. Next, I reviewed the extant studies on the importance of school leadership in increasing student achievement, and finally discussed the principal's roles both formal and informal - in the hiring process, which often includes district level processes prior to a principal ever seeing a candidate.

\section{Teacher Quality: Why It Matters}

The study of teacher quality starts with the question of whether teachers have any effect on student achievement or is student achievement primarily explained by factors out of the realm of control of schools and teachers. If teacher quality does not matter, or matters little relative to other factors within the control of policy-makers, then increasing teacher pay to a level commensurate to other professionals would be unnecessary, as would the provision of professional development, additional pay for additional expertise, or attainment of more and higher levels of education.

In a landmark study of educational equity, Coleman et al. (1966) reported that, although only a minor proportion of differences in student achievement could be attributed to differences among schools and that most difference were related to family, peer group, and neighborhood characteristics, there were some teacher characteristics that 
appeared to coincide with higher student achievement. The teacher's score on an assessment of verbal ability was found to have the highest positive correlation to student achievement of the few teacher characteristics captured in the study. Other positive correlations revolved around the teacher's level of education, as well as the educational level of the teacher's parents. Coleman et al. found that the positive relationship between teacher quality and student achievement was greater at upper grade levels, indicating that there was a cumulative effect for a student having consecutive high quality teachers.

The Coleman Report spurred four decades of investigation and debate about whether and how much teachers matter to student achievement. A number of subsequent studies produced findings contrary to those of the Coleman Report (Aaronson, Barrow, \& Sander, 2007; Chamberlain, 2013; Chetty, Friedman, \& Rockoff, 2014b; Hanushek, 1979; Hanushek \& Rivkin, 2012; Konstantopoulos, 2011; Rivkin, Hanushek, \& Kain 2005; Rockoff, 2004).

In a paper devoted to the discussion of statistical and measurement issues related to the estimation of teacher value added measures, Hanushek (1979) delivered some important insights based on his review of existing research and methodologies, while acknowledging the incontrovertible evidence that teacher quality is important in increasing student achievement. In a study to determine the extent to which teachers affect student academic achievement using achievement and panel data from roughly 10,000 students and 300 teachers over ten years, Rockoff (2004) found evidence that there are large differences in teacher quality within schools and that a single standard deviation in teacher quality increases student scores by nearly one-tenth of a standard deviation in both reading and mathematics on standardized assessments. Rivkin, 
Hanushek, and Kain (2005) found large differences between teachers in affecting student achievement that were not driven by family factors, and stated forcefully that "Teachers and therefore schools matter importantly for student achievement" (p. 449). Aaronson, Barrow, and Sander (2007) found that there was a significant difference in $9^{\text {th }}$ grade mathematics achievement based on the student learning from an average teacher and one who was one standard deviation above average. Konstantopoulos (2011) used regression analysis of longitudinal data from the Tennessee STAR project to measure the persistence of teacher effects realized in early grades on future student achievement, finding that a student, given instruction by three consecutive teachers with value added results in the 85th percentile would experience almost $1 / 3$ of a year's added growth in achievement in comparison with a teacher with average value added results. This study confirms other research in emphasizing the importance of effective teachers in the early grades.

In a distillation of existing research on teacher value added measurement in response to increased attention by policy-makers of this model, Hanushek and Rivkin (2012) regarding the economic link between teacher quality as measured by value added models and future earnings by current students, along with the effect on national economic growth, the authors suggest that a teacher in the top $15 \%$ on value added can add more than $\$ 400,000$ in lifetime earnings to a class of 20 students. They further argued that there could be tremendous growth in national Gross Domestic Product by eliminating the lowest performing 5\%-8\% of teachers in the nation's classrooms. Using a factor model to estimate the effect on college attendance and future earnings that were related to unobserved teacher effects, Chamberlain (2013) found that a one standard deviation increase in teacher effectiveness does have a positive influence on college 
attendance of .79 percent. This finding buttresses the notion that the teacher to which a student is assigned has a long term impact on life outcomes. In a follow-up study in the same year to attempt to provide answers to the above-mentioned question of the longterm positive effect on students' adult outcomes of having been taught by a teacher with higher value added scores, Chetty, Friedman, and Rockoff (2014b) used regression analysis to control for earlier test results and other observable student and family characteristics and found a strong relationship on students' future college attendance, the quality of the residential neighborhood, an increase in lifetime earnings, and a reduced probability of giving birth as a teenager. Chetty et al. also found that improvements in the quality of English teachers in this study had a greater correlation with positive outcomes than improvements in the quality of math teachers. Authors discuss several policy implications and suggest that increased compensations for teachers to ameliorate the risk they would take by being evaluated using a value added measure is estimated at one-tenth the amount of the increase in student lifetime earnings generated based on substituting an average teacher for a teacher with a value added score in the bottom five percent of value added scores.

In something of a contrary position on the importance of teachers in student achievement, Pokropek and Sikora (2015) found no effect on the variance in exam results among Polish students, suggesting that much of the variance can be attributed to the possession of heritable traits. The authors indicate that this study confirms over 50 years of past studies across cultures that student factors, inherent from birth, account for 55\% of the difference in educational outcomes. These findings illustrate the importance of controlling for past student performance in measuring teacher contributions to student 
achievement. Even if inherent student characteristics explain a majority of educational outcomes, there remains a significant amount of variance that can be explained by other factors, including the effect of teachers.

While finding that there are systematic differences in school quality that have an effect on student academic achievement, research suggests an important relationship between the setting in which teachers work and the measured quality of teachers (Sass, Hannaway, Xu, Figlio, \& Feng, 2012). In a quantitative study with data on more than 17,000 teachers in two states, they found that the differences in teacher effectiveness in high poverty schools may be driven by greater variation of teacher quality in those school. The "best" teachers on these high poverty schools are similar to the "best" teachers in lower poverty schools, but the least effective teachers in high poverty schools are much less effective than the least effective teacher in lower poverty schools. Though there is a difference in the quality based on experience, Sass et al. suggest that peer effects in lower poverty schools may magnify the positive effects of experience. In other words, teachers in higher poverty school may improve less each year than those in lower poverty schools. In an interesting finding on teacher mobility, the researcher found that some teacher who were less effective when in a higher poverty school became more effective when transferring to a school with lower poverty. This clearly has implications for reducing achievement gaps between higher and lower poverty schools and indicates that teacher performance may be more dependent on school setting than on inherent observable and unobservable - teacher characteristics.

Though the evidence indicates that teachers matter, there remains questions about how teacher effectiveness is measured (Aaronson, Barrow, \& Sander, 2007; Chetty, 
Friedman, \& Rockoff, 2014a; Hanushek \& Rivkin, 2012; Konstantopoulos, 2011; Rivkin, Hanushek, \& Kain, 2005; Rockoff, 2004; Rothstein, 2010; Sass, Semykina, \& Harris, 2014), whether cognitive achievement alone is the ideal method by which to measure educational success (Hanushek, 1979), and the implications of such measurements on teachers and students (Harris, 2010; Koedel, Mihaly, \& Rockoff, 2015). Rockoff (2004) was among the first researchers in the field of value added to point out that currently aligned compensation strategies based on teacher credentials may not yield better results on student achievements, and that principal ratings of teachers may capture important aspects of teaching not easily identified by student test scores.

In a 2007 report, Aaronson, Barrow, and Sander confirmed past research illustrating the difficulty in parsing out the observable characteristics that could indicate which teachers are more effective, finding that no more than $10 \%$ of the variation could be explained by these observable characteristics. This finding leads to the conclusion that, though principals may be able to discern teacher quality during the post-hire period, there is little definitive information available to administrators to guide them in the selection of teachers who are able to perform at above average levels during the selection process

In a study critical of many of the value added models currently in use, Rothstein (2010) found that the models impossibly found large effects on fourth grade student achievement based on the assignment of the fifth grade teacher, indicating that none of the models are able to account for assignment bias. The author expresses a distinct lack of confidence that widely used models can identify good teachers due to unobserved nonrandom assignment of students who may be perceived as those who are likely to make faster learning gains. He concludes that student sorting, even when controlling for 
student demographic factors makes value added models "poorly suited to identifying the effects of teacher characteristics on student achievement" (p. 35).

Using Florida data from public, non-charter middle schools collected for eight years on norm-referenced math assessments to test whether omitting a variety of student level variable from value added models made any difference, Sass, Semykina, and Harris (2014) found that nearly every substitution and assumption used in the six commonly used value-added achievement models were rejected as satisfactorily producing unbiased estimates of teacher productivity. The authors were unable to determine, without true random sampling of students and teachers, the amount of bias produced by the various models, but it was clearly determined that the models produced little overlap among them when predicting high- or low-performing teachers. An implication to the study is that the simplistic assumptions about individual student achievement - as complicated as they appear - may not be sufficient to discover the truth. The authors note that, "More complex processes appear to be at work" (p. 22) when determining the causes of differing levels of student academic achievement, though they do not seek to discount teacher characteristics as important to student achievement.

In answer to the above studies, using a quasi-experimental design to investigate whether teacher value added models are biased by student sorting and if the models can provide an unbiased measure of teacher quality related to improving results on standardized tests, Chetty, Friedman, and Rockoff (2014a) used a dataset of more than a million students in grades three through eight matched with parent data from tax records containing information on household income, retirement savings, and mother's age when the child was born. They found that there was little selection bias based on observable 
student characteristics and that the method does provide an accurate prediction of teacher quality (as measured by improving test scores in math and English). They note that the data indicates that teacher quality does matter in these scores, but make no judgment as to whether this translates into better long-term outcomes for students who have higher quality teachers. Contrary to other findings, their analysis finds that there is almost no difference in teacher value added scores related to teacher experience.

Regardless of the presence or lack of bias in value added models, Rivkin, Hanushek, and Kain (2005) point out that the results fail to isolate readily observable teacher characteristics that can reliably assist in identifying teachers who are more effective. Similarly, Konstantopoulos (2011) tackles the consistent finding that many observable teacher characteristics appear to have little or no effect on student achievement by stating, "It is important to recognize that failure to find some set of measured teacher characteristics that is related to student achievement does not mean that all teachers have the same effectiveness in promoting achievement" (p. 1,545), as well as identifying the pressing need to study the characteristics of more effective teachers in an attempt to identify characteristics that contribute to effectiveness, but which may not fit easily into current statistical models. In 2012, Hanushek and Rivkin made note that little of the variation in student standardized test scores can be explained by observable characteristics of the students' teachers and - though he had few concerns about uncontrolled sorting bias - the authors did admit that family response to perceived teacher quality, along with unpredictable bias in the assignment of students to particular teachers by the principal remains a difficult issue for researchers. 
In a prescient question preceding much of the debate on the validity of value added modeling to predict teacher effectiveness, Hanushek (1979) questioned whether the measure researchers typically use to determine educational success - the standardized achievement test score - is the best way to predict future academic success or increases in positive adult outcomes for the students under study. He suggested these measurements of cognitive skills may not be the most important factor of a student's matriculation through the school system in determining future success.

In an essay on explaining possible uses for value added models, Harris (2010) noted several important points for the use of such models in schools. He stresses the principle of fairness, arguing that any accountability system must honor the idea that educators should only be accountable for factors they have the ability to control given the fact that there are many inherent and uncontrollable inequalities brought to school by students that have accumulated between birth and the time a student comes in contact with a particular teacher. Harris outlines options for the possible use of value-added models, such as using it as one data point in a wider teacher evaluation system or as part of a low-stakes (for individual teachers) whole school model of school program evaluation. He further points out that many schools that are labeled as low achieving or failing are actually high performing because they are able to produce higher levels of improvement from baseline measures than other schools whose students begin with higher levels of initial attainment and without many of the pre-existing negative variables that often hamper student achievement.

A thorough review of the value added literature conducted by Koedel, Mihaly, and Rockoff (2015) suggested that, though there are still many questions and on-going 
debate regarding the efficacy of teacher value added, and especially its use in retain/fire decisions, there is some general consensus around the issue. The authors find that studies consistently estimate that - even given the instability and possible bias - the use of teacher value added improves student achievement more than not using it. Further, though the effect fades over time, the impact of a teacher who performs one standard deviation above the mean on teacher value added measures can have tremendous positive financial and educational attainment effects on the student in their class, as well as lower the likelihood of negative effects, such as teen-age childbearing. There is some concern about the micro-consequences. Even small measurement effects that unjustly label a teacher as low performing can have severe financial consequences for an individual teacher. The authors also acknowledge the difficulty in measuring teacher value added in areas other than elementary reading and math, which has policy implications on the amount and quality of student testing.

Among researchers into teacher effects on student achievement, there is a divide on what makes an effective teacher. On one side, there are the researchers that focus on inputs - observable characteristics that improve student academic performance. On the other side, researchers who focus on teacher value added contend that very little of the variation in teacher quality (as measured by value added) can be explained by observable characteristics. This contention is colorfully illustrated by the findings in a research report describing the results of three distinct experiments by Strong, Gargani, and Hacifazlioglu (2011). They first tested whether observers from a variety of backgrounds including trained administrators, teacher educators, and children could predict a whether a teacher was in a high value added group or not based on the rating of a short video 
lesson. They found little accuracy in the ratings. In fact, the children in the study correctly predicted the teacher's value added with 50\% accuracy, while every other rater was less accurate, including administrators who correctly judged the teacher's performance only $31 \%$ of the time. To confirm these results, and to rule out alternative explanations for the first experiment's results, the researchers replicated the experiment using teachers and raters from a different state, with wider distinctions in value added scores, and more experienced raters. They found essentially the same results, with the accuracy of the ratings being somewhat lower than they would have been by assigning them based on chance. However, the researchers identified a small group of subjects that most raters scored accurately, hoping that they could discover some common characteristics that could be used in the development of a more accurate measurement instrument. In the third experiment, they used highly trained raters, the raters viewed the entire lesson and then used a research based, high quality rating instrument to categorize the teacher in the high or low value added group. The results of the third experiment indicated that the raters could have been just as accurate by flipping a fair coin. This sets up something of a chicken and egg conundrum in that - for purposes of hiring a teacher who does not yet possess any evidence of their ability to add value as an effective teachers - it is impossible to discern before hiring if the teacher has the ability to increase student achievement. The understanding and synthesis of these sometimes divergent findings is one of the important drivers in framing the need for additional research in this area.

An example of this synthesis of views among researchers is found in a literature review on teacher effects by Jackson, Rockoff, and Staiger (2014), which found evidence 
that - given adequate controls - teacher value added measures can be accurate predictors of teacher effectiveness across time, but that the use of such a tool to make career decisions during the early stages of a teacher's tenure may make such a decision unreliable. The authors suggest that, rather than basing decisions on teacher effectiveness on a single measure, a more nuanced and accurate picture may emerge by developing an index of various non-significant (when taken alone) teacher characteristics. In order to inform the compilation of this list of characteristics, it is important to know which characteristics school leaders in the field find valuable.

Regardless of how it is measured, and despite differences in the size of teacher effects among various researcher, research suggests that teachers do indeed matter. That teachers do in fact make a difference in student academic achievement is an important first step in the journey to answer the real question begged by an affirmative response: What makes a good teacher? There are varying views in the literature regarding the particular characteristics or attributes that identify a teacher as effective, with some suggesting that personal characteristics, such as empathy, intelligence, or enthusiasm are the most important attributes of an effective teacher, while others argue that professional characteristics like teacher certifications, experience, and advanced degrees held are more reliable indicators of effectiveness. In the next section, I will review the current state of the literature regarding the characteristics of effective teachers.

\section{Professional Characteristics}

Professional characteristics include such things as advanced degrees held, the selectivity of a teacher's undergraduate institution, certification, experience, and specialized coursework in particular subject areas. A characteristic can be deemed 
professional if the characteristic is related to professional preparation, as opposed to personal characteristics, which are deemed as inherent traits in an individual regardless of training or preparation.

There is near universal agreement among researchers who have studied the effect of teachers' holding advanced degrees that the holding of such degrees has no significant relationship with increasing student achievement (Clotfelter, Ladd, \& Vigdor, 2007; Hanusheck, 1971; Jepson, 2005; Rockoff, Jacob, Kane, \& Staiger, 2011; Whitehurst, 2002). Among the earliest studies to attempt to identify teacher characteristics that do have a positive correlation with increased student achievement was one by Hanushek (1971), which utilized a sample of over 1,000 students from a large California school district along with teacher data similar to that collected by Coleman (1966) and noted that advanced degrees were not factors that appeared to be highly related to student performance on standardized tests. This study was clearly not as sophisticated as those to come later, though the results have been confirmed using more powerful models that control for prior student achievement and student assignment bias. Grover Whitehurst (2002), in a presentation during a White House Conference focused on teacher preparation, reviewed existing research on the importance of teachers and the characteristics that make one teacher more effective than another, and suggested ways in which teacher effectiveness may be increased. He concluded that many of the observable characteristics of teachers are not strong indicators of effectiveness, including advanced degrees.

There is some indication in the literature that student performance is related to college selectivity. In a very carefully explained examination of 21 studies meeting strict 
criteria, Wayne and Youngs (2003) reached and reported several conclusions. Among those conclusions was that there is some positive relationship between the ratings of a teacher's college of attendance and student performance and the authors suggested that further examination was needed. Wayne and Youngs noted that the ratings themselves are dependent on many factors that may have their own biases and can be fluid year to year based on changes in a particular college. They further found that the relationship between teachers' degrees and coursework indicated a clear positive relationship only in that high school students perform better on mathematics assessments if their teachers have more coursework and degrees in mathematics. In a 2007 quantitative study of longitudinal data on student achievement, Clotfelter, Ladd, and Vigdor found positive correlations to higher student achievement among teachers who graduated from a more competitive undergraduate institution and for those who hold National Professional Teaching Standards Board certification. Rockoff, Jacob, Kane, and Staiger (2011), in a study of a wide variety of teacher characteristics on math achievement confirmed that Teach For America corps members tend to be significantly more effective than traditionally certified teachers, though the retention rate for such teachers is quite low.

The research thus far reviewed in this section appears to be borne out in the field. Liu, Liu, Stonge, and Xu (2016) conducted a mixed methods study to determine specific teacher characteristics sought by principals in China and compared these results with their United States counterparts. Consistent with research on American principals (Engel, 2013), this study found that whether or not the teacher had an advanced degree and the perceived quality of the teacher education program from which the candidate graduated were among the lower rated teacher characteristics valued by principals. 
There exist very few studies that examine the relationship between student achievement and emphasis in teacher preparation regarding a focus on content knowledge versus a focus on pedagogical knowledge. Wayne and Youngs (2003) and Winters, Dixon, and Green (2012) come to the same conclusions regarding coursework, both finding clear positive relationships between high school students performing better on mathematics assessments and their teachers having more coursework and degrees in mathematics. Rockoff, Jacob, Kane, and Staiger (2011) found that teachers' self-reported SAT scores or college selectivity had no significant correlation with the academic achievement of their students.

Teacher certification as traditionally conceived - licensure through state agencies - is not correlated to higher levels of student achievement (Clotfelter, Ladd, \& Vigdor, 2007; Jepsen, 2005; Kane, Rockoff, \& Staiger, 2008); however, there is some indication that Teach for America teachers, who are not certified in the traditional manner and teachers who obtain a national certification through the National Board for Professional Teaching Standards may be associated with higher student achievement. Kane, Rockoff and Staiger, (2008) sought to determine whether there was a link between teacher certification status and student achievement in reading and math utilizing a large data set from New York City schools. The authors found no effect on student achievement between certified and uncertified teachers. They do find a significant difference between certified teachers and Teach for America (TFA) teachers with the students assigned to TFA teachers having higher achievement in mathematics. In a study that utilized a rich data set from the early 1990s to search for a link between teacher characteristics and student achievement, Jepsen (2005), using a data set of two early elementary national 
cohorts each made up of nearly 10,000 students in over 200 schools, concluded that teacher certification had no significant effect on student achievement. Somewhat contrary to Jepson, Clotfelter, Ladd, and Vigdor (2007), using a rich administrative data set from North Carolina, did find a significant negative correlation to student achievement for those who held provisional or emergency teaching certificates which indicates that having a standard teacher certification did bring added value to student achievement. These authors also reported significant positive correlations to student achievement for who hold National Professional Teaching Standards Board certification Much of the past research reviewed has discussed teacher characteristics that have little to no effect on student academic achievement, but teacher experience is one characteristic that many researchers have found to have a positive impact (Clotfelter, Ladd, \& Vigdor, 2007; Jepsen, 2005; Kane, Rockoff, \& Staiger 2008; Nye, Konstantopoulos, \& Hedges, 2004; Whitehurst, 2002). Hanushek (1971), was among the first to explore the relationship and he found little relationship between a teachers' experience and student achievement on standardized tests. Wayne and Youngs (2003) reported several conclusions of an in-depth review of 21 studies, including that teacher experience is a variable that may be related to student achievement, but is too difficult to interpret as a meaningful independent variable for a variety of reasons. In a study utilizing the large amount Tennessee STAR data, Nye, Konstantopoulos, and Hedges (2004) measured the strength of teacher effects and whether these effects varied based on teacher characteristics, and the socioeconomic status of students in a school and the school as a whole found positive, though weak, correlations between experienced and inexperienced teachers. This was followed by Stronge, Ward, and Grant who, in 2011 
conducted an ambitious study to try to isolate effective instructional practices and teacher behaviors that resulted in student learning gains (as predicted by achievement on standardized assessments). They found, in the first phase of their study that there was no correlation between student achievement and the few demographic variables studied, including years of experience.

Other researchers that followed, though, have reported more robust positive relationships. Grover Whitehurst (2002) reported that there is strong evidence that teachers' level of experience was a strong predictor of effectiveness in raising student achievement. Jepsen (2005) found there was some confirmation that teacher experience is significant for both reading and mathematics while analyzing a rich data set from the early 1990s. In a 2007 quantitative study of longitudinal data on student achievement, Clotfelter, Ladd, and Vigdor were able to report several findings regarding the correlation between teacher factors and student achievement. Among those findings, they found that teacher experience was positively related to student achievement, with over half the gains occurring in the first two years. Kane, Rockoff, and Staiger (2008) confirmed this trend using a large set of student achievement data in reading and mathematics from New York City schools, finding that teacher experience in the first few years is significantly correlated with increased student achievement.

The research literature provides strong confirmation that teachers possessing higher levels of content knowledge are more likely to be associated with higher levels of student achievement (Metzler \& Woessmann, 2012; Rockoff, Jacob, Kane, \& Staiger, 2011; Siegle, Rubenstein, \& Mitchell, 2014; Whitehurst, 2002; Winters, Dixon, \& Greene, 2012). Grover Whitehurst (2002) noted that, especially in high school math and 
science courses, higher levels of teacher content knowledge was a strong predictor of effectiveness in raising student achievement. Rockoff, Jacob, Kane, and Staiger (2011), in a study of a wide variety of teacher characteristics on math achievement found that higher levels of content knowledge by a teacher led to gains in student achievement in mathematics. In a 2012 study, Winters, Dixon, and Greene confirmed other studies that show that more coursework in mathematics and presumably possession of greater content knowledge by the teacher indicate a positive relationship to student achievement in that subject. In a study designed to investigate the relationship between teacher academic skills and student achievement, Metzler and Woessmann (2012) used a Peruvian data set restricted to small, mostly rural schools with one teacher per grade in order to control for within school sorting. The authors' findings indicate that teacher subject knowledge has a significant effect on student achievement in mathematics, but not in reading. An increase of one standard deviation in math knowledge by the teacher was associated with a $9 \%$ of a standard deviation increase in student mathematical achievement, and suggests that teacher subject matter knowledge, at least in mathematics, is one observable factor that may influence student achievement.

Finally, Siegle, Rubenstein, and Mitchell (2014) found that overwhelming attribution was ascribed to the teachers of the high performing students that were part of their focus groups. Teachers' knowledge of their subject matter was deemed as highly important in student motivation. Students who felt that that the teachers were unprepared or unable to do more than present information from the text were something of a joke and reported that they had less motivation to work hard. Conversely, teachers who were masters of their subject matter and were able to make connections between their subject, 
other subjects, and to current events and contexts were viewed as highly

motivational. This theme of an intelligent teacher remained important in creating task value for students, meaning teachers were able to weave interdisciplinary themes into their instruction and allow students to study a topic in more depth.

Harder to measure and evaluate than years of experience, level of education, and even content knowledge, effectively transmitting knowledge is done through the organization and management of a group of students and using particular skills to impart that knowledge to those students. Measuring the factors of classroom management and teaching skill is difficult and often imprecise work (Siegle, Rubenstein, \& Mitchell, 2014; Strong, Gargani, \& Hacifazlioglu, 2011) and very often relying on rating scale of dubious validity (Harris \& Sass, 2014; Kennedy, 2008; Steinberg \& Garrett, 2016; Stronge, Ward, \& Grant, 2011). In a study designed to determine the extent to which students' incoming academic performance influenced their teachers' observational performance as measured by their evaluator, Steinberg and Garrett (2016) found that English teachers assigned higher achieving students were rated in the top performance quintile at more than twice the rate of teachers assigned the students with the lowest incoming achievement scores. This poses obvious questions of validity when using observational performance data to determine the quality of teachers. Though many of the studies that indicate the relationship between student achievement and teacher performance are quantitative, there are hundreds of qualitative studies investigating teachers' qualifications. Kennedy (2008) conducted an in-depth review of the qualitative literature around this subject. Kennedy found that students themselves may impact teacher practices. Kennedy found that studies in her review suggested knowledge of both subject matter and teaching practice evolves 
over time, as it interacts with experience and changing beliefs about teaching that could be affected by almost any life circumstance. This may further confound efforts to definitively determine the ingredients of an effective teacher. Harris and Sass (2014) analyzed data from a mid-sized Florida district to conclude that there was not a significant correlation between principal ratings on knowledge/teaching skills/intelligence, and teacher value added measures.

Despite these inherent difficulties, several researchers have found positive relationships between measures of teaching skill and classroom management and increases in student academic achievement (Harris, Ingle, \& Rutledge, 2014; Kane, Taylor, Tyler, \& Wooten, 2011; Rockoff \& Speroni, 2011; Stronge, Ward, \& Grant, 2011). In a quantitative study of panel data and student achievement scores from Cincinnati, Kane, Taylor, Tyler, and Wooten (2011) found that controlling for teacher experience, an average student showed an increase of two percentile points in math and 3 percentile points in reading over a single year by being assigned a teacher in top $25 \%$ as rated on teaching practices versus being assigned to a teacher rated in the lowest $25 \%$ on the same measure. The results of the research indicate that it is possible that teacher effectiveness can be divined based on teacher observations, rather than only on achievement gains, which would ameliorate the anxiety that an evaluation system incentivize teaching only "to the test" at the expense of teaching other valuable skills and dispositions. Rockoff and Speroni (2011) investigated the relationship to student achievement of subjective and objective teacher value added evaluations and found that subjective evaluations by carefully trained professionals were significantly related to the objective measures of teacher effectiveness. The authors suggest that the finding 
indicates that the correlation between the two types of evaluations may provide information on the portion of teaching skill that contributes to higher student performance that are not able to be captured through more objective measures. Stronge, Ward, and Grant (2011) identified four dimensions of teacher effectiveness, including classroom management, classroom organization, the establishment of positive relationships, and the encouragement of responsibility. Though insignificant, there were clear differences between top and bottom quartile teachers on all teacher effectiveness variables measured, which the authors indicated may be combined and constructed in such a way as to be predictive of a teacher who can engender higher student achievement.

In a quantitative study using a national sample, Barile, Donohue, Anthony, Baker, and Weaver (2012) found that the student-teacher classroom climate did not have an effect on standardized math achievement, but did have a significant negative relationship with students dropping out, meaning that a positive student teacher climate was associated with students staying in school. They also found that - controlling for other student and school variables - students who were from homes with a lower socioeconomic status were more apt to report negative student-teacher climate than those from higher socioeconomic families.

In a mixed methods study comparing principal ratings of teacher effectiveness (both overall and with regard to specific characteristics) with value-added estimates of teacher effectiveness, Harris, Ingle, and Rutledge (2014) included a qualitative component that illuminated many of the complications inherent in judging teacher effectiveness. One finding pertinent to the topic of teaching skills is that, among all the 
characteristics rated by principals, only the principal rating of "strong technical skills" was significantly related to value added estimates in both reading and mathematics.

\section{Personal Characteristics}

The classification of teacher characteristics is not a precise exercise. They lie on a continuum ranging from clearly professional characteristics, such as the type of teaching certificate one holds to the purely personal characteristic, such as level of empathy or caring. For the purpose of the review of existing research, this study will consider a characteristic personal if it is a characteristic that is inherent in an individual and would exist regardless of professional preparation or training.

There has been no empirical research that provides evidence of the effect of interpersonal skills, such as cooperativeness and ability to work well with others. Harris and Sass (2014) found there was no significant correlation between principal ratings on teacher interpersonal skill, knowledge/teaching skills/intelligence, motivation/enthusiasm, and works well with others and teacher value added measures. However, Siegle, Rubenstein, and Mitchell (2014) pointed to qualitative evidence that such characteristics as maintaining positive social relationships are important to students. The authors indicate overwhelming attribution was ascribed to the teachers of the high performing students that were part of their focus groups. The ability of a teacher to form positive social relationships was seen by participants as highly important, meaning the students responded to their teacher's appropriate level of interest in their personal lives, though they note that teachers must be careful to maintain professional boundaries so as not to alienate their students. Students further valued 
teachers who empowered them to complete challenging work at a high level, which developed their self-efficacy.

Numerous studies have lent credence to the idea that more effective teachers have higher degrees of intelligence. (Hanushek, 1971; Harris \& Rutledge, 2010; Siegle, Rubenstein, \& Mitchell, 2014; Whitehurst, 2002). Hanushek (1971) utilized a sample of over 1,000 students from a large California school district along with teacher data similar to that collected by Coleman (1966) and found that general ability among teachers did seem to have an impact, independent of the educational level of the teacher. He also found that by substituting teachers with low verbal ability for high verbal ability, achievement levels increased between 0.2 and 0.4 grades levels. This study was clearly not as sophisticated as those to come later, though the results have been confirmed using more powerful models that control for prior student achievement and student assignment bias. Grover Whitehurst (2002) presenting findings on teacher effectiveness during a White House Conference focused on teacher preparation, determined that recruiting more pre-service teachers with greater cognitive ability was a high priority for improving student learning.

Harris and Rutledge (2010) noted that cognitive ability is one of the four factors of effectiveness shared between the education and non-education literature. The authors note that, though there has been little in the way of modern research into the relationship of teacher cognitive ability in education settings, the strong relationships on the same measure in other fields seem like to carry over into the more complex skill set required in teaching. There are four factors that appear in the non-educational literature, including cognitive ability, experience, personality, and education. Of these, the only two consistent 
predictors for all workers was cognitive ability and experience. Siegle, Rubenstein, and Mitchell (2014), report that high ability students highly value a teacher with high levels of intelligence to help create challenging tasks and make important cross curricular connections.

Other researchers disagree with the notion that high intelligence is one of the few factors required to be an effective teacher (Aloe \& Becker, 2009; Andrew, Cobb \& Giampietro, 2005). In a 2005 review of the relationship between teacher verbal ability and teacher quality, Andrew, Cobb and Giampietro posit the commonsense notion that the job of teacher clearly requires good verbal ability (presenting information, communicating with parents and administrators, explaining complicated concepts, etc.), but questioned whether it is one of the few things that are required to be an effective teacher. After conducting a review of many of the studies cited by proponents of the position that teacher verbal ability is highly important to buttress their arguments, they concludes that there is an overall positive relationship between teacher verbal ability and teacher effectiveness, but that it is not supportive of the sweeping claims sometimes made on the topic. They went on to report on a study seeking to determine whether verbal ability was a useful predictor of teaching ability. Verbal ability was operationalized using the GRE and teacher performance was operationalized using supervisor ratings of the subject's performance. The authors found that there was no relationship between verbal ability and teacher ability as measured in this study. In fact, they found that a few of the teachers scoring low on verbal ability were highly rated by their supervisors. This, again, illustrates the tension in determining what it means to be an effective teacher and how best to get these teachers into our classrooms. 
In a scathing report of a meta-analysis of 19 studies which examined the oftrepeated claims of a strong predictive linkage between teacher verbal ability and student achievement (Aloe \& Becker, 2009), the authors conclude that this relationship is either non-existent or very weak. They note that the data set used by Coleman (1966) and the study results are old - almost 50 years old in fact - and that such older research may have inherent weaknesses based on factors that may have changed during the intervening decades. Interestingly, they also discussed the fact that - if one operationalizes verbal ability using the SAT verbal scores in which white students perform better - relying on these weak findings to influence teacher certification may lead to less diversity in the teaching corps than would otherwise be present. Further, the authors noted that when the government agencies make policy statements encouraging certification standards that rely on such findings, there can be real and negative consequences to relying on overstated research findings.

Despite the notion that both enthusiasm and motivation are self-evidently important to success in nearly any endeavor, there is little evidence in the research that either of these attributes are important to teacher effectiveness. While Harris and Rutledge (2010), in their review of the literature comparing effectiveness research in education to similar literature in non-educational fields, found that "personality", which can be synonymous with enthusiasm is one of the four factors shared between educational and non-educational effectiveness research. The authors also noted that the two fields use two widely different measures of effectiveness, with teacher effectiveness being measured solely by standardized achievement tests and non-teacher effectiveness being measured with a more holistic supervisor rating. 
Rockoff, Jacob, Kane, and Staiger (2011), in a study of a wide variety of teacher characteristics on math achievement, compared the effect of personality traits, such as extraversion or conscientiousness, and found that they are not good predictors of student achievement, but were highly correlated with positive subjective evaluations. This is interesting because it tends to call into question the results of a large literature that finds that these kinds of traits predict job performance. But, job performance in much of this literature is measured by subjective performance evaluations, so it may be possible that subjective evaluations are not measuring job performance at all, but rather personality traits. On the other hand, taken as a whole, subjective evaluations were confirmed to have a significant relationship to student achievement, meaning that though individually, conscientiousness and extraversion may not be significant, teacher personality factors do appear to affect student achievement as a whole.

Harris and Sass (2014) buttressed the notion of the lack of clear correlation between enthusiasm and motivation with student achievement. They used data from a mid-sized Florida district to determine what observable teacher traits are associated with a teacher's ability to raise student achievement levels, and what other factors principals consider when evaluating teacher effectiveness. Researchers concluded that there was no significant correlation between principal ratings on teacher interpersonal skill, knowledge/teaching skills/intelligence, motivation/enthusiasm, and works well with others and teacher value added measures. However, in the qualitative study by Siegle, Rubenstein, and Mitchell (2014) on of the manner in which teacher characteristics influenced student motivation, they find that high performing students rated teacher passion as important to their own motivation. 
Though it does not fit neatly into either a professional or personal category, research has demonstrated a definite relationship between the place where a teacher candidate lives or matriculates and where they are employed and this can have an impact on teacher qualities available (Boyd, Lankford, Loeb, \& Wyckoff, 2005; Fowles, Butler, Cowen, Streams, \& Toma, 2014). In a description of an administrative dataset from the state of New York, it was noted that $61 \%$ of first-time teachers took a position within 15 miles of their hometown (Boyd, Lankford, Loeb, \& Wyckoff, 2005). Further, it was four times as likely for a teacher to be employed within five miles of his or her hometown as one only 40 miles away. These statistics gives some indication that the talent pool from which administrators pick teachers is limited by geography and the surrounding population. Paired with findings noting that teacher credentials matter to student achievement (Clotfelter, Ladd, \& Vigdor, 2007), there is a long-term imperative for school leaders to improve their student achievement outcomes since, in many respects, they truly are educating the future teachers in their own schools. In fact, it may be advisable that administrators actively identify individuals with preferable characteristics among their high school populations and encourage them to consider becoming teachers. In a study to determine if there were differences in placement patterns based on teacher candidate credentials between rural and non-rural school districts, Fowles, Butler, Cowen, Streams, and Toma (2014) found that the vast majority of teachers were initially employed in districts that were less than a two hour drive from where they graduated from college. Despite this finding, they also noted that the pre-service teachers with the strongest credentials and who graduated from an Appalachian undergraduate institution were more likely to obtain their first job outside of Appalachia, while the weaker- 
credentialed candidates were less likely to move outside that environment. The authors also detected a substantial bias for Appalachian districts to hire candidates from Appalachia, rather than those from outside the area, and posited that this could be because of cultural norms or a willing exchange of lower quality teachers for less likelihood for attrition.

To summarize, the relationship between teacher performance - defined as the ability to increase student achievement on standardized tests - and both professional and personal characteristics is complicated. The is wide agreement that experience, holding a degree from a more selective university, and possessing strong content knowledge are all important predictors of teacher effectiveness, with the two latter characteristics having a possible relationship to general intellectual ability. There is also some evidence that technical teaching skill and classroom management are also predictive. Teacher certification, as traditionally conceived, has no relationship to student achievement, though teachers certified through Teach for America or the National Board of Professional Teaching Standards did seem to have a greater impact on student achievement.

\section{School Leadership: How and Why It Matters}

The wide ranging responsibilities and influence of the school principal in every aspect of school operations and management would seem to clearly indicate that school achievement must be strongly influenced by the leadership and activities of the principal. Anecdotal evidence of school turnaround efforts almost always focus on the role of the principal as being the significant change-maker. This belief has even entered popular culture through the 1989 movie Lean On Me, which was a chronicle of one such 
turn-around effort led by real-life principal Joe Clark at an inner city high school in New Jersey. Academic research appears to back up this widely held belief that the influence of the principal is important to school performance. Principals' myriad job responsibilities include teacher supervision and retention, establishment of disciplinary strategies and cultural norms, resource allocation, scheduling, and the provision of professional development related to curriculum and instruction.

The evidence found in the literature indicates that educational leaders do have an effect on student achievement (Bastian \& Henry, 2015; Coelli \& Green, 2012; Dhuey \& Smith, 2014; Grissom, 2011; Grissom, Kalogrides, \& Loeb, 2015; Karadag, Bektas, Cogaltay, \& Yalcin, 2015; Louis, Dretzke, \& Wahlstrom, 2010; Robinson, Lloyd, \& Rowe, 2008), though the effects are often indirect and a result of decisions the influence the climate and staffing of the school.

Robinson, Lloyd, and Rowe (2008) performed an unusual meta-analysis to determine the relationship between principal leadership and student achievement. In the first phase, they compared transformational leadership to instructional leadership, finding that instructional leadership has a much stronger correlation to increased academic achievement than did transformational leadership. The authors did note, however, that, "in general, abstract leadership theories provide poor guides to the specific leadership practices that have greater impacts on student outcomes" (p. 658). In the second phase, the researchers derived five dimensions of leadership from the existing studies to determine the relative strength of the relationship between each dimension and student achievement. They found that all five - which include goal and expectation establishment, strategic resourcing, planning, coordinating and evaluating, teacher 
professional development, and ensuring an orderly environment - are statistically significant, but that the construct of planning and participating in teacher development is by far the strongest, possibly because this help principals understand the instructional needs of the teachers in their schools. In another study related to principal leadership, Louis, Dretzke, \& Wahlstrom (2010) conducted mixed method survey research on the relationship between teachers' professional community, shared leadership, instructional leadership and trust in the principal on instruction and student achievement (operationalized through student test scores). They found that principal leadership had an important, if indirect, positive influence on student achievement.

Extrapolating from past research clearly linking higher teacher turnover to low school performance, Grissom (2011) conducted a quantitative analysis of national survey data to investigate the link between teacher turnover in schools with a high number of disadvantaged students and principal effectiveness. Grissom found that, when the principal effectiveness variable was added to the regression model, joining the student demographic variables, the effect of the demographic variable dropped significantly in comparison, indicating that principal effectiveness explains a large part of teacher satisfaction and could lead to decreased turnover as teachers consider the cost-benefit of leaving a school or staying. Further, he found that in disadvantaged schools, the principal's influence on teacher satisfaction was greater than in other schools. This research clearly indicates the importance of the principal in influencing teacher attrition and, by retaining a more experienced and stable teaching force, student achievement. Coelli and Green (2012) conducted a study in Canada to estimate the effects of principals on high school graduation rates and student achievement. They found that 
there is a significant difference in the outcomes of different principals. After adjusting their model to allow time for a new principal to have full effect, the authors conclude that a principal who is a single standard deviation above the mean can increase student achievement levels at least 2.5 percentage points. Though this particular study did not isolate what principal characteristics were responsible for improving student outcomes, it is strong evidence that principals can have significant impact on student achievement.

In a similar study to Coelli and Green, but focusing on the elementary school level, Dhuey and Smith (2014) found that principals do have differing impacts - which confirms that they do have impacts - on student achievement on standardized tests. The results indicated that a shift from a principal performing at the median level related to value added to one performing at the 75th percentile can increase student scores up to 0.193 standard deviations.

In a quantitative study conducted by Bastian and Henry (2015) using administrative data on first-time principal characteristics and school characteristics in which they worked, findings indicated that there are significant differences in school performance based on certain principal characteristics. Higher average achievement gains were significantly associated with principals who posted higher scores on principal licensure tests and those who held National Board Certification as a teacher. They also found that principals who had previously served as assistant principals in a school with higher value added were significantly more likely to see higher student achievement gains in their new schools, though there is no significant association between achievement gains and becoming principal of a school after serving as assistant principal in the same school. Finally, there was a significant negative relationship in achievement 
gains when an individual becomes principal in a school where he or she once served as a teacher, at least in a usually smaller elementary school environment.

Grissom, Kalogrides, and Loeb (2015) conducted a study investigating three different value-added model approaches for assessing principal effectiveness and compared each of these models to non-test measures of school performance, including district evaluations of principal performance and school climate surveys administered to teachers, parents, and students. The findings call into question the validity for policymakers of utilizing such measures due to wide variations between the most simplistic (also, the one with most conceptual issues regarding attribution of results to factors over which a principal has no control) based on overall school effectiveness and more sophisticated approaches taking into account principal tenure and controlling for student fixed effects. The approach that was most highly correlated with the non-test measure was also the most simplistic, which the authors suggested may indicate bias of the nontest results based on school performance. Even so, the results of all three models did point out quantifiable differences in school effectiveness that can be attributable to the principal. They conclude, that though certainly an imperfect measure of principal performance, the fact that principals are partially evaluated based on school effectiveness as measured by student test scores may focus additional principal attention on these issues and may improve student achievement.

Karadag, Bektas, Cogaltay, and Yalcin (2015) conducted a meta-analysis of 57 research studies to determine if these studies provided an affirmative answer to the research question of whether educational leadership has a positive effect on student achievement. Their results indicated that educational leadership did have a significant 
positive effect on student achievement, though it left open the question of whether that effect was direct or indirect. They also noted that among particular styles of leadership, instructional leadership had a larger effect than other styles, such as transformational, situational, or distributed. The authors further found that the effect appeared to be larger at the elementary school level than at the middle or high school level, perhaps because of the school size.

The academic literature clearly establishes that school leadership has an influence on student academic achievement. The characteristics of the leader and the nature of the leadership as evidenced through the use of time and leadership strategies are varied and may be subject to school specific circumstances such as school demographic considerations (Bastian \& Henry, 2015; Dhuey \& Smith, 2014; Fuller \& Hollingsworth, 2014; Grissom, Loeb, \& Master, 2013; Horng, Klasik, \& Loeb, 2010; Louis, Dretzke, \& Wahlstrom, 2010).

In the report of a study that clearly demonstrated that the work of a principal is complex and subject to many intervening circumstances, Horng, Klasik, and Loeb (2010) analyzed the relationship between principal time use across a variety of school circumstances. A surprising finding, given the increased focus on instructional leadership as part of the principal's job was that principals spend approximately $10 \%$ of their time on instructional related tasks, as opposed to tasks related to administration, organizational management, internal relations, and external relations. The authors found that there was a significant difference in the amount of time spent on instructional tasks between principals who lead high performing schools as opposed to those who lead low performing schools. A similar difference was noted between principals of schools where 
there were more minority and economically disadvantaged students and principals of schools with few students falling into these categories. The researchers noted that that the direction of any relationship is difficult to determine, since a principal's focus on more administrative tasks (including student discipline) as opposed to instructional tasks may be due to the necessity of doing so based on school demographic conditions. This study repeated earlier suggestions that the heavy focus on instructional leadership at the expense of organizational management - also necessary to the success of a school - may have detrimental effects on school performance.

Preparation for school leadership must focus on both the emotional side of leadership, such as sharing leadership and developing positive professional relationships, as well as the pure technical instructional elements in order to have the greatest impact on student achievement (Louis, Dretzke, \& Wahlstrom, 2010). In reporting the results of their mixed method survey research, they note that their analysis suggests that principal leadership is clearly comprised of more than instructional leadership, but also consists of the willingness to develop community and share leadership with teachers.

In seeking to isolate the manner in which principals used the time they devote to instructional activities and provide analysis regarding which instructional activities were positively correlated to increased student achievement, Grissom, Loeb, and Master (2013) utilized a mixed methods approach of in-person principal observations over three years and semi-structured interviews to determine the time principals spent on particular instructional activities and the reasons behind that time allocation. They used regression analysis to link these findings with student achievement data - both overall and broken down by school levels and various student demographic factors. Their findings noted 
that principals in their study devoted $12.7 \%$ of their time to instructional activities, varying between levels and school demographic factors, with the bulk of that time spent on informal classroom walkthroughs. Their analysis concluded that there was actually a significant negative association with these walkthroughs and school effectiveness related to student achievement. The authors found that the one activity that showed a significant positive correlation with increased school effectiveness was coaching teachers, especially when this coaching was perceived by the teachers as professional development. This study clearly assumes that the principal, through the allocation of his or her time, has a role to play in improving student achievement.

Dhuey and Smith (2014) found no significant relationship on student achievement relating to either the experience of the principal or the length of a principal's tenure. Their results indicated that a shift from a principal performing at the median level related to value added to one performing at the 75 th percentile can increase student scores up to 0.193 standard deviations. This study was conducted using elementary principals as the sample, so the results may not be applicable to larger middle or high schools.

In a critical review of the literature regarding principal evaluation, Fuller and Hollingsworth (2014) concluded that using statistical models that estimate student growth are replete with problems that make them highly inappropriate to evaluate principals. The authors reviewed all then existing measure in the United State, from the most simplistic statistical models equating student achievement scores to principal effectiveness to very complex value added models that seek to control for student, school, and teacher effects. Given the serious flaws in each approach, the policy recommendations resulting from the review were very sparse, and mostly included the 
admonition that statistical estimates - at best - should only be used as discussion pieces or screening devices and the authors urged policymakers to be patient and avoid implementing systems that may actually be counterproductive to school improvement. In their notes, the reviewers made a point to emphasize that the research on value added modeling should be continued as a possible way to identify characteristics of successful principals.

In a quantitative study conducted by Bastian and Henry (2015) using administrative data on first-time principal characteristics and school characteristics in which they worked, the findings indicated that there are significant differences in school performance based on certain principal characteristics. Higher average achievement gains were significantly associated with principals who posted higher scores on principal licensure tests and those who held National Board Certification as a teacher. They also found that principals who had previously served as assistant principals in a school with higher value added were significantly more likely to see higher student achievement gains in their new schools, though there is no significant association between achievement gains and becoming principal of a school after serving as assistant principal in the same school. Finally, there was a significant negative relationship in adjusted average achievement gains when an individual becomes principal in a school where he or she once served as a teacher, at least in a usually smaller elementary school environment.

After reviewing existing research into the role of the principal and how the principal's leadership style and activities relate to student achievement, it is clear that the same affirmative answer applies here as when the question is applied to teachers. Principal leadership does matter to student and school performance. 


\section{Teacher Hiring}

Before principals can apply their personal preferences regarding teacher characteristics in the hiring process, they must have candidates from which to choose their teaching staff. Teacher candidate recruitment and initial screening is a district office function that can have deep impacts on the quality of the teaching force. The literature provides insight into some ways in which district recruit candidates, and the varying outcomes of those efforts (Ballou, 1996; Balter \& Duncombe, 2008; Lee, 2005; Liu \& Johnson, 2006; Metzger \& Wu, 2008; Young \& Delli, 2002)

In a quantitative study designed to measure whether job applicants for teaching positions in public schools who possessed stronger academic backgrounds and superior cognitive ability were more likely to obtain employment, Ballou (1996) found that such factors did not yield an advantage. The author attempted to address various rational reasons for why this might be an optimal situation in public education, investigating whether the same two factors yielded an advantage in other fields (they did), and whether hiring authorities in public schools increased organizational effectiveness through reduced attrition by hiring lower ability candidates (they did not). Ballou concluded that the finding represent a suboptimal outcome and suggested it may be due to lack of accountability in public schools to improve performance results, and that efforts to increase teacher supply may lead to an exacerbation of the problem by creating a larger pool of less qualified candidates for teacher positions. The finding that principals give no preference to candidates who appear to be otherwise more highly qualified give rise to the question of why this is so, and which characteristics do principals find more important. 
Young and Delli (2002) conducted a study in two school districts that used the commercially available Teacher Perceiver Instrument (TPI) to determine the extent of the relationship between the TPI scores and post-employment subjective and objective measures of teacher performance. The objective measure consisted of the rate of teacher absenteeism. The subjective measure consisted of a principal rating of each teacher on a 10 point scale related to each of the 12 themes purportedly measured by the TPI. The authors found that the postemployment ratings of teacher performance were predicted by the scores on the Teacher Perceiver Instrument. The complete version of the TPI accounted for $6.2 \%$ of the variance in subjective ratings and $5.8 \%$ of the objective ratings. The researchers concluded that, based on the constructed themes included in the TPI and assuming these themes are true measures of teacher effectiveness, the use such an instrument provided school principals with a reliable source of empirical data on which to base teacher selection.

Dennis Lee (2005) authored an article providing insight and advice to school district leaders on how to best recruit quality candidates for teaching positions in a highly competitive environment where securing the best talent has wide-ranging implications for student learning and district culture. He argued that the district superintendent must be a major player, both as the person setting the tone and as a hands-on participant that can then judge the strengths and weaknesses of the recruitment process. Lee outlined a process by which a district develops a distinct "value proposition" (p. 265) which essentially answers the question of why a candidate for a teaching position would rather accept a position in one district over a competitor district. In the article, he advocated for an aligned process starting with developing the value proposition, developing the 
personnel, including current teachers, who will participate in the interview and selection process, and post interview analysis through questionnaires about the perceived effectiveness of the recruitment and selection process. He concluded with the admonition that a district must intentionally differentiate itself from other districts if it hopes to consistently recruit the best talent for its most important positions.

Balter and Duncombe (2008) conducted a study on district recruitment strategies and how the level of recruitment related to the quality of teacher applicants. Applicant quality was defined as a composite measure including certification status, certification test scores, and college selectivity. The authors found that the size and resources of the school district had a significant effect on the scope of recruitment activity. Further, they found a positive association between districts that engaged in a larger array of recruiting practices and teacher qualifications.

In a meta-analysis of 24 existing research studies comparing results on the commercially produced Gallup Teacher Perceiver Interview (TPI) to five assumed indicators of teacher quality defined as absenteeism, observer ratings, administrator ratings, student ratings, and student gains on test scores, Metzger and $\mathrm{Wu}(2008)$ found little to recommend the instrument as a method to predict teacher quality. The administrator-evaluator ratings correlated most positively with the TPI and less absenteeism, but has a much smaller relationship with ratings by trained outside observers. While concluding the TPI performs as well as other structured interview instruments used in various professions, they note their doubt that it actually measures what matters in effective teaching and point out that the varying results across different grade levels may point to instability of the results. The authors call for additional 
research into these type of instruments due to their increasing popularity as a screening tool.

Once the school district provides teacher applicants to the school leadership for selection, as is done in districts with a decentralized teacher selection process, the responsibility for making teacher selection becomes that of the school leader operating within the framework of school policy or practice. There are a number of variations in school hiring processes, including the promotion of the school and recruitment of candidates to a particular school that the literature indicates as having an impact on the quality and effectiveness of the teachers that are employed at a school (Broadley \& Broadley, 2004; DeArmond, Gross, \& Goldhaber, 2010; Engel \& Curran, 2016; Liu \& Johnson, 2006; Napper, 2010; Schumacher, Grigsby, \& Vesey, 2015; Staiger \& Rockoff, 2010).

Broadley and Broadley (2004) conducted a study to investigate the extent to which principals exhibited different teacher selection styles and how any differences may affect the focus of the school from a student achievement standpoint. The researchers generated 51 statements related to principal preferences and asked participants to sort those statements in order of importance. They then analyzed the results of the sorting and identified eight different teacher selection styles. The authors found that a majority of principals clustered in two particular styles: Child first with staff fit and Collegiality. The results indicate that principals tend to exhibit more care that a new teacher fit into the existing culture of the school than other factors that could influence student achievement and highlight the need for principals to be aware of their styles when considering its effect on school culture. 
In a quantitative study using survey research from 486 first-year and second-year teachers in four states to determine how the hiring process is related to job-fit between teachers and schools, Liu and Johnson (2006) found that the vast majority of teachers are hired through a decentralized process with the district office primarily providing logistical and screening support. However, the authors conclude that most schools who operate under such a decentralized hiring process do not take advantage of this control. As evidence, they pointed out that less than $10 \%$ of teachers are observed teaching a sample lesson and that less than half of new teachers report even moderate agreement that the hiring process gave them an accurate picture of the school where they worked and the job for which they were hired. The researchers noted that "quality information does not come without a cost." (p. 351) and that many of the most promising mechanisms to ensure good job fit take significant amounts of time, such as forming hiring committees and observing sample lessons, and that the hiring process often occurs at the busiest time of the year for most principals.

In a qualitative study using structured interviews to explain differences in recruitment and hiring processes in various locations and demographic contexts within a single urban school district, DeArmond, Gross, and Goldhaber (2010) reported a number of insights into the advantages and pitfalls of a decentralized hiring process. They found that schools fell into two broad categories - either active recruiters with consistency in what they were looking for in a teacher, or passive in recruitment and inconsistent regarding preferred teacher characteristics - and that the category was nearly always determined based on principal attitudes and preferences. There was near universal agreement that it was difficult to determine teacher quality in the interview process as it 
was structured, which led most schools to hire based on perceived candidate dispositions, such as genuineness and to make decisions based on gut reactions rather than any real data. The authors did note that the district used a pre-screener as a check for applicant quality prior to candidates being sent for interview at the school level. One overarching finding was that school location and demographics make a large difference in the supplyside of the hiring equation. Schools located in poor neighborhoods or those with higher crime rates had more difficulty attracting quality candidates and this leads to a long-term issue with inequity for the students and families in those communities.

Norwegian school districts have the latitude under national school laws to hire teachers through either a centralized process controlled by district administrators or through a decentralized process in which the school principal determines which teacher candidate is hired. Schools and districts in Norway are judged on their level of educational efficiency, which is a measure of teacher reported results in three subject areas controlling for a number of student and family characteristics. In a study investigating the relationship between school efficiency and the level of decentralization in hiring, Napper (2010) found that school districts that decentralized the hiring process, and devolving hiring decision authority to individual school principals were significantly more likely to be rated higher on the measure of efficiency. The author noted that there are several issues that may confound the data related primarily to teacher supply and the fact that all large districts have moved to a decentralized hiring model, making direct comparisons impossible.

In a review of existing research regarding teacher value added, the effects of teacher experience, the cost of teacher turnover, and the inability to confidently discern 
teacher quality during the initial hiring process, Staiger and Rockoff (2010) provided some sweeping recommendations to change the system based on research findings to date. They argue that the current system of erecting high bars to hiring and granting tenure as a matter of course should be reversed in a manner that eases the cost and complication of initial hire and then systematically eliminate $80 \%$ of new hires each year based on teacher value added estimates. The researchers conducted simulations to calculate that the net results to teacher quality would be academic achievement gains of .08 student level standard deviations as compared to the current system. This is comparable to gains achieved at great cost through drastic reductions in class size in early elementary grades. The authors did acknowledge the many practical barriers to the implementation of such a system, including the likely demand for additional initial compensation to justify the risk of likely termination after the first year. Other barriers not considered were the fact that school administrators do not have value added measures available to many of their teachers or the considerable opposition of teacher labor unions to allowing $4 / 5$ th of their new members to be terminated as a matter of policy after the first year.

A quantitative study using teacher surveys to identify specific teaching behaviors related to four specific domains of teaching (classroom management and organization, organizing instruction, implementing instruction, and monitoring student progress and potential) and comparing them using multiple regression techniques to identify significant relationships to student growth on standardized tests in language arts and mathematics was conducted to guide principals in identifying effective teaching behaviors (Schumacher, Grigsby, and Vesey, 2015). The authors used a convenience 
sample of 600 teachers in two metropolitan school districts in Texas to gather data on the identified behaviors through a survey. The researchers found that, taken together these four teaching domains did have a significant correlation with student performance growth in both subject areas. Taken individually, only the domain of implementing instruction was significant for both subjects. Classroom management and organization was significantly correlated in language arts, but not mathematics, while organizing instruction was significant in mathematics, but not language arts. Monitoring student progress, considered in isolation was significant for both subjects, but the correlation was negative, indicating that - absent the other factors - monitoring progress was not an effective activity. The study concluded with advice to school administrators urging them to develop their interview questions around the four domains in order to procure teachers more likely to exhibit classroom behaviors that the study indicated may lead to higher student growth in these subject areas.

In a qualitative study of a sample of 31 Chicago Public School principals, Engel and Curran (2016) found that more than half of the principals surveyed utilize a small number of strategic recruitment practices when selecting teachers, and - possibly due to comparably fewer applicants and the need for more specialized candidates - high school principals on average engaged in more of these practices. Researchers found differences in the use of strategic hiring practices based on school achievement levels, with principals in higher achieving schools utilizing more strategic practices than those in low achieving schools. In reporting on several example interviews, the authors illustrated that the strategic hiring practices used varied widely, and tended to be more widespread in schools that might be a less attractive work environment. Researchers painted a picture 
of the importance of principals in this area where there is a great deal of autonomy. Principals can easily and without personal consequence fail to engage in strategic practices to hire teachers and this decision can have a great impact on student achievement over the long term. While it may be difficult to measure how application of these practices affects student learning in the short term, it seems clear that there must be an effect.

Regardless of the number of teacher applicants that are finally presented to the school by district screening practices and - in a district with decentralized teacher hiring practices - how a particular school formally processes such applicants, the school principal has a great deal of influence in which candidate is ultimately hired to teach in a school. This fact makes the exploration of principal preferences for teacher characteristics important to that ultimate selection.

\section{Principal Preferences of Teacher Characteristics in Hiring}

Beginning in the mid-1980s, researchers have been studying the issue of the preferred characteristics for teacher candidates among various hiring authorities, mostly school principals. Broberg, (1987) was among the first to define teacher characteristics as either professional or personal, and most subsequent researchers followed and extended this strategy (Cannata \& Engel, 2012; Engel, 2013; Harris, Ingle, \& Rutledge, 2014; Harris, Rutledge, Ingle, \& Thompson, 2010; Liu, Liu, Stronge, \& Xu, 2016; Rutledge, Harris, \& Ingle, 2010) Other researchers, including Abernathy, Forsyth, and Mitchell (2001), as well Baker and Cooper (2005), investigated the same preferences, but also looked at other areas that might influence such preferences, such as prior knowledge 
of the candidate or college selectivity of the principal. One study by Jacob and Lefgren (2008), sought to compare principals' stated preferences to teacher value added measures. Broberg (1987) sought to determine whether there was a difference in the preferred characteristics of teacher candidates between the chief hiring officers in urban districts and rural districts. The author noted that, though at the time of his study there was very little agreement on criteria that defines a good teacher, any criteria developed falls into two broad categories. One is professional characteristics that one can acquire through training or study. The other category is personal characteristics which are inborn or developed through habit or inclination. The result of the analysis is that there were very few differences in the preferred characteristics between the chief hiring officer in urban and rural districts. In both, the three highest ranked professional characteristics included having an understanding of children, possessing knowledge of teacher skills and the ability to motivate. The top three personal characteristics were the ability to work with students, good communication skills, and enthusiasm.

With the addition of several demographic variables, Abernathy, Forsyth, and Mitchell (2001) analyzed the results of a correlational study about the perceptions and beliefs of undergraduate students, teacher education faculty, and principals regarding the importance of a variety of teacher characteristics during the hiring process. Overall, they found significant relationships between the perceptions of principals and of teacher education students on both the hiring factors and on the portfolio factors related to their importance in the hiring process. Specifically, principals in this study ranked previous successful teaching experience as most important, followed by cooperating teacher evaluation, samples of teaching/management skills, having prior knowledge of the 
candidate, and recommendation from school personnel. The lowest ranked of the 18 indicators included the university where certification was obtained, involvement in professional organizations, and whether or not the candidate held a graduate degree. Interestingly, the results also indicated that principals tended to value the ability to manage a classroom higher than other teaching behaviors, such as assessment or lesson planning.

In a quantitative study designed to test whether principals who were graduates from more selective colleges were more likely to hire teachers also from more selective colleges, Baker and Cooper (2005) found that such principals were more than twice as likely to do so. One of the authors' assumptions is that principals who attended more selective undergraduate institutions are more likely to have higher academic standards, whether a result of being exposed to higher standards in college or more deeply embedded family and personal values that led the individual originally to attend a more selective college. The authors suggested that, given the results of this study - along with the results of previous research finding a positive relationship between the selectivity of a teacher's undergraduate institution and student achievement - an efficient long-term solution to improving urban schools would be to recruit principals who graduated from more selective institutions.

Jacob and Lefgren (2008), in a study designed to determine the extent to which principals subjective ratings of teachers correlate with teacher effectiveness as measured using teacher value added estimation. The principals rated teachers on eleven characteristics, including "dedication and work ethic, classroom management, parent satisfaction, positive relationship with administrators, positive relations with colleagues, 
role model for students, student satisfaction with teacher, and ability raise math and reading achievement" (p.108). The authors made note of the "noise" to which principals are subject in evaluating teachers - aside from formal performance observations or data reviews. These include such things as reports or complaints (or compliments) from parents, the teacher's daily interactions with and exposure to other faculty and the principal, and informal observations in working with students. All these things can cloud a principal's objectivity when judging teacher effectiveness. The authors found that principals were able to identify top teachers in reading, according to value added measures, $55 \%$ of the time and $70 \%$ of the time in mathematics through their observation process. They further found little ability for principals to rate or rank those in the middle $60 \%$ to $80 \%$ of teachers. The researchers did discover that that principal evaluations of teacher performance are highly correlated to other outputs valuable to parents, such as student satisfaction with a teacher, which suggests that principals may rate teachers according to outside influences rather than simply what they observe in the classroom.

Harris, Rutledge, Ingle, and Thompson (2010) conducted a mixed methods exploratory study to determine principals' preferred characteristics and found that principals seemed to favor a mix of different professional and personal characteristics. In fact, they found that the preferences were often specific to each vacancy and the mixture of characteristics desired often depended on the mix of characteristics found in existing faculty and the existing school culture. When analyzing the rankings, the characteristic of caring was ranked, on average, as most important overall, though it was followed closely by strong teaching skill and less so by knowledge of subject matter. Intelligence was given a low ranking based on the twelve characteristics on the list, but the authors 
surmised from further analysis that principals made the assumption that candidates would be sufficiently intelligent based on the fact that they graduated from college and held teacher certification. The authors also posited that it is possible that other factors sometimes found in highly intelligent people, such as dullness or disinterest, may mitigate any advantage given them by their native intelligence. Somewhat surprisingly given prior research that teacher experience is a predictor of the ability to raise student performance, this characteristic was overshadowed with principals having some preference for less experienced (read non-tenured) teachers that were more pliable and obviously easier to dismiss if they perform poorly. Most principals in this study weighted perceived quality over any demographic characteristics such as race, sex, or age, but several expressed that they were cognizant of those factors when weighing the other characteristics.

Rutledge, Harris, and Ingle (2010) conducted a mixed methods study to develop an understanding of how principals' hiring practices are affected by teacher quality and high-stakes accountability. In addition to qualitative interviews and principal rating scales to determine preferred teacher characteristics, the authors measured the principals' tendency toward bridging (embrace and implement) and buffering (shield and resist) regarding high stakes accountability systems when making teacher hiring decisions. The results indicated that test based accountability influenced principals' preferences, with a majority of principals reporting that they sought candidates with professional characteristics aligned with increasing student performance for accountability purposes, such as knowledge of subject matter and teaching skills. The results tended to support the theory that schools deemed as "stronger," meaning they already performed well on 
state accountability exams were less likely to express a strong preference for professional qualities linked to increasing test scores and more likely to express preferences for personal characteristics not as directly related to increasing test results.

To see whether this focus on accountability was expressed differently based on school context, Cannata and Engel (2012) conducted a study of charter school principals and traditional school principals to determine if there were differences between the two related to the relative emphasis on hiring decisions, the importance attached to specific teacher characteristics and whether principal or school characteristics made any difference. The researchers administered surveys to 89 principals (49 traditional and 40 charter) and used regression analysis to find that charter school principals tended to focus more of their time on hiring decisions, but also found that this may be due to the relatively higher number of vacancies at charter schools due to attrition. They also found that principals of charter schools placed greater weight on teacher agreement with the stated mission and vision of the school than their traditional school counterparts. Further, the charter principals weighed a candidate's willingness to take on additional duties as more important than traditional school principals. There was agreement between the two in giving the highest ranking to a teacher candidates perceived compassion for students, and both ranked teacher certification and ability to produce achievement gains in the top five.

Extending past research on principal preferences, Engel (2013) conducted a comprehensive mixed method study in a large urban district to determine the teacher characteristics most valued by principals and whether this valuation varied based on school demographics or performance levels. The author isolated the four most common 
characteristics mentioned by principals in the interviews. They were "teachers care about children, have content knowledge, are willing to give extra time or bring something extra to classroom, and have classroom management skills" (p.64). There were differences in the preferences based on the achievement level of the schools, with principals in higher achieving schools placing more value on content knowledge and teaching skill, while those in lower achieving schools more often mentioned classroom management and willingness to do extra work. Principals in low wealth schools believed that teachers, to be effective, must have a level of empathy for the conditions the students in the school face. Interestingly, during the interviews, the researcher detected a lack of concern with how principals gauged or recognized content knowledge and teaching skills. Though each was highly ranked in importance, there was little attention paid to how these skills were evaluated. Classroom management was ranked first among principals at lowachieving schools, while it was ranked seventh at high-achieving schools. Engel also found qualitative differences in preferences based on race and gender of the principal. These results were mirrored in the quantitative portion of the study as well. Engel noted that, in the era of high stakes accountability, that it would be expected that principals' focus during the hiring process would be on characteristics that tend to improve test results, such as instructional methodology or content knowledge. However, this was not the case. More important to the principals in this study were characteristics related to operational concerns, such as classroom management and willingness to do extra assignments after school. She wondered if the focus on these operational characteristics was present due the difficulty of ascertaining those more instructional in nature. Engel explicitly noted that her work extends that of Harris, Rutledge, Ingle, and Thompson 
(2010), and concluded by noting that her research has generated still more questions for future research. Specifically, she asked, "Do principals in different contexts (e.g., rural districts, more advantaged suburban districts) look for different things when they are hiring teachers." (p. 82) and noted that additional exploration in different contexts will help us understand these variations in preferences.

In a mixed methods study comparing principal ratings of teacher effectiveness (both overall and with regard to specific characteristics) with value-added estimates of teacher effectiveness, Harris, Ingle, and Rutledge (2014) included a qualitative component that illuminated many of the complications inherent in judging teacher effectiveness. The sample size was relatively small - 30 principals and 294 teachers - but the analysis was more in-depth than many studies of value added in that it included results of open-ended interviews with the principals regarding the teachers they had also rated on an effectiveness scale. The fact that the study was conducted in a Florida school district, a state with an aggressive stance on teacher evaluation using value added models, was important as it illustrated that even in this high-stakes environment, principals valued characteristics that were not specifically linked to test score improvement. One important finding was that, consistent with past research (Jacob \& Lefgren, 2008), there was more overlap between the principal ratings and the value added estimates at the high end of the effectiveness spectrum, indicating that principals are able to identify their most effective teachers. The teacher characteristics rated by principals included the following eleven elements grouped into four categories: intelligent, knows subject, strong teaching skills, and communication skills, grouped into a "technical skill" category; works well with me and works well with team, grouped into a "team player" category; caring, motivated, and 
enthusiastic, grouped into an "affect" category; and contributes to school and contributes to community, grouped into a "contributes beyond class" category. Of these four categorical factors, only the principal rating of "strong technical skills" was significantly related to value added estimates in both reading and mathematics. The authors suggest that principal ratings of teachers, similar to teacher ratings of students, is bound up in perceptions of effort and other "soft" skills that make up what principals perceive as a good teacher.

The latest research in this area mirrored Engel's 2013 study, though in a far different geographic and cultural context. Liu, Liu, Stronge, and Xu (2016) conducted a mixed methods study to determine specific teacher characteristics sought by principals in China and compared these results with the United States counterparts. Qualitative interviews yielded the following list of personal characteristics that Chinese principals in this study preferred: "nicely dressed, no use of profanity, humble, having a positive attitude, happy, humorous, patient, and diligent" (p.112). As for professional characteristics, the author grouped them into three distinct categories - love of education, professional ethics, and professional knowledge and ability. In the first category, principals listed love of the teaching profession, philosophical fit within the school, lack of complaint about working condition, obedience to school administration. Within the professional ethics category principals noted a desire for their candidates to exhibit a high level of moral integrity, set a good example for students, respect their students, attend to developing student self-esteem, caring, fairness, and an interest in students' background, Relating to professional knowledge and skills, desired characteristics included effective communication, high levels of content knowledge, organizational 
skills, technological competence, self-reflection, creativity, and being a lifelong learner. The qualitative analysis done in this study confirmed that Chinese principals sought much the same characteristics as their American counterparts. Teacher enthusiasm, ability to create a positive classroom environment, and classroom management were the most highly rated characteristics of the 13 surveyed. Also consistent with research on American principals, this study found that the lower rated characteristics included whether or not the teacher had an advanced degree and the perceived quality of the teacher education program from which the candidate graduated.

\section{Summary of Literature Review Findings}

In summary, existing research is consistent in the broad questions, but becomes less definitive when attempting answer more specific, and ultimately more useful question related to the role of teaching in student achievement and how to best leverage that role to increase student learning.

It is clear from reviewing the research hat teachers matter. Statistical investigations confirm that there is a relationship between the performance of teachers and the amount that those teachers' students are able to learn. The earliest studies tended to look at school effects, rather than the effects of individual teachers, but this quickly evolved with the application of econometrics such as value added measurement using standardized test scores to the estimation of the effects of individual teachers.

This estimation is not without peril and certainly not without disagreement in methodology or results. There exist clear concerns about the reliability and validity of the estimations related to teacher value added, and these concerns become even more urgent with the application of these formulaic computations to teacher evaluation, 
compensation, and retention. The debate over methodology within the academic community rages on. It is an open question as to whether fixed school effects or fixed student effects are adequately controlled in the value added estimation. Even more difficult is the unpredictability of human motivation and influences in a value added estimate. Even so, taken on a large scale, an academic consensus has emerged that, at least in the subjects and grades for which researchers can collect sufficient data, value added modeling clearly has shown that individual teachers can make a significant difference in the achievement of their students, with social and economic consequences that far outweigh their salaries.

Knowing that teachers are important in student achievement, and that certain teachers are clearly more effective than others quickly lead researchers to wonder what causes some teachers to perform better than others. Though social scientists have long sought to identify the characteristics of more effective teachers, even before teacher effectiveness was defined as higher scores on standardized tests, the lack of sufficiently accurate measurement of many difficult to observe teacher characteristics leave practitioners on their own when determining what characteristics to value when interviewing teacher candidates. In fact, much of the research points out characteristics which do not have a significant relationship to student learning. For example, characteristics such as attendance at selective colleges, advanced academic degrees, teaching experience beyond the first few years, and teacher certifications have not consistently been correlated with increase student achievement. A few characteristics have clear and consistent relationships. In this category, one can safely state that teachers who have more experience are more effective than those with no experience and general 
cognitive ability is related to higher student achievement. There were also some indication that subject matter expertise and teachings skill have some positive correlation with increased student achievement, particularly in secondary mathematics courses.

In much the same way as teacher are important, the research is clear that principals have a significant effect on student academic achievement. This relationship is even harder to isolate into discrete characteristics because the principal has an impact on so many different facets of the school - be it through the establishment of the culture, organization of the schedule, determination of the curriculum, evaluation of teachers, and - perhaps most importantly - teacher hiring.

The interaction between the importance of the teacher in student achievement, the importance of the principal in school performance, and the primary role of the principal in the hiring of teachers leads one inexorably to the question of how principals make hiring decisions that will ultimately determine the level of student learning in a school's classrooms. Before the principal makes a selection, a candidate for a teaching position must navigate the application and interview process at the district level. The variations in recruitment and screening processes can be much different based on a number of district factors, such as location, relative wealth, size, the type of screening that is completed, and the level of decentralization in the hiring process.

The above factors influence the quality and number of candidates from which a principal can choose. The basis on which that choice is made flows from a complex interaction of school culture, principal philosophy, school setting and demographic makeup, the mode of school governance, and principal experience. There were a number of combinations and characteristics identified with varying levels of importance, but teacher 
caring for children, content knowledge, willingness to go beyond minimal expectations and classroom management were among the consistently high rated characteristics. Interestingly, two of the characteristics related to increased student achievement - experience and high cognitive ability - were rarely rated as highly important to principals. This can be explained by the possible assumption of the principal that a teacher who graduated from college and became certified has sufficient cognitive ability, and possibly by the notion that an inexperienced teacher may have fewer bad habits to unlearn, or is easier to terminate than a teacher with more experience and possibly with tenure. 


\section{CHAPTER III}

\section{METHODOLOGY}

The purpose of this study was to determine the characteristics of teacher applicants preferred by school leaders - specifically principals and assistant principals in rural and suburban school districts when hiring teachers and whether these preferred characteristics vary based on the characteristics of the school or the characteristics of the school leader. In addition to determining the underlying dimensions of the Preferred Teacher Applicant Characteristics Survey instrument, this study examined the relationship between a school's characteristics (poverty, school performance category, average teacher experience, and the school leader's age, gender, current role, and years in current role) and a school leaders' preferences for teacher applicant characteristics.

The previous chapter demonstrated the importance of teachers in student achievement and examined the characteristics of teachers that may contribute to effectiveness; however, the chapter also indicated the need for further research into school leaders' preferences for specific teacher characteristics. This chapter will discuss the research design, data sources, sample, the conceptual framework, data collection procedures and data analysis procedure that guided this study. It also explains the operationalization of the dependent and independent variables and the statistical model utilized in this investigation. Finally, it clarifies the limitations of this study and concludes with a summary. 


\section{Research Design}

A non-experimental survey design was used to examine the relationship of school characteristics and school leader factors to school leaders' preferred characteristics of teacher applicants. The survey design included collecting survey data in the summer of 2017, a time when hiring decisions were an important task for many of the school leaders in the study. An exploratory factor analysis was utilized to examine dimensions underlying patterns among the 31 survey items that were designed to measure preferred teacher applicant characteristics. The retained factors from the factor analysis served as the dependent variables. Then, a series of standard multiple regression analyses (depending on the number of retained factors) were performed by regressing the dependent variables on the independent variables, which reflected both school and school leader characteristics. This research design effectively utilized data to test the hypotheses noted in the next section (Creswell, 2009).

\section{Research Questions}

There were two research questions in this study. The first research question was to determine the underlying dimensions of the Preferred Teacher Applicant Characteristics Survey (PTACS) instrument. The second research question, which depended on the number of factors retained from the exploratory factor analysis and was answered using a series of multiple regressions, was to examine the relationship between a school's characteristics (poverty, school performance category, average teacher experience, and the school leader's age, gender, current role, and years in current role) and a school leaders' preferences for teacher applicant characteristics? 
To examine whether these relationships exist and the strength of any such relationships, once the underlying dimensions were identified and named, I examined the following:

1. The relationship between a school's characteristics (poverty, school performance category, average teacher experience, and the school leader's age, gender, current role, and years in current role) and the school leader's preferences for teacher candidate's personal characteristics.

2. The relationship between a school's characteristics (poverty, school performance category, average teacher experience, and the school leader's age, gender, current role, and years in current role) and the school leader's preferences for teacher candidate's professional characteristics.

3. The relationship between a school's characteristics (poverty, school performance category, average teacher experience, and the school leader's age, gender, current role, and years in current role) and the school leader's preferences for teacher candidate's ancillary characteristics.

4. The relationship between a school's characteristics (poverty, school performance category, average teacher experience, and the school leader's age, gender, current role, and years in current role) and the school leader's preferences for teacher candidate's demographic characteristics.

\section{Conceptual Framework: School Leader Perceptions and Hiring}

The study's design was informed by a conceptual framework identified below

(figure 1) that identifies key factors identified in the literature that may be related to school leader's differing preferences of the various characteristics of teacher candidates, 
such as school poverty, school performance category, and experience level of the faculty, as well as school characteristics including age, years of teaching experience, years of administrative experience, and level of teaching experience (elementary, middle, or high). School poverty is measured by the percentage of students in the school that qualify for free or reduced price lunch. School performance category is the rating assigned on the School Report Card by the Kentucky Department of Education.

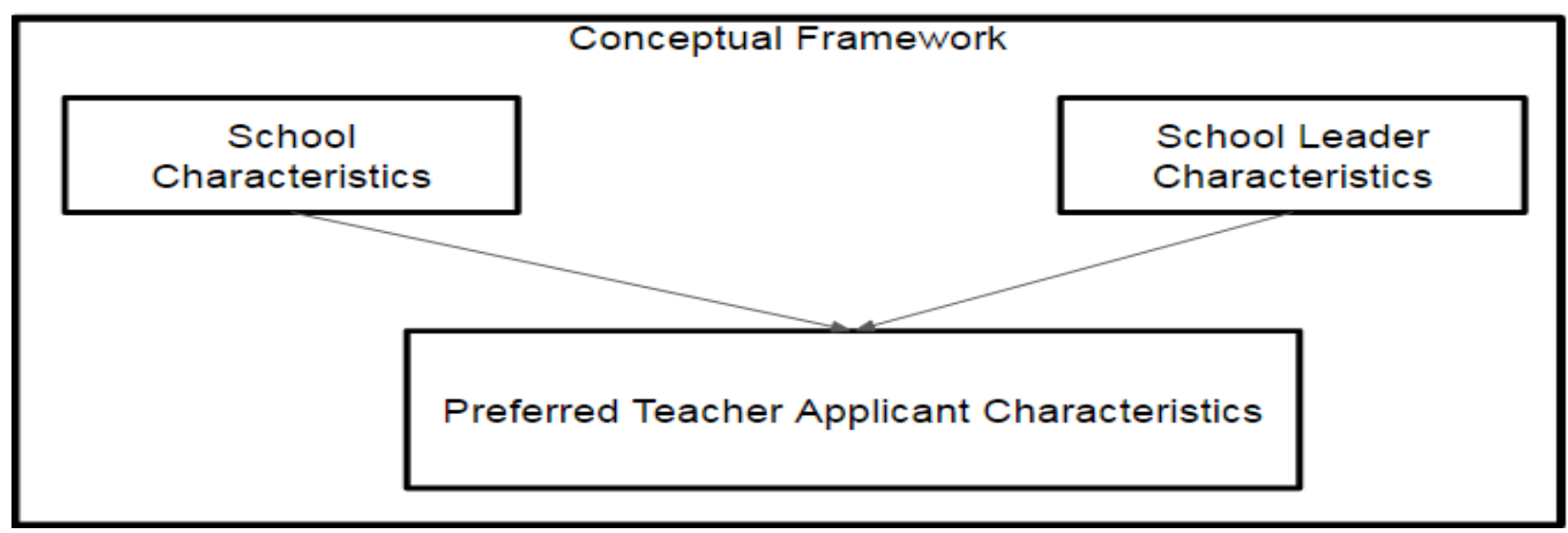

Figure 1. Conceptual Framework for School Factors and Preferred Teacher Characteristics

\section{Study Participants}

This study was designed to contribute to the research literature regarding school leader's preferences for characteristics of teacher candidates. Past research (Engel, 2013) addressed this question in the context of an urban district and suggested future research should be conducted in other contexts. The current study gathered data from school leaders in rural and suburban districts located adjacent to two large urban school district in Kentucky. The urban districts, which the rural and suburban districts studied surround, serve approximately 137,000 students. The students in the urban districts are $51.5 \%$ minority, $62.2 \%$ receive free or reduced price lunch, $12.0 \%$ receive special education services, and 9.0\% are English Language Learners. The districts employ 8,873 teachers. 
In total, the surrounding rural and suburban districts serve 85,075 students. The students in the surrounding rural and suburban districts are $18.9 \%$ minority, $47.4 \%$ receive free or reduced price lunch, $13.0 \%$ receive special education services, and 3.2\% are English Language Learners. The districts employ a total of 5,203 teachers (Kentucky Department of Education, 2016).

\section{Sampling}

In the current study, the population included all school leaders in rural and suburban school districts situated outside large urban districts in Kentucky. The sampling frame of this study was based on a list of principals and assistant principals in the 12 rural and suburban school districts surrounding the two urban school districts. A convenience sample is an example of a non-probability sampling technique which should not be used to make inferences about the total population, but can serve to suggest ideas that may be tested using more generalizable methods when the population is assumed to be homogenous (Ilker, Sulaiman, \& Rukayya, 2016). The number of potential respondents was 300 once permission was granted by all school districts and the data was collected during the summer of 2017. Though a larger sample size is preferable, the ratio of participants to variables is acceptable in this study (Comrey \& Lee, 1992), and sample size rules are highly variable. Henson and Roberts (2006) conclude that the best rule is to collect the "largest possible sample for a factor analysis" (p. 402). The school leaders are employed by the rural and suburban school districts targeted in the sampling frame. Principals and assistant principals were chosen for this sample because this study's research questions were directly related to school leader perceptions and the most direct source of school leader perceptions are the school leaders themselves. This sample 
was selected because it fulfilled the intent of this study to measure the preference of school leaders in rural and suburban districts with regard to teacher applicant characteristics. There were 272 recorded responses. Thirty-nine incomplete survey responses were removed from the data set. An additional 24 responses were removed due to the respondent's school having no associated performance rating level due to being an alternative school, vocational technical school, or preschool, bringing the completed number of surveys to 209 . This represents a $69.7 \%$ response rate with a nearly equal number of assistant principal and principals.

\section{Measures}

The Preferred Teacher Applicant Characteristics Survey (PTACS) was the instrument used to gather the data for the study. The survey package included two parts: participant demographic information and the PTACS. The demographic information collected included race/ethnicity, gender, age, participants' educational and professional experience, current position, years of experience in their current role, and the name of their school and district. The school and district name was used to access information regarding school characteristics from publicly available administrative data found in the Kentucky School Report Cards, which are collected by the Kentucky Department of Education. The participants were asked to respond to 31 survey items designed to measure their preferences for teacher applicant characteristics. The estimated time to complete the survey was approximately 10 minutes (See Appendix A for full survey).

\section{Preferred Teacher Applicant Characteristics Survey (PTACS)}

The survey included a rating of 31 teacher applicant characteristics around two broadly identified theoretical constructs - personal characteristics and professional 
characteristics - and provided key information on the characteristics used by school leaders when hiring teachers. The instrument was created based on the guidelines of scale development (DeVellis, 2016), including the specification of the measure's purpose, as well as characterizing the sample in which the instrument will be administered. Personal characteristics measured include motivation, creativity, intelligence, and ability to work well with others, content knowledge, teaching skills, and ability to raise test scores. Professional characteristics measured include certification status, prior experience, level of education, and previous exposure to diversity. Two dimensions were identified for the PTACS: personal characteristics and professional characteristics. The personal characteristics dimension includes 15 items and the professional characteristics dimension includes 16 items, most of which were adapted from open-ended interviews in a mixed methods study conducted by Harris, Rutledge, Ingle, \& Thompson (2010) and an on-line survey administered to Chicago Public School administrators as reported by Engel (2013). Responses were provided on a five-point Likert scale $(1=$ Not at all Important to $5=$ Extremely Important $)$.

\section{Validity}

According to Devilles (2003), the validity of the items on a survey instrument relates to the extent to which the scale measures the variable of interest to the researcher. The instrument underwent pilot testing to ensure adequacy of content (e.g., language, clarity of instructions) and to investigate its psychometric properties via an exploratory factor analysis. Likewise, subject matter experts were used to inspect relevancy of items as a source of gathering content validity evidence of the instrument. Problematic items were reviewed for modification or elimination from the instrument. Since the instrument 
was only recently developed, no psychometric information on the scores from the instrument were available. Results from the planned exploratory factor analysis were used to provide some evidence for the construct validity scores from the PTACS.

\section{Reliability}

Survey reliability refers to the consistency of results produced by a survey instrument (Ritter, 2010). This is measured by testing the extent to which the variation in the results are caused by variation across respondents (Devilles, 2003). Cronbach's alpha was also computed on the final sample once data collection was complete. A computed coefficient alpha of greater than .7 was considered acceptable following the George and Mallery (2003) rule of thumb.

\section{Operationalization of variables}

\section{Independent Variables}

The independent variables in this study are operationalized as specific measurable attributes as follows:

1. School Poverty Level - Ratio level variable expressing the percentage of students qualifying for free or reduced price lunch.

2. School Achievement Level - Nominal level variable defined as the overall school performance rating assigned by the Kentucky Department of Education. The ratings are - from highest to lowest - Distinguished, Proficient, and Needs Improvement. The variable was dummy coded into two variables to identify the three school performance levels.

3. Experience Level of Teaching Faculty - Ratio level variable expressing the average years of teacher experience of the teaching faculty. 
4. Age - Ratio level variable expressing the respondent's chronological age in years.

5. Years of Experience in Current Role - Ratio level variable denoting the number of years the respondent has served in his or her current role.

6. Total Years of Professional Education Experience - Ratio level variable denoting the total number of years the respondent has been employed as a professional educator.

7. Gender - Nominal level variable indicating whether the respondent identifies as either male or female. 0s were assigned to male school leaders, and 1s were assigned to female school leaders.

8. Current Role - Nominal level variable indicating role of either principal or assistant principal. 0s were assigned to principals and 1s were assigned to assistant principals.

9. Work Location - Ordinal level variable identifying the school level and/or structure including elementary school, middle school, combined middle/high, high school, vocational/technical school, or alternative school.

10. Highest Level of Education - Ordinal level variable denoting the respondents level of education, identified as either Bachelor's degree, Master's degree, Specialist's degree, or Doctoral degree. 0s were assigned to those holding a Bachelor's degree, 1s were assigned to those holding a Master's degree, 2s were assigned to those holding Specialist's degree, and 3s were assigned to those holding a Doctoral degree.

11. Race/Ethnicity - Nominal level variable representing the race or ethnicity with which the respondent self-identifies with the choices being Asian/Pacific Islander, 
Black/African American, Hispanic, Mixed Ethnicity, Native-American, and White. In the sample collected, there were no respondents who self-identified as Hispanic, Mixed Ethnicity or Native American, so this variable was dummy coded into two distinct variables - Asian/Pacific Islander $(0=$ non-Asian/Pacific Islander, $1=$ Asian/Pacific Islander $)$, Black/African American $(0=$ nonBlack/African American, 1 = Black/African American)- with White being the baseline variable.

\section{Dependent Variable}

The dependent variable in this study are the school leaders' preferences for particular teacher applicant characteristics. This variable was assessed by the PTACS which uses a 5-point Likert-type scale with the choices consisting of 1) Not at all Important, 2) Very Unimportant, 3) Moderately Important, 4) Very Important, and 5) Extremely Important. There are 31 statements to which the respondent expressed a preference and these items were subjected to an exploratory factor analysis to determine the dependent variables used in the multiple regression analyses.

\section{Procedures}

An on-line survey was conducted to gather data on background variables as well as to administer the PTACS to capture school leader preferences for characteristics of teacher applicants. An electronic web-based survey was chosen due to convenience, rapidity of data collection, and because sensitive personal information is not being sought in this research (Sue \& Ritter, 2012).

Data collection was based on the Tailored Design Method and used a mixed mode model to enhance the response rate of the survey (Dillman, Smyth, \& Christian, 
2014). Dillman, Smyth, and Christian suggest “... using multiple survey modes as a means of communication to encourage response in a single mode may be a more powerful way of mixing modes to improve survey response and the quality of those responses than simply providing an alternative mode for responding to a survey" (p. 14). The researcher contacted the superintendent of each target school district personally via email and telephone to discuss the research and request their cooperation and assistance with introducing the survey to the school leaders employed in his or her district. The researcher also requested the superintendent's assistance in forwarding communications to the school leaders because the school leaders may feel a higher sense of trust in completing the survey if it comes from a local district official who is well known to the potential respondent. A list of school leaders' work emails were also requested and obtained. The superintendent of the targeted districts were provided with text for a personal email requesting assistance and a written purpose and description of the research that he or she forwarded to the principals and assistant principals in the selected district. The researcher provided a link to the survey to the superintendent to forward to the school leaders as part of the email. The researcher followed up directly with an email the following day to potential respondents, repeating the request and explanation, and expressing appreciation if the school leader had already completed the survey. A second email request was sent through the superintendent five days later for those who had not responded at that time. Five days after this, a final email follow-up was delivered to those who had not completed the survey. See Appendix B for data collection information. The total data collection period for each sampled district was ten 
days. The survey instrument was administered electronically using an online survey system (Qualtrics).

\section{Data Analysis}

Descriptive statistics for each major variable were reported. Basic assumptions were checked prior to major analyses. In order to test normality of all variables, the researcher examined skewness and kurtosis of the variables, and linearity was assessed using scatterplots.

An exploratory factor analysis was conducted to determine if there were underlying relationship patterns among the 31 survey items that might explain school leaders' preferences for certain teacher characteristics. The retained factors from the factor analysis served as the dependent variables in the subsequent analyses. Following the exploratory factor analysis, a series of standard multiple regression analyses were conducted to determine the relationship of the independent variables with the dependent variables and the relative influence of the various independent variables on the principal preferences for personal or professional characteristics among teacher applicants. Prior to conducting the multiple regressions, major assumptions were checked.

\section{Assumptions}

Prior to conducting the main statistical analyses, several assumptions were checked. Stevens (2009) notes that four factors must be met, including samples size, multivariate normality, linearity, and outliers among variable, though Field (2009) lists several others. Each of the following assumptions were examined prior to reporting descriptive statistics and significant findings for the regression analysis: 
1. Sample Size - There are many different rules on samples size using regression models, most based on the number of predictors to be used. This study proposed to collect seven distinct predictor values. According to Fields (2009), a sample size of 200 is sufficient for examining medium effect with up to 20 variables, thus actual sample size of 209 responses with 7 predictors provides ample data.

2. Normality -- The assumption of normality in the distribution of residuals (i.e., the difference between the predicted model and the data observed are very close to zero. This assumption of the variables was be checked by examining the skewness and kurtosis of a histogram and a Q-Q plot.

3. Linearity -- The relationship between the predictor and outcome variables needs to be linear. This was examined by inspecting the results of a scatterplot.

4. Multicollinearity - This exists when there are two or more predictor variables that are perfectly correlated, meaning there is no way to determine which predictor is causing the effect. I tested this assumption by examining the Variable Inflation Factor for any factor greater than 10 , which is an indication of the presence of multicollinearity (Fields, 2009).

5. Homoscedasticity - This simply means that the error terms (residuals) for each level of the predictor are equal. This assumption was tested by examining the standardized residuals using scatter plots.

\section{Exploratory Factor Analysis}

The Preferred Teacher Applicant Characteristics Survey (PTACS) instrument contains 31 items on a 5-point ordinal Likert-type scale. The literature on which the PTACS was developed (Engel, 2013; Harris, Rutledge, Ingle, \& Thompson, 2010) 
suggest that two dimensions - professional and personal - underlie the 31 items, but as the instrument is newly developed, it was important to conduct an exploratory factor analysis as a data reduction technique in order to determine and analyze these underlying factors. Henson and Roberts (2006) note that exploratory factor analysis is useful for testing the integrity or the measurement instrument, but also identify the constructs that undergird the data and which of these constructs best describes the original variables. In new instrument development, Henson and Roberts note that exploratory factor analysis can be used to assess and refine items based on theoretical expectations. The sample size of 209 completed surveys was sufficient to meet the normal assumptions of factor analysis, and this adequacy was buttressed by the research base underlying the survey instrument.

Factors were extracted using Principal Component Analysis, one of the most common method of extraction utilized by researchers (Plucker, 2003; Henson \& Roberts, 2006). Decisions on which factors to retain were based on three evaluations: eigenvalues greater than 1, the scree test, and parallel analysis (Plucker, 2003; Henson \& Roberts, 2006). The eigenvalue greater than 1 rule and the scree test are both methods to examine the percentage of variance explained by a particular factor, while parallel analysis compares a similar analysis to a random data set, with only those factors in the actual data with eigenvalues which exceed those in the random set are retained. Once the number of factors to retain factors were determined, I subjected them to an orthogonal rotation to identify specific variables' contribution to the factor, with factor structure coefficients having value of .40 or greater being used to help name the factor (Pituch $\&$ Stevens, 2016). In order to confirm the results of the Principal Components Analysis, I 
conducted a Parallel Analysis, which compares the observed eigenvalues of the extracted factors to eigenvalues extracted from a simulated random data set (O’Conner, 2000).

\section{Multiple Regression}

A multiple regression analysis (Field, 2009) was performed on the data to determine the relative influence of the various independent variables on the principal preferences for personal or professional characteristics among teacher applicants. According to Field (2009), regression analysis is used to "predict values of the dependent variable from one or more independent variables" (p. 198). Using a modification of Engel's (2008) research, the model of school leader's survey responses will be a function of their own demographic characteristics, along with those of the schools where they are employed. The exploratory factor analysis described in the previous section, in conjunction with the findings of past research (Engel, 2013; Harris, Rutledge, Ingle, \& Thompson, 2010), were used to determine the constructs entered into the general multiple regression equation:

$$
Y_{i}=\left(a_{i}+\beta_{1} X_{i 1}+\beta_{2} X_{i 2}+\ldots+\beta_{n} X_{n}\right)+\varepsilon_{i}
$$

where $\mathrm{Y}_{\mathrm{i}}$ is the predicted mean scores of the items loading significantly (.40 or higher) on the each factor yielded by the exploratory factor analysis of the results of the PTACS survey adjusted by researcher judgement regarding previous research; $\mathrm{X}_{\mathrm{i} 1}$ is the first independent variable, $X_{\mathrm{i} 2}$ is the second independent variable and so on, and $\beta$ is the amount of change in $\mathrm{Y}$ for one unit change in $\mathrm{X}$.

\section{Limitations of the Study}

There are a number of limitations of this study. The survey sampled school leaders in suburban and rural areas surrounding two major metropolitan areas. While this 
sample was purposeful based on the intent to extend the results of previous studies conducted inside metropolitan areas, it must be noted that the results may not be applicable to urban school districts or rural districts not surrounding a major metropolitan area. There is also the possibility of bias based on the position of the researcher, who is the superintendent in one of the districts where data is being collected. This study incorporates a definition of school leader as being either a principal or assistant principal. As the principal serves as the primary decision maker in the hiring process, and is subject to the pressure and consequences of making these decisions, the inclusion of assistant principals in the sample may have skewed the data in some undetermined way. Finally, as this was a convenience sample obtained in districts surrounding two distinct metropolitan areas, the data may not be generalizable to all suburban and rural districts surrounding metropolitan districts throughout the nation. Indeed, the findings are only generalizable to the present sample and time period from which the data were collected.

\section{Summary of Methodology}

In this study, I investigated the relationship between a school's characteristics and school leaders' preferences for teacher applicant characteristics, and also the relationship between school leader's own characteristics and school leaders' preferences for teacher applicant characteristics. A 31 question survey on school leaders' preferences for teacher applicant characteristics, which included school and school leader demographic and other identified characteristics, was administered to 209 school leaders in twelve school districts surrounding two major metropolitan area in the summer of 2017. I reported descriptive statistics for each major variable, checked basic assumptions prior to major 
analyses, tested normality of all variables by examining skewness and kurtosis of the variables, and assessed linearity using scatterplots. I then conducted exploratory factor analysis to determine significant factors which served as the dependent variables in a series of a multiple regression analysis to answer the two identified research questions. 


\section{CHAPTER IV}

\section{RESULTS}

The purpose of this study was to determine the qualities and characteristics valued by school leaders in suburban and rural school districts when hiring teachers, and whether

those valued characteristics varied based on demographics of the school or background of the school leader. To address the two research questions posed in this study, I utilized descriptive statistics, an exploratory factor analysis, and multiple regression to analyze survey data gathered from school leaders currently working in suburban and rural districts surrounding two urban districts in Kentucky. This section will describe the results of this analysis, first by examining and explaining the descriptive statistics of the independent variables, then by describing the results of the exploratory factor analysis used to determine the dimensions underlying the Preferred Teacher Applicant Characteristics Survey, and finally by reporting the results of a series of standard multiple regressions to describe the relationship between the independent variables and the dependent variables (or factors). The results, taken collectively, will provide information on the teacher applicant characteristics most valued by school leaders in a rural or suburban school setting. 


\section{Descriptive Statistics}

Descriptive statistics for frequencies are reported in the tables below for each independent variable. There are separate tables for school leader characteristics (See Tables 1 and 2) and for school characteristics (See Table 3).

Table 1

Descriptive Statistics of School Leader Characteristics $(N=209)$

\begin{tabular}{lcrr}
\hline School Leader Nominal Characteristics & Frequency & Percent & Cum. Percent. \\
\hline Current Role & 107 & 51.2 & 51.2 \\
Principal & 102 & 48.8 & 100.0 \\
Assistant Principal & & & \\
Gender & 91 & 43.5 & 43.5 \\
Male & 118 & 56.5 & 100.0 \\
Female & & & \\
Work Location & 91 & 43.5 & 43.5 \\
Elementary School & 53 & 25.4 & 68.9 \\
Middle School & 5 & 2.4 & 71.3 \\
Combined Middle/High & 60 & 28.7 & 100.0 \\
High School & & &
\end{tabular}

Highest Level of Education

Master's Degree

Specialist's Degree

Doctoral Degree

Race

\begin{tabular}{lccr} 
Asian/Pacific Islander & 1 & 0.5 & 0.5 \\
Black/African American & 3 & 4.3 & 4.8 \\
White & 199 & 95.2 & 100.0 \\
\hline Note. Other choices for Race were Hispanic, Mixed Ethnicity, and Native American
\end{tabular}


The number of participants in this study was 209 . In total, $43.9 \%(n=91)$ of the sample were males and $56.5 \%(n=118)$ were females, while nationally, $48.5 \%$ of principals are males and 51.5\% are female (National Center for Education Statistics, 2013). In Engel's 2013 study regarding principal preferences of teacher characteristics, which this study serves to extend, $30.0 \%$ of the principals were male and $70 \%$ were female. The mean age of the school leaders who participated in the survey was 42.5 (SD $=7.07$ ) years, with the youngest respondent aged 28 years and the oldest reporting an age of 70 years. The average age is less than the Engel's sample, where the average age was 54.0 years old, while NCES data (2013) indicates that the mean age of principals nationally is 48 years, and 47 years in Kentucky. The mean total years of responding school leaders' professional education experience is $17.92(\mathrm{SD}=6.42)$ years, ranging from 5 years to 40 years.

Among Kentucky schools, $63.5 \%$ are elementary schools, $18.3 \%$ are middle schools, $1.6 \%$ are middle/high schools, and $16.5 \%$ are high schools. In this study, $43.5 \%$ $(n=91)$ of respondents worked in an elementary setting, $25.4 \%(n=53)$ worked in a middle school, $2.4 \%(n=5)$ worked in a combined middle/high school, and $28.7 \%(n=$ $60)$ worked in a high school. Of the respondents in this study, $60.3 \%(n=126)$ held a Master's degree compared to $85 \%$ of Engel's sample and $61.7 \%$ nationally. The doctoral degree was held by $2.9 \%(n=6)$ of respondents, while $11 \%$ of the respondents in Engel's study, and $9.9 \%$ in the national data from NCES held the same degree. Engel did not report the number of principals with a Specialist degree, but $36.8 \%(n=77)$ of respondents in this study reported holding that degree as compared to $26.3 \%$ of principals in the US. 
In this study, $95.2 \%(n=199)$ of respondents were White, $4.3 \%(n=6)$ were Black/African American, and 0.5\% $(n=1)$ were Asian/Pacific Islander. This closely mirrors Kentucky teachers, the ranks from which principals often come, with 95.5\% White, 3.5\% Black/African American, and less than 1\% reporting other races. Nationally, $80.3 \%$ of principals are White, $10.1 \%$ are Black/African American, $6.8 \%$ are Hispanic, and 2.8\% are classified as Other. In Engel's sample from a large urban area, $27 \%$ were White, $49 \%$ were Black/African American, 14\% were Hispanic, and less than $0.1 \%$ were Asian. Both the racial makeup of the sample and of the state may be a result of the rural nature of the districts studied and the state as a whole. Figure 2 shows the breakdown of the age of the PTACS respondents.

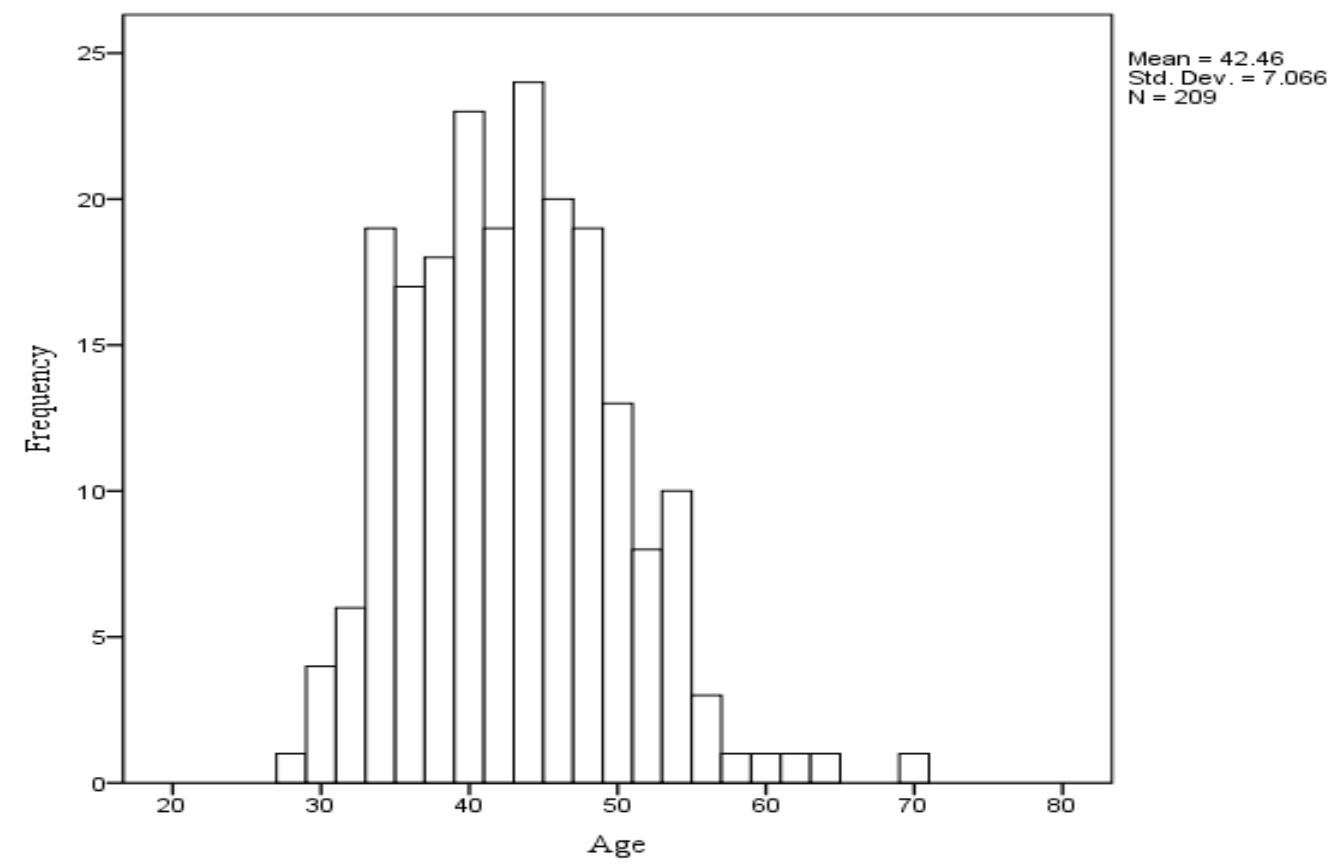

Figure 2. Age distribution of PTACS respondents.

Table 2 describes the number of years the respondent has served in his or her current role as a school leader, either assistant principal or principal. On this variable, the lowest reported number of years was 1 , while the highest number of years in the current 
role was 25 with the mean value of $4.38(\mathrm{SD}=3.944)$ years. The large percentage of school leaders in the lowest range is reflective of the literature on principal tenure. Fuller and Young (2008), in a study of school principals in Texas, found the average principal tenure to be 4.51 years. Nationally, National Center of Education Statistics data indicates that $73 \%$ of principal have been in position less than five years. (NCES, 2013).

Table 2

Total years in current role of PTACS respondents $(N=209)$

\begin{tabular}{lccc}
\hline \multicolumn{1}{c}{ Year Range } & Frequency & Percent & Cumulative Percent \\
\hline $0-5$ years & 149 & 71.3 & 71.3 \\
$6-10$ years & 43 & 20.6 & 91.9 \\
$11-15$ years & 14 & 6.7 & 98.6 \\
$16-20$ years & 3 & 1.4 & 100.0 \\
More than 20 years & 1 & $<0.1$ & 100.0 \\
\hline
\end{tabular}

Table 3 reports the school characteristics in which the leaders worked including the school's poverty level, the experience level of the teaching faculty, and the school rating on the Kentucky accountability system, namely "Needs Improvement", "Proficient", and "Distinguished".

School leaders serving in schools rated as Needs Improvement represented 27.3\% $(n=57)$ of the sample, compared to $30.6 \%$ of schools in Kentucky. School leaders serving in schools rated as Proficient in the state accountability system made up $34.4 \%$ (n $=72$ ) as compared to $42.2 \%$ in the state. School leaders serving in schools rated as Distinguished made up $38.3 \%$ of the sample, exceeding the $27.2 \%$ of schools in the state with the same rating. 
Table 3

Descriptive Statistics of School Characteristics $(N=209)$

\begin{tabular}{lccr}
\hline School Characteristics & Mean & Min & Max \\
\hline School Poverty Level & $47.0 \%$ & $6.8 \%$ & $79.8 \%$ \\
Average Faculty Experience in Years & 11.6 & 6.4 & 21.0 \\
\hline
\end{tabular}

\begin{tabular}{llll}
\hline School Achievement Level & Frequency & Percent & Cum. Percent
\end{tabular}

$\begin{array}{lccr}\text { Needs Improvement } & 57 & 27.3 & 27.3 \\ \text { Proficient } & 72 & 34.4 & 61.7 \\ \text { Distinguished } & 80 & 38.3 & 100.0\end{array}$

Another school characteristic reported was poverty rate, as measured by the percentage of students qualifying for free or reduced price school lunch. The 209 school leaders worked in schools with average poverty rating of $47.0 \%(\mathrm{SD}=16.2)$, compared to the overall poverty rate in Kentucky schools of $60 \%$ (Kentucky Department of Education, 2016). Engel's 2013 study utilized a poverty measure based on qualifying for free lunch only, and that rate was $40.6 \%$. Kentucky's percentage of students qualifying for free lunches is $54.4 \%$.

\section{Assumptions}

Internal consistency reliability coefficient of the scores from the PTACS were computed for the 31 response items. The items represented characteristics of teacher applicants extracted from the research literature and respondents were asked to rate each item on a five-point Likert scale $(1=$ Not at all Important to $5=$ Extremely Important $)$. 
The Cronbach's Alpha for these 31 items was .84, exceeding the standard of .70 (George \& Mallery, 2003) and indicating an acceptable level of internal consistency reliability of the scores from the PTACS. Internal consistency reliability coefficient of the subscales are reported below as part of the exploratory factor analysis results.

The normality of the 31 initial items to be used in the exploratory factor analysis were checked (see Table 4 for a complete list). In the examination of skewness, all independent and dependent variables fell within the range of -2 and +2 as indicated by George and Mallery (2003). The examination of kurtosis revealed the same lack of normality on the dependent variables indicating school leaders' preference for applicant's high expectations for students and the applicant's ability to increase student achievement beyond standardized tests.

\section{Exploratory Factor Analysis}

The Preferred Teacher Applicant Characteristics Survey (PTACS) instrument contains 31 items on a 5-point Likert scale. The literature suggests that the 31 items are best described by one of two dimensions - professional or personal. An exploratory factor analysis, which was conducted as a data reduction technique to either confirm these dimensions or to suggest other underlying dimensions in answer to my first research question.

I conducted an exploratory factor analysis (EFA) on the PTACS data using IBM SPSS Version 24.0 to run a principal component analysis with a varimax rotation on the correlations of 31 teacher applicant characteristic items. Prior to conducting the EFA, assumptions of sample size, inter-correlations, and normality were checked. The Kaiser Myer-Olkin measure of sampling adequacy was .781, which indicated that the data was 
suitable for principal component analysis (Kaiser, 1974). Bartlett's test of sphericity $\left(\chi^{2}=\right.$ 2145.469, $d f=465, p<.001)$ was significant indicating there were significant correlations between the variables, allowing me to continue with the analysis. Normal QQ plots were examined for each item and appeared normally distributed with the plots adhering closely to the line of normality. Decisions on which factors to retain were based on three criteria: eigenvalues greater than 1, the scree test, and parallel analysis (Plucker, 2003; Henson \& Roberts, 2006). The eigenvalue greater than 1 rule and the scree test are both methods to examine the percentage of variance explained by a particular factor, while parallel analysis compares a similar analysis to a random data set, with only those factors in the actual data with eigenvalues which exceed those in the random set are retained. A factor structure coefficient of .40 or greater was deemed significant in this study (Pituch \& Stevens, 2016).

\section{Factor Structure of Preferred Applicant Characteristics}

The initial solution from the principal component analysis indicated that nine components had eigenvalues greater than 1 , which explained approximately $61.4 \%$ of the total variance. Both eigenvalue greater than 1 and the scree plot suggested nine factors, three of which were trivial factors and only two items had factor loadings greater than .40. A parallel analysis suggested four factors (Appendix C). A parallel analysis makes suggestions for the number of factors to retain by comparing factors that have eigenvalues greater than 1 based on raw data as well as randomly generated data. Based on these criteria as well as on the nature represented by each factor, a four-factor structure was deemed the best structure for the PTACS. 
The retained four factors explained $43.0 \%$ of the total variance. After rotating the retained factors orthogonally (varimax rotation), the first factor had 12 items loading significantly using the .40 cut-off criterion as suggested by Pituch and Stevens (2016). The first factor contained 12 characteristics and accounted for $15.1 \%$ of the variance. The first factor contained the following items: enthusiasm, caring, cooperativeness, thoughtfulness/reflectiveness, flexibility, motivation, willingness to give extra effort/go above and beyond, positive role model for students, ability to work well with others, high expectations of students, communication skills, and commitment to professional development. In accordance with the theoretical construct employed in the survey design, and based on the factor loadings, I named the first factor "Personal." The second factor contained 10 characteristics and accounted for $11.9 \%$ of the variance. The second factor included the following items: level of education/degrees earned, content knowledge, ability to raise student test scores; certification status, prior experience, classroom management skills, teaching skills, ability to increase student achievement beyond standardized tests, teaching philosophy, and intelligence. This factor was also found in the theoretical construct and based on the factor loadings, this factor was named "Professional." The third factor containing six characteristics was new and explained $8.1 \%$ of the total variance. The third factor included the following items: fluency in language other than English, previous exposure to diversity, postsecondary education institution attended, creativity, technological proficiency, and organizational skills. After examining the item names and the factor structure coefficients, I named this factor "Ancillary." The fourth factor contained three characteristics and explained $7.8 \%$ of the variance. The fourth factor included the following items: race, gender, and place of 
residence (distance from school with vacancy). This factor was named "Demographic" based on the factor loadings. Detailed information on the items and factor coefficients is presented in Table 4.

Table 4

Factor Structure Matrix for Teacher Applicant Characteristics Factors

Applicant Characteristic $\quad$ Personal Professional Ancillary Demographic

\begin{tabular}{lcccc}
\hline Applicant's enthusiasm & .71 & .03 & .06 & -.19 \\
Applicant's caring & .63 & -.10 & .18 & -.04 \\
Applicant's cooperativeness & .61 & .23 & -.08 & -.4 \\
$\begin{array}{l}\text { Applicant's } \\
\text { thoughtfulness/reflectiveness }\end{array}$ & .59 & .12 & .11 & .16 \\
Applicant's flexibility & .58 & .07 & .26 & -.07 \\
$\begin{array}{l}\text { Applicant's motivation } \\
\text { Applicant's willingness to give }\end{array}$ & .57 & -.10 & .09 & .07 \\
extra effort/go above and beyond & .56 & .17 & -.03 & .26 \\
$\begin{array}{l}\text { Applicant is a positive role model } \\
\text { for students }\end{array}$ & .54 & .11 & -.01 & .08 \\
$\begin{array}{l}\text { Applicant's ability to work well } \\
\text { with others }\end{array}$ & .53 & .08 & -.21 & -.03 \\
$\begin{array}{l}\text { Applicant's high expectation of } \\
\text { students }\end{array}$ & .51 & .31 & -.03 & .04 \\
$\begin{array}{l}\text { Applicant's communication skills } \\
\begin{array}{l}\text { Applicant's commitment to } \\
\text { professional development }\end{array}\end{array}$ & .50 & .23 & .08 & -.26 \\
$\begin{array}{l}\text { Applicant's level of } \\
\text { education/degrees earned }\end{array}$ & -.11 & .63 & .28 & .05 \\
\end{tabular}




\begin{tabular}{|c|c|c|c|c|}
\hline Applicant's content knowledge & .08 & .62 & .20 & -.11 \\
\hline $\begin{array}{l}\text { Applicant's ability to raise } \\
\text { student test scores }\end{array}$ & .17 & .62 & .01 & -.06 \\
\hline Applicant's certification status & -.01 & .60 & .04 & .18 \\
\hline Applicant's prior experience & -.13 & .58 & .24 & .07 \\
\hline $\begin{array}{l}\text { Applicant's classroom } \\
\text { management skills }\end{array}$ & .32 & .54 & -.04 & -.26 \\
\hline Applicant's teaching skills & .56 & .53 & .02 & -.13 \\
\hline $\begin{array}{l}\text { Ability to increase student } \\
\text { achievement beyond standardized } \\
\text { tests }\end{array}$ & .32 & .49 & -.04 & .01 \\
\hline Applicant's teaching philosophy & .30 & .42 & .11 & .25 \\
\hline Applicant's intelligence & .22 & .41 & .33 & -.10 \\
\hline $\begin{array}{l}\text { Applicant's fluency in languages } \\
\text { other than English }\end{array}$ & -.02 & .01 & .67 & .18 \\
\hline $\begin{array}{l}\text { Applicant's previous exposure to } \\
\text { diversity }\end{array}$ & -.00 & .06 & .61 & .07 \\
\hline $\begin{array}{l}\text { Applicant's postsecondary } \\
\text { education institution attended }\end{array}$ & -.11 & .24 & .60 & .18 \\
\hline Applicant's creativity & .38 & -.13 & .55 & .08 \\
\hline $\begin{array}{l}\text { Applicant's technological } \\
\text { proficiency }\end{array}$ & .18 & .38 & .52 & -.23 \\
\hline Applicant's organizational skills & .34 & .25 & .42 & -.08 \\
\hline Applicant's race & -.04 & -.09 & .06 & .89 \\
\hline Applicant's gender & -.02 & -.08 & .06 & .88 \\
\hline
\end{tabular}


Applicant's place of residence

\begin{tabular}{lcccc}
\hline Eigenvalues & 4.69 & 3.70 & 2.51 & 2.42 \\
\% of Variance & 15.12 & 11.93 & 8.08 & 7.82 \\
\hline
\end{tabular}

\section{Reliability Analysis of Constructed Dependent Variables}

To assess the reliability of the four factors identified and named in the Principal Component Analysis, a reliability analysis was conducted on each factor using the characteristics identified by the factor structure coefficients. The Cronbach's alpha of the first factor, "personal characteristics" - made up of 12 characteristics - was .814 . For the "professional characteristic" factor, made up of 10 characteristics, the Cronbach's alpha was .783. The third factor, made up of six characteristics and named "ancillary characteristics" had a Cronbach's alpha of .674. The fourth factor, called "demographic characteristics" had a Cronbach's alpha of .737. According to George and Mallery (2003), the results of Cronbach's alpha for "personal characteristics" is considered good, while the test for "professional characteristics" and "demographic characteristics" was deemed acceptable, and "ancillary characteristics" was in the upper end of the questionable range.

\section{Correlational Analysis}

A correlational analysis was conducted to examine the relationship between demographic variables and the four retained factors (See Table 5). The observed correlation coefficient between age and the number of years of teaching experience for females was $.80(p<.01)$, which was expected. The relationship between the two 
variables was significant, strong, and shared approximately $64 \%\left(r^{2}=.6368\right)$ of the common variance. On the same factors for males, the correlation coefficient was .93 $(p<$ $.01)$, which was significant, strong, and shared approximately $86 \%\left(r^{2}=.8574\right)$ of the common variance. The observed correlation coefficient between the number of years in the current role and age for females was .52 $(p<.01)$, which was significant and shared approximately $27 \%\left(r^{2}=.2683\right)$ of the common variance, while a weaker significant correlation between the same variables was found for males, $.43(p<.01)$, sharing approximately $18 \%\left(r^{2}=.1806\right)$ of the common variance. Similarly, the observed correlation coefficient between years of educational experience and years in current roles was significant and stronger for females, .54 $(p<.01)$ sharing approximately $29 \%$ of the common variance $\left(r^{2}=.2948\right)$, as compared to males, $.48(p<.01)$ which was significant, sharing approximately $23 \%\left(r^{2}=.2256\right)$ of the common variance.

Table 5

Pearson's correlation coefficients values among continuous independent values and four dependent variables

Age YrEdExp YrCrRle PersCh ProfCh AncCh DemoCh

\begin{tabular}{cccccccc}
\hline Age & & $.93^{* *}$ & $.43^{* *}$ & .08 & .05 & .03 & -.02 \\
YrEdExp & $.80^{* *}$ & & $.48^{* *}$ & .06 & -.04 & .04 & -.03 \\
YrCrRle & $.52^{* *}$ & $.54 * *$ & & -.03 & -.13 & -.20 & .09 \\
PerslCh & .17 & .12 & .08 & & $.35^{* *}$ & $.24 *$ & -.02 \\
ProfCh & .06 & .06 & -.09 & $.44^{* *}$ & & $.40^{* *}$ & .05 \\
AncCh & .08 & .09 & -.04 & $.34 * *$ & $.41^{* *}$ & & .16 \\
DemoCh & -.11 & -.12 & -.05 & .06 & -.03 & $.21 * *$ & \\
\hline
\end{tabular}

Note. Correlations for Female participants $(n=118)$ are presented below the diagonal, and correlations for Male participants are presented above the diagonal. ${ }^{*} \mathrm{p}<0.05$. $* * \mathrm{p}<0.01$ 
For females, the observed correlation coefficient between personal characteristics and professional characteristics was $.44(p<.01)$. The relationship between the variables was weak, though significant, and shared approximately $19 \%\left(r^{2}=.1927\right)$ of the common variance. The same variable had an observed correlation coefficient of .35 $(p<.01)$ for males, which was significant and weaker than the females and shared approximately $12 \%$ $\left(r^{2}=.1204\right)$ of the common variance. The observed correlation coefficient between ancillary characteristics and professional characteristics for females was significant at .41 $(p<.01)$, which was a weak relationship between the two variables sharing approximately $17 \%\left(r^{2}=.1665\right)$ of the common variance. This was nearly equal to the observed correlation coefficient for males between the same variables of .40 $(p<.01)$, which was significant and shared approximately $16 \%\left(r^{2}=.1624\right)$ of the common variance. Finally, the observed correlation coefficient between ancillary characteristics and demographic characteristics for females was .21 $(p<.01)$. This is significant, though weak and shared approximately $5 \%\left(r^{2}=.0454\right)$ of the common variance. For these variables, there was not a significant relationship for males in the sample.

\section{Multiple Regression Analysis}

Multiple regression analysis was used to investigate the remaining research question: Is there a relationship between a school's characteristics (poverty, school performance category, average teacher experience, and the school leader's age, gender, current role, and years in current role) and a school leader's preferences for teacher applicant characteristics?

Independent variables were school poverty level, school performance category, average teacher experience, school leader's age, school leader's years in current role, 
school leader's gender, and school leader's current role. The dependent variables in the series of analyses were the four factors derived from the exploratory factor analysis named personal characteristics, professional characteristics, ancillary characteristics, and demographic characteristics. In each multiple regression analysis each dependent variable (factor) was regressed on the seven independent variables.

\section{Assumptions}

Assumptions were examined prior to the performing the regression analysis included sample size, normality of the dependent variables, multicollinearity, linearity, homoscedasticity, and outliers. There were 7 independent variables measured, meaning the sample size of 209 records is almost double the 140 required. The results of the Shapiro-Wilk tests indicated that all four dependent variables were not normally distributed. However, the examination of the histograms and Q-Q plots indicated a more normal distribution for professional characteristics and ancillary characteristics, while the personal characteristics and demographic characteristics appeared heavily skewed across the sample. The results described above can be found in Appendix D. Examination of the correlation tables for each regression analysis revealed no collinearity issues among the independent variables on any of the four dependent variables with no correlations approaching 0.70 on the Pearson Correlation coefficient.

\section{Regressions}

The first regression analysis explored the relationship between a school's characteristics (poverty, school performance category, average teacher experience, and the school leader's age, gender, current role, and years in current role) and the school leader's preferences for teacher applicant personal characteristics. The overall regression 
was statistically significant, $F(8,200)=2.638, p<0.01$, with adjusted $R^{2}$ of .095 indicating that $9.5 \%$ of the variance in preferences for teacher applicant personal characteristics was predictable from the linear combination of the seven independent variables. This can be classified as a medium effect size (Cohen, 1988). Six of the seven predictors in the model were not significant. However, the independent variable for gender $(\beta=.149, t=3.323, p<0.01)$ had a significant relationship with the school leader's preferences for teacher applicants' personal characteristics, which includes enthusiasm, caring, cooperativeness, thoughtfulness/reflectiveness, motivation, willingness to give extra effort, positive role model, ability to work well with others, high expectations of students, communication skills and commitment to professional development. This indicates a .229 increase in standard deviation units with females showing a significant preference for personal characteristics as compared to males (See Table 6).

Table 6

Regression of Personal Characteristics on Predictor Variables $(N=209)$

\begin{tabular}{lcccc}
\hline Variable & Unstan. $\beta$ & Stan. $\beta$ & $t$ & Sig. \\
\hline Poverty & -.071 & -.036 & -.413 & .680 \\
SchRt1 & -.059 & -.081 & -.857 & .392 \\
SchRt2 & -.076 & -.112 & -1.410 & .160 \\
FacExp & .011 & .073 & 1.004 & .317 \\
Age & .005 & .111 & 1.341 & .181 \\
YrCrRle & -.004 & -.047 & -.597 & .551 \\
Gender & .149 & .229 & 3.323 & .001 \\
LdrRole & -.082 & -.128 & -1.712 & .088 \\
\hline
\end{tabular}


The second regression analysis (See Table 7) explored the relationship between a school's characteristics (poverty, school performance category, average teacher experience, and the school leader's age, gender, current role, and years in current role) and the school leader's preferences for teacher applicant professional characteristics. The overall regression analysis was not significant $F(8,200)=0.979, p>0.01$.

Table 7

Regression of Professional Characteristics on Predictor Variables $(N=209)$

\begin{tabular}{lcccc}
\hline Variable & Unstan. $\beta$ & Stan. $\beta$ & $t$ & Sig. \\
\hline Poverty & .106 & .040 & .452 & .651 \\
SchRt1 & -.110 & -.115 & -1.179 & .240 \\
SchRt2 & -.023 & -.026 & -.311 & .756 \\
FacExp & .000 & -.003 & -.034 & .973 \\
Age & .009 & .153 & 1.793 & .074 \\
YrCrRle & -.018 & -.169 & -2.104 & .037 \\
Gender & .043 & .050 & .709 & .479 \\
LdrRole & .003 & .004 & .049 & .961 \\
\hline
\end{tabular}

The third regression analysis (See Table 8) explored the relationship between a school's characteristics (poverty, school performance category, average teacher experience, the school leader's age, gender, current role, and years in current role), and the school leader's preferences for teacher applicant ancillary characteristics was also not statistically significant $F(8,200)=1.0302, p>0.01$. 
Table 8

Regression of Ancillary Characteristics on Predictor Variables $(N=209)$

\begin{tabular}{lcccc}
\hline Variable & Unstan. $\beta$ & Stan. $\beta$ & $t$ & Sig. \\
\hline Poverty & .320 & .112 & 1.269 & .206 \\
SchRt1 & .074 & .071 & .736 & .463 \\
SchRt2 & .041 & .042 & .519 & .604 \\
FacExp & .018 & .087 & 1.157 & .249 \\
Age & .010 & .147 & 1.730 & .085 \\
YrCrRle & -.021 & -.178 & -2.231 & .027 \\
Gender & -.002 & -.002 & -.025 & .980 \\
LdrRole & .030 & .033 & .429 & .668 \\
\hline
\end{tabular}

Finally, the fourth regression analysis (See Table 9) explored the relationship between a school's characteristics (poverty, school performance category, average teacher experience, and the school leader's age, gender, current role, and years in current role) and the school leader's preferences for teacher applicant demographic characteristics. It too was not statistically significant $F(8,200)=0.571, p>0.01$.

Table 9

Regression of Demographic Characteristics on Predictor Variables $(N=209)$

\begin{tabular}{lcccc}
\hline Variable & Unstan. $\beta$ & Stan. $\beta$ & $t$ & Sig. \\
\hline Poverty & -.141 & -.038 & -.420 & .675 \\
SchRt1 & .049 & .036 & .364 & .716 \\
SchRt2 & .019 & .015 & .179 & .858 \\
FacExp & .032 & .120 & 1.580 & .116 \\
Age & -.010 & -.119 & -1.378 & .170 \\
YrCrRle & .009 & .056 & .687 & .493 \\
Gender & .045 & .037 & .511 & .610 \\
LdrRole & -.065 & -.053 & -.689 & .492 \\
\hline
\end{tabular}




\section{Summary of Results}

The first research question in this study was to determine the underlying dimensions on the Preferred Teacher Applicant Characteristics Survey (PTACS). An exploratory factor analysis was conducted to determine these underlying dimensions. The results from a principal component analysis with varimax rotation showed that a four factor structure was most appropriate and included the following: 1) professional characteristics representing 12 of the 31 items, 2) personal characteristics representing 10 of the 31 items, 3) ancillary characteristics representing 6 of the 31 items, and 4) demographic characteristics representing 3 of the 31 items. The underlying dimensions were used as the dependent variables in the multiple regression analyses to investigate the remaining research question.

Following the exploratory factor analysis, a series of four multiple regression analyses were conducted using the seven predictor variables (poverty, school performance category, average teacher experience, and the school leader's age, gender, current role, and years in current role), using the factors described above as the dependent variable in each regression. This was done in order to answer the second research question: Is there a relationship between a school's characteristics (poverty, school performance category, average teacher experience, and the school leader's age, gender, current role, and years in current role) and a school leaders' preferences for teacher applicant characteristics? The first regression model - the analysis of the predictors' relationship to school leaders' preferences for teacher applicant personal characteristics -

revealed that the independent variable for gender was significantly associated with school 
leaders' preferences for personal characteristics with a medium effect size. The remaining three regression models were not significant predictors of the school leaders' preferences for teachers' professional, ancillary, or demographic characteristics. 


\section{CHAPTER V \\ DISCUSSION AND CONCLUSIONS}

This study was undertaken to extend the research of Engel (2013), who conducted a mixed methods study examining principal preferences for various teacher applicant characteristics. Engel, whose study was conducted in a large urban school district, found that a mixture of personal and professional characteristics were most highly valued and that there were differences in principal preferences between principals serving in high achieving schools and low achieving schools. Those in higher achieving schools tended to value professional skills, such as high levels of content knowledge and teaching skills, while principals in lower achieving schools tended to favor personal characteristics such as empathy and willingness to go above and beyond. Engel suggested that further research was needed in districts situated in different contexts.

This study was intended to pursue the same basic questions in a quantitative study undertaken in suburban and rural school districts when hiring teachers along with investigating whether those valued characteristics varied based on demographics of the school or the background of the school leader. In addition, this study was designed to investigate the underlying dimensions of a new survey instrument developed to measure school leaders preferences using theoretical constructs found in the teacher selection literature (Engel, 2008; Engel, 2013; Harris, Rutledge, Ingle, \& Thompson, 2010; Rutledge, Harris \& Ingle, 2010). 
The literature reviewed in preparation for this study focused on the importance of the teacher in student achievement, various characteristics related to teacher effectiveness, how school leaders attempt to divine these characteristics prior to making hiring decisions, and finally, an examination of the current state of knowledge regarding school leaders' preferences for particular characteristics. Using the literature review, I developed a simple conceptual framework to inform the study centered on the characteristics of the school setting and the characteristics of the school leader. The literature described differences in preferences related to school characteristics, but there were fewer findings related to the background of the school leader and how that background affected the teacher applicant characteristics valued during the teacher selection process. The literature identified two general categories of teacher applicant characteristics, personal characteristics and professional characteristics. The Preferred Teacher Applicant Characteristics Survey (PTACS) was developed around 31 items identified in the literature.

The research methodology was designed for two purposes. The first purpose was to determine the underlying dimensions in the PTACS survey instrument. As noted above, the research literature classified teacher characteristics as either professional or personal. An exploratory factor analysis and a parallel analysis was utilized to test these classifications using the PTACS instrument. The second purpose was to determine if seven predictor variables representing both school leader and school leader characteristics had a significant effect on the preferences of school leaders for the underlying dimensions discovered during the exploratory factor analysis. 
The PTACS survey was administered to school leaders, defined as principals and assistant principals in 12 rural and suburban school districts, all surrounding two urban districts in Kentucky. The urban districts that are proximal to the rural and suburban districts studied served approximately 137,000 students. The students in the urban districts were $51.5 \%$ minority, $62.2 \%$ received free or reduced price lunch, $12.0 \%$ received special education services, and 9.0\% were English Language Learners. The districts employed 8,873 teachers. In total, the surrounding rural and suburban districts served 85,075 students. The students in the surrounding rural and suburban districts were $18.9 \%$ minority, $47.4 \%$ received free or reduced price lunch, $13.0 \%$ received special education services, and 3.2\% were English Language Learners. The districts employed a total of 5,203 teachers (Kentucky Department of Education, 2016). A total of 209 completed surveys were used in the analysis and were matched with publicly available school demographic and performance data for the school where each school leader was employed.

The exploratory factor analysis of the PTACS instrument supported the literature related to teacher characteristics, in that many of the items loaded on the personal factor and professional factor. The analysis indicated that the PTACS also measured separate characteristics loading onto two other factors, referred to here as ancillary characteristics and demographic characteristics. Ancillary characteristics are best described as characteristics that augment a teacher applicant's attractiveness and includes such things as technological proficiency, exposure to diversity, and creativity. The demographic characteristics are items that tend to be inherent and relatively unchangeable at the time of consideration for employment, such as race, gender, and place of residence. 
The most notable result of the four multiple regression analyses was that female respondents significantly valued personal characteristics in this study more than did male respondents. This significant finding quantitatively confirms findings by Engel's 2013 study that found qualitative differences in principal preferences related to gender even given the different, rural and suburban versus urban, context of the present study. The remaining multiple regression models examining professional, ancillary, and demographic dependent variables did not reveal any significant relationships.

The findings regarding female respondents significantly preferring personal characteristics as compared to male respondents confirms one of Engel's findings, which is particularly important given the findings in other studies. For example, while Siegle, Rubenstein, and Mitchell (2014) found qualitative evidence that personal characteristics were important to students, Harris and Sass (2014), and Rockoff, Jacob, Kane, and Staiger (2011) found that personal characteristics were not correlated with student achievement (though they were highly correlated with positive subjective evaluations).

\section{Conceptual Framework and Limitations}

The conceptual framework that informed this study was grounded in the literature surrounding teacher effectiveness and principal preferences for teacher applicant characteristics, which indicated that the contextual characteristics of the school, including demographic considerations such as poverty and performance, and characteristics of the school leaders, including gender and experience, may have an effect on the school leaders preferences for particular teacher applicant characteristics. This study sought to investigate whether those findings, particularly those of the 2013 study conducted by 
Engel in an urban setting, would hold in a different context, namely rural and suburban districts in a largely rural state.

As discussed in Chapter III, there are a number of limitations of this study. The survey sampled school leaders in suburban and rural areas surrounding two major metropolitan areas. While this sample was purposeful, based on the intent to extend the results of previous studies conducted inside metropolitan areas, it must be noted that the results may not be applicable to urban school districts or rural districts not surrounding a major metropolitan areas. There was also the possibility of bias based on the position of the researcher, who was the superintendent in one of the districts where data was collected. This study incorporated a definition of school leader as being either a principal or assistant principal. As the principal serves as the primary decision maker in the hiring process, and is subject to the pressure and consequences of making these decisions, the inclusion of assistant principals in the sample may have skewed the data in some undetermined way. Finally, as this was a convenience sample obtained in districts surrounding two distinct metropolitan areas, the data may not be generalizable to all suburban and rural districts surrounding metropolitan districts throughout the nation. Indeed, they are only generalizable to the current sample and discrete time period from which the data were collected.

Another possible limitation to the generalizability of this study is that the results may exhibit some social desirability response bias. Though the participants were assured that individual data would not be revealed, design of the study required the name of the school where the leader worked in order to match the school demographic data. Together with the fact that the respondent was likely aware that the researcher was personally 
acquainted with the respondent's supervisor may have led some respondents to answer questions in ways that would be more socially acceptable than they may otherwise have answered. This could also be related to the racial composition of the sample of school leaders, which was $95.2 \%$ white and working in school districts that enroll only $18.9 \%$ minority students. This homogeneity of the samples and school contexts may have led to similar values and responses to the survey.

The four factors extracted through the exploratory factor analysis process explained $43 \%$ of the total variance in the PTACS survey. The variance explained by the four factors' percentage is satisfactory, though relatively low (Hair, 2010). This may be a confirmation of several researchers' (Aaronson, Barrow, \& Sander, 2007; Hanushek and Rivkin, 2012; Konstantopoulos , 2011; Rivkin, Hanushek, \& Kain, 2005) conclusions that the underlying characteristics that make a teacher effective, and presumably preferable to a school leader making hiring decisions, are difficult to discern or observe.

\section{Implications for Practice}

There are several implications arising from this study related to educational practice, both in what the study did find, and in what it did not. The finding that female respondents' place a significantly higher value on personal characteristics than do male respondents suggests that females may select candidates for employment who exhibit these characteristics. Given that in both Engel's 2013 study and this study, the sample contained a higher percentage of female administrators than male, as compared to male respondents, teacher education programs may consider emphasizing the importance of personal characteristics both in the admissions process and in pre-service classes. Since most eventual administrators receive their initial grounding in educational philosophy and 
research during their preservice teacher training, it may be useful to include work examining teacher characteristics that are more likely to increase student achievement. While the question of what characteristics make an effective teacher is not yet definitively answered, evidence does exist that can inform preservice teachers of some characteristics they should seek to develop in themselves over the course of their careers and this awareness should begin during initial preparation, especially discussion of National Board of Professional Teaching Standards certification process. Finally, pProspective teachers should understand the differences in preferences based on the school leader's gender and adjust the emphasis of their interview responses to accentuate their strengths in the personal realm, such as enthusiasm, caring, and commitment to professional learning. While it was not the intent to inform factors that may increase the likelihood of pre-service teacher applicants being hired, the findings in this study may suggest which characteristics are preferred by female principals and male principals—and thus which of the characteristics to emphasize in the application and interview process.

Alternatively, principal education programs may wish to acknowledge the differences in teacher applicant preferences based on the gender of the school leader, but should provide learning in their preparation courses that emphasize the other teacher characteristics that have been shown to lead to increased student achievement. More comprehensive investigations into teacher characteristics that tend to lead to increased student achievement may also be appropriate for inclusion in principal preparation programs. Research is clear that certification does matter, particularly those with intensive trainings like Teach for America graduates and teachers holding certification from the National Board for Professional Teacher Standards (Clotfelter, Ladd, \& Vigdor, 
2007; Kane Rockoff, \& Staiger, 2008), and future principals should understand that research indicates significant differences in student achievement when teacher hold such credentials. Similarly, teacher content knowledge should be emphasized as an important predictor of student achievement, as it has been found to improve student academic performance (Wayne \& Youngs, 2003; Winters, Dixon, \& Greene, 2012). Specific discussion on these findings with potential principals and specific examination of a prospective principal's biases in preferences during teacher selection, particularly regarding gender differences among school leaders, could be important to hiring teachers who can increase student academic achievement. Clearly acknowledging that school leaders have their own biases and preferences, and by methodically examining these biases in light of existing evidence on student achievement, may lead to more effective hiring practices and higher levels of student academic success. This should be the goal of every decision a principal makes, especially that most important decision of which teacher applicant is hired.

\section{Implications for Future Research}

There remains a tremendous amount of research to be conducted in this area of study. This study marks the first large-scale use of the Preferred Teacher Applicant Characteristics Survey (PTACS) and it was in a relatively narrow and homogenous context (rural and suburban school districts surrounding large urban districts). Additional use of the same survey in different contexts will be useful to further examine the underlying dimensions of the PTACS and to compare the findings in urban Kentucky districts with the findings of this study to shed further light on the preferences of school leaders' preferences of teacher applicant characteristics. 
Given the amount of variance explained by the underlying dimensions of the PTACS using exploratory factor analysis, another avenue of investigation may be a qualitative or mixed methods study to delve deeper into teacher applicant characteristics and how school leaders' perceptions of those characteristics influence hiring decisions. Another possibility would be to design a companion survey or interview protocol that collects additional background and demographic information on both the school leaders and the particular school context and utilize a forced choice ranking system to determine them most important characteristics and whether or not the importance of such characteristics vary depending on school context or school leader background. Through continued research and refinement, it should be possible to isolate and examine the teacher applicant characteristics that are most important to student achievement. 


\section{REFERENCES}

Aaronson, D., Barrow, L., \& Sander, W. (2007). Teachers and student achievement in the Chicago public high schools. Journal of Labor Economics, 25, 95-135.

Abernathy, T. V., Forsyth, A., \& Mitchell, J. (2001). The bridge from student to teacher: What principals, teacher education faculty, and students value in a teaching applicant. Teacher Education Quarterly, 28, 109-119.

Aloe, A. M., \& Becker, B. J. (2009). Teacher verbal ability and school outcomes: Where is the evidence? Educational Researcher, 38, 612-624.

Andrew, M., Cobb, C., \& Giampietro, P. (2005). Verbal ability and teacher effectiveness. Journal of Teacher Education: The Journal of Policy, Practice, and Research in Teacher Education, 56, 343-354.

Association for Supervision and Curriculum Development. (2015). Comparison of the No Child Left Behind Act to the Every Student Succeeds Act [Chart]. Retrieved December 03, 2016, from http://www.ascd.org/ASCD/pdf/siteASCD/policy/ESEA_NCLB_ComparisonCha rt 2015.pdf

Baker, B. D., \& Cooper, B. S. (2005). Do principals with stronger academic backgrounds hire better teachers? Policy implications for improving high-poverty schools. Educational Administration Quarterly, 41, 449-479. doi: 10.1177/0013161x04269609

Ballou, D. (1996). Do public schools hire the best applicants? The Quarterly Journal of Economics, 111, 97-133.

Balter, D., \& Duncombe, W. D. (2008). Recruiting highly qualified teachers: Do district recruitment practices matter? Public Finance Review, 36, 33-62. doi: $10.1177 / 1091142106293949$

Barile, J. P., Donohue, D. K., Anthony, E. R., Baker, A. M., \& Weaver, S. R. (2012). Teacher-student relationship climate and school outcomes: Implications for educational policy initiatives. Journal of Youth and Adolescence, 41, 256-267. 
Bastian, K. C., \& Henry, G. T. (2015). The apprentice: Pathways to the principalship and student achievement. Educational Administration Quarterly: The Journal of Leadership for Effective and Equitable Organizations, 51, 600-639.

Bohrnstedt, G., Kitmitto, S., Ogut, B., Sherman, D., and Chan, D. (2015). School composition and the black-white achievement gap (NCES 2015-018). U.S. Department of Education, Washington, DC: National Center for Education Statistics. Retrieved [12/03/2016] from

https://nces.ed.gov/nationsreportcard/subject/studies/pdf/school_composition_and the bw achievement_gap_2015.pdf

Boyd, D., Lankford, H., Loeb, S., \& Wyckoff, J. (2005). The draw of home: How teachers preferences for proximity disadvantage urban schools. Journal of Policy Analysis and Management, 24, 113-132.

Broadley, G., \& Broadley, K. (2004). The employment styles of school principals recruiting beginning teachers. Educational Research, 46, 259-268.

Broberg, J. P. (1987). Ranking criteria for hiring newly certified teachers: A Delphi technique (Unpublished doctoral dissertation). Oklahoma State University, Stillwater.

Bush, J. (2014). The best solution to our nation's failing educational system is empowering parents. National Review Online. Retrieved December 03, 2016, from http://www.nationalreview.com/article/369444/we-need-school-choice-now-jeb$\underline{\text { bush }}$

Cannata, M., \& Engel, M. (2012). Does charter status determine preferences? Comparing the hiring preferences of charter and traditional public school principals. Education Finance and Policy, 7, 455-488.

Carleton, D. (2002). Landmark congressional laws on education. Westport, Conn.: Greenwood Press.

Chamberlain, G. E. (2013). Predictive effects of teachers and schools on test scores, college attendance, and earnings. Proceedings of the National Academy of Sciences of the United States of America, 110, 17176-82.

Chetty, R., Friedman, J. N., \& Rockoff, J. E. (2014a). Measuring the impacts of teachers I: Evaluating bias in teacher value-added estimates. American Economic Review, 104, 2593-2632. 
Chetty, R., Friedman, J. N., \& Rockoff, J. E. (2014b). Measuring the Impacts of Teachers II: Teacher Value-Added and Student Outcomes in Adulthood. American Economic Review, 104, 2633-2679

Clotfelter, C., Ladd, H., \& Vigdor, J. (2007). How and why do teacher credentials matter for Student achievement? doi: 10.3386/w12828

Coelli, M., \& Green, D. A. (2012). Leadership effects: School principals and student outcomes. Economics of Education Review, 31(1), 92-109.

Cohen, J. (1988). Statistical power analysis for the behavioral sciences $\left(2^{\text {nd }} e d.\right)$. Hillsdale, NJ; Lawrence Erlbaum

Coleman, J. S., Campbell, E. Q., Hobson, C. J., McPartland, J., Mood, A. M., Weinfeld, F. D., \& York R. L. (1966). Equality of educational opportunity. Washington: U.S. Dept. of Health, Education, and Welfare, Office of Education.

Comrey, A. L., \& Lee, H. B. (1992). A first course in factor analysis ( $2^{\text {nd }}$ ed.). Hillsdale, NJ; Lawrence Erlbaum.

Cresswell, J.W. (2009). Research design: Qualitative, quantitative, and mixed methods approaches. Thousand Oaks, California: SAGE Publications.

Darling-Hammond, L. (2000). Teacher quality and student achievement: A review of state policy evidence. Education Policy Analysis Archives 8 (1), 1-44. http://epaa.asu.edu/ojs/article/view/392.

DeArmond, M., Gross, B., \& Goldhaber, D. (2010). Is it better to be good or lucky? Decentralized teacher selection in 10 elementary schools. Educational Administration Quarterly: The Journal of Leadership for Effective and Equitable Organizations, 46, 322-362.

DeVellis, R. F. (2016). Scale development: Theory and applications (4th Edition.). Thousand Oaks, California: Sage.

Dhuey, E., \& Smith, J. (2014). How important are school principals in the production of student achievement? Canadian Journal of Economics, 47, 634-663.

Dillman, D. A., Smyth, J. D., \& Christian, L. M. (2014). Internet, phone, mail, and mixed-mode surveys: The tailored design method (4th edition.). Retrieved from http://public.eblib.com.echo.louisville.edu/choice/publicfullrecord.aspx? $\mathrm{p}=17627$ $\underline{97}$

Engel, M. (2008). Principals' and districts' hiring practices: An exploration of the demand side of the teacher labor market (Doctoral dissertation). Retrieved from https://search-proquest-com.echo.louisville.edu/pqdtglobal/docview 
Engel, M. (2013). Problematic preferences? A mixed method examination of principals' preferences for teacher characteristics in Chicago. Educational Administration Quarterly: The Journal of Leadership for Effective and Equitable Organizations, 49, 52-91.

Engel, M., \& Curran, F. C. (2016). Toward understanding principals' hiring practices. Journal of Educational Admin Journal of Educational Administration, 54, 173-190. doi: 10.1108/jea-04-2014-0049

Field, A. P. (2009). Discovering statistics using SPSS: And sex drugs and rock ' $n$ ' roll $\left(3^{\text {rd }}\right.$ ed.). London: SAGE

Fowles, J., Butler, J. S., Cowen, J. M., Streams, M. E., \& Toma, E. F. (2014). Public Employee Quality in a Geographic Context: A Study of Rural Teachers. The American Review of Public Administration, 44, 503-521.

Fuller, E. J., \& Hollingworth, L. (2014). A bridge too far? Challenges in evaluating principal effectiveness. Educational Administration Quarterly: The Journal of Leadership for Effective and Equitable Organizations, 50, 466-499.

Fuller, E., \& Young, M. D. (2008). The revolving door: Principal turnover in Texas. Texas Study of Secondary Education, 17(2), 14-19.

George, D., \& Mallery, P. (2003). SPSS for Windows step by step: A simple guide and reference. 11.0 update (4th ed.). Boston: Allyn \& Bacon.

Grissom, J. A. (2011). Can good principals keep teachers in disadvantaged schools? Linking principal effectiveness to teacher satisfaction and turnover in hard-tostaff environments. Teachers College Record, 113, 2552-2585.

Grissom, J. A., Kalogrides, D., \& Loeb, S. (2015). Using student test scores to measure principal performance. Educational Evaluation and Policy Analysis, 37, 3-28.

Grissom, J. A., Loeb, S., \& Master, B. (2013). Effective instructional time use for school leaders: Longitudinal evidence from observations of principals. Educational Researcher, 42, 433-444.

Hair, J. F. (2010). Multivariate data analysis: A global perspective. Upper Saddle River, N.J.: Pearson Education.

Hanushek, E. (1971). Teacher characteristics and gains in student achievement; Estimation using micro data. The American Economic Review, 61, 280-288.

Hanushek, E. A. (1979). Conceptual and empirical issues in the estimation of educational production functions. The Journal of Human Resources, 14, 351-388. doi: $10.2307 / 145575$ 
Hanushek, E. A., \& Rivkin, S. G. (2012). The distribution of teacher quality and implications for policy. Annual Review of Economics, 4, 131-158.

Harris, D. N. (2010). Clear away the smoke and mirrors of value-added. The Phi Delta Kappan, 91, 66-69.

Harris, D. N., Ingle, W. K., \& Rutledge, S. A. (2014). How teacher evaluation methods matter for accountability: A comparative analysis of teacher effectiveness ratings by principals and teacher value-added measures. American Educational Research Journal, 51, 73-112.

Harris, D. N., \& Rutledge, S. A. (2010). Models and predictors of teacher effectiveness: A comparison of research about teaching and other occupations. Teachers College Record, 112, 914-960.

Harris, D. N., Rutledge, S. A., Ingle, W. K., \& Thompson, C. C. (2010). Mix and match: What principals really look for when hiring teachers. Education Finance and Policy, 5, 228-246.

Harris, D. N., \& Sass, T. R. (2014). Skills, productivity and the evaluation of teacher performance. Economics of Education Review, 40, 183-204.

Henson, R. K., \& Roberts, J. K. (2006). Use of exploratory factor analysis in published research: Common errors and some comment on improved practice. Educational and Psychological Measurement, 66, 393-416.

Horng, E. L., Klasik, D., \& Loeb, S. (2010). Principal's time use and school effectiveness. American Journal of Education, 116, 491-523.

Ilker, E., Sulaiman, A. M., \& Rukayya, S. A. (2016). Comparison of convenience sampling and purposive sampling. American Journal of Theoretical and Applied Statistics. 5, 1-4. doi: 10.11648/j.ajtas.20160501.11

Jackson, C. K., Rockoff, J. E., \& Staiger, D. O. (2014). Teacher effects and teacherrelated policies. Annual Review of Economics, 6, 801-825.

Jacob, B. A., \& Lefgren, L. (2008). Can principals identify effective teachers? Evidence on subjective performance evaluation in education. Journal of Labor Economics, $26,101-136$.

Jefferson, T. (n.d.). Thomas Jefferson to Charles Yancey, 6 January 1816 [Letter]. Retrieved December 03, 2016, from http://founders.archives.gov/documents/Jefferson/03-09-02-0209 
Jepsen, C. (2005). Teacher characteristics and student achievement: Evidence from teacher surveys. Journal of Urban Economics, 57, 302-319.

Kaiser, H. F. (1974). An index of factorial simplicity. Psychometrika, 39, 31-36

Karadag, E., Bektas, F., Cogaltay, N., \& Yalcin, M. (2015). The effect of educational leadership on students' achievement: A meta-analysis study. Asia Pacific Education Review, 16, 79-93.

Kane, T. J., Rockoff, J. E., \& Staiger, D. O. (2008). What does certification tell us about teacher effectiveness? Evidence from New York City. Economics of Education Review, 27, 615-631.

Kane, T. J., Taylor, E. S., Tyler, J. H., \& Wooten, A. L. (2011). Identifying effective classroom practices using student achievement data. Journal of Human Resources, 46, 587-613.

Kennedy, M. M. (2008). Contributions of qualitative research to research on teacher qualifications. Educational Evaluation and Policy Analysis, 30(4), 344-367.

Kentucky Department of Education. (2016). School Report Card 2015-2016. Retrieved from http://applications.education.ky.gov/SRC/

Koedel, C., Mihaly, K., \& Rockoff, J. E. (2015). Value-added modeling: A review. Economics of Education Review, 47, 180-195.

Konstantopoulos, S. (2011). Teacher effects in early grades: Evidence from a randomized study. Teachers College Record, 113, 1541-1565.

Lee, D. M. (2005). Hiring the best teachers: Gaining a competitive edge in the teacher recruitment process. Public Personnel Management, 34, 263-270.

Liu, S., Liu, C., Stronge, J., \& Xu, X. (2016). Teacher characteristics for success in the classroom: Chinese principals' perceptions for hiring decisions. Asia Pacific Education Review, 17, 107-120.

Liu, E., \& Johnson, S. M. (2006). New teachers' experiences of hiring: Late, rushed, and information-poor. Educational Administration Quarterly: The Journal of Leadership for Effective and Equitable Organizations, 42, 324-360.

Louis, K. S., Dretzke, B., \& Wahlstrom, K. (2010). How does leadership affect student achievement? Results from a national US survey. School Effectiveness and School Improvement, 21, 315-336. doi:10.1080/09243453.2010.486586 
Metzger, S. A., \& Wu, M. (2008). Commercial teacher selection instruments: The validity of selecting teachers through beliefs, attitudes, and values. Review of Educational Research, 78, 921-940.

Metzler, J., \& Woessmann, L. (2012). The impact of teacher subject knowledge on student achievement: Evidence from within-teacher within-student variation. Journal of Development Economics, 99, 486-496.

Monk, D. H. (1994). Subject matter preparation of secondary mathematics and science teachers and student achievement. Economics of Education Review, 13 (2), 125-45.

Naper, L. R. (2010). Teacher hiring practices and educational efficiency. Economics of Education Review, 29, 658-668.

Norman, J. (2016, June 13). American's confidence in institutions stays low. [Web log review]. Retrieved December 21, 2016, from http://www.gallup.com/poll/192581/americans-confidence-institutions-stayslow.aspx

Nye, B., Konstantopoulos, S., \& Hedges, L. (2004). How large are teacher effects? Educational Evaluation and Policy Analysis, 26, 237-257.

O'Connor, B. P. (2000). SPSS and SAS programs for determining the number of components using parallel analysis and Velicer's MAP test. Behavior Research Methods, Instrumentation, and Computers, 32, 396-402.

Pituch, K. A., \& Stevens, J. P. (2016). Applied multivariate statistics for the social sciences: Analyses with SAS and IBM's SPSS (6 ${ }^{\text {th }}$ ed.). New York: Rouledge.

Plucker, J. A. (2003). Exploratory and confirmatory factor analysis in gifted education: Examples with self-concept data. Journal for the Education of the Gifted, 27, 2035.

Pokropek, A. A., \& Sikora, J. (2015). Heritability, family, school and academic achievement in adolescence. Social Science Research, 53, 73-88.

Ritter, N. L. (2010, February). Understanding a widely misunderstood statistic: Crohnbach's $\alpha$. Paper presented at annual meeting of the Southwest Educational Research Association, New Orleans, LA.

Rivkin, S., Hanushek, E., \& Kain, J. (2005). Teachers, schools, and academic achievement. Econometrica, 73, 417-458. 
Robinson, V. M., Lloyd, C. A., \& Rowe, K. J. (2008). The Impact of Leadership on Student Outcomes: An Analysis of the Differential Effects of Leadership Types. Educational Administration Quarterly, 44, 635-674.

Rockoff, J. (2004). The impact of individual teachers on student achievement: Evidence from panel data. The American Economic Review, 94, 247-252.

Rockoff, J. E., Jacob, B. A., Kane, T. J., \& Staiger, D. O. (2011). Can you recognize and effective teacher when you recruit one? Education Finance and Policy, 6, 43-74.

Rockoff, J. E., \& Speroni, C. (2011). Subjective and objective evaluations of teacher effectiveness: Evidence from New York City. Labour Economics, 18, 687-696.

Rothstein, J. (2010). Teacher quality in educational production: Tracking, decay, and student achievement. Quarterly Journal of Economics, 125, 175214.doi:10.1162/qjec.2010.125.1.175

Rutledge, S. A., Harris, D. N., \& Ingle, W. K. (2010). How principals bridge and buffer the new demands of teacher quality and accountability: A mixed-methods analysis of teacher hiring. American Journal of Education, 116, 211-242.

Sass, T. R., Hannaway, J., Xu, Z., Figlio, D. N., \& Feng, L. (2012). Value added of teachers in high-poverty schools and lower poverty schools. Journal of Urban Economics, 72, 104-122.

Sass, T. R., Semykina, A., \& Harris, D. N. (2014). Value-added models and the measurement of teacher productivity. Economics of Education Review, 38, 9-23. doi:10.1016/j.econedurev.2013.10.003

Schumacher, G., Grigsby, B., \& Vesey, W. (2015). Determining effective teaching behaviors through the hiring process. International Journal of Educational Management, 29, 139-155.

Siegle, D., Rubenstein, L. D., \& Mitchell, M. S. (2014). Honors students' perceptions of their high school experiences: The influence of teachers on student motivation. Gifted Child Quarterly, 58, 35-50.

Staiger, D. O., \& Rockoff, J. E. (2010). Searching for effective teachers with imperfect information. The Journal of Economic Perspectives, 24, 97-117.

Steinberg, M. P., \& Garrett, R. (2016). Classroom Composition and Measured Teacher Performance: What Do Teacher Observation Scores Really Measure? Educational Evaluation and Policy Analysis, 38, 293-317.

Stevens, J. (2009). Applied multivariate statistics for the social sciences (5th edition.). New York (N.Y.): Routledge. 
Strong, M., Gargani, J., \& Hacifazlioglu, O. (2011). Do we know a successful teacher when we see one? Experiments in the identification of effective teachers. Journal of Teacher Education: The Journal of Policy, Practice, and Research in Teacher Education, 62, 367-382.

Stronge, J. H., Ward, T. J., \& Grant, L. W. (2011). What makes good teachers good? A cross-case analysis of the connection between teacher effectiveness and student achievement. Journal of Teacher Education: The Journal of Policy, Practice, and Research in Teacher Education, 62, 339-355.

Sue, V. M. \& Ritter, L. (2012). Conducting Online Surveys. Thousand Oaks, California: Sage Publications.

United States. (1983). A nation at risk: The imperative for educational reform. Washington, DC: The National Commission on Excellence in Education.

Usdan, M. D. (2016). The ever debatable federal role: Implications for education policy. Institute for Educational Leadership. Retrieved from http://epfp.iel.org/resource/resmgr/Files/The_Ever_Debatable_Federal_R.pdf

U.S. Department of Education. Institute of Education Sciences, National Center for Education Statistics. (2013). Schools and Staffing Survey (SASS). Retrieved from https://nces.ed.gov/surveys/sass/tables/PFS1213_2014064_p1n_002.asp

Wayne, A., \& Youngs, P. (2003). Teacher characteristics and student achievement gains: A review. Review of Educational Research, 73, 89-122.

Winters, M. A., Dixon, B. L., \& Greene, J. P. (2012). Observed characteristics and teacher quality: Impacts of sample selection on a value added model. Economics of Education Review, 31, 19-32.

Whitehurst, G. J. (2002). Research on teacher preparation and professional development. In White House Conference on Preparing Tomorrow's Teachers. Retrieved August 13, 2016, from http://www2.ed.gov/admins/tchrqual/learn/preparingteachersconference/whitehurs $\underline{\text { t.html }}$

Young, I. P., \& Delli, D. A. (2002). The validity of the teacher perceiver interview for predicting performance of classroom teachers. Educational Administration Quarterly: The Journal of Leadership for Effective and Equitable Organizations, 38, 586-612. 


\section{APPENDIX A}

\section{Preferred Teacher Applicant Characteristics Survey (PTACS)}

\section{Opening question on Survey:}

You are being invited to participate in a research study by answering the following online survey about your preferred characteristics in applicants for teaching positions. The instrument will provide key information on the personal attributes preferred by administrators when hiring teachers.

There are no known risks for your participation in this research study. The information collected may not benefit you directly. However, the information learned in this study may be helpful to others. The information you provide will be collected and analyzed to assess whether there are significant differences in preferred teacher applicant characteristics among stake holder groups (e.g., assistant principals, principals, central office administrators). Your completed survey will be collected using the Qualtrics survey software and stored on password protected, university owned computers. The survey will take approximately 5 minutes to complete.

Individuals from the Department of Educational Leadership, Evaluation, and Organizational Development, the Institutional Review Board (IRB), the Human Subjects Protection Program Office (HSPPO), and other regulatory agencies may inspect these records. In all other respects, however, the data will be held in confidence to the extent permitted by law. Should the data be published, your school, district, individual identity, or individual responses will not be disclosed.

Taking part in this study is voluntary. By answering survey questions you agree to take part in this research study. You do not have to answer any questions that make you feel uncomfortable. You may choose not to take part at all. If you decide to be in this study, you may stop taking part at any time. If you decide not to be in this study or if you stop taking part at any time, you will not lose any benefits for which you may qualify. 
If you have any questions, concerns, or complaints about the research study, please contact Mr. Keith Davis at 502-744-7500 or Dr. Kyle Ingle at 502-852-6097.

If you have any questions about your rights as a research subject, you may call the Human Subjects Protection Program Office at (502) 852-5188. You can discuss any questions about your rights as a research subject, in private, with a member of the Institutional Review Board (IRB). You may also call this number if you have other questions about the research, and you cannot reach the research staff, or want to talk to someone else. The IRB is an independent committee made up of people from the University community, staff of the institutions, as well as people from the community not connected with these institutions.

If you have concerns or complaints about the research or research staff and you do not wish to give your name, you may call 1-877-852-1167. This is a 24 hour hot line answered by people who do not work at the University of Louisville.

\section{If you are willing to complete this survey, please select YES.}

Y Yes (1)

No (4)

Condition: No Is Selected. Skip To: End of Survey.

Which best describes your current role?

Assistant Principal (3)

Principal (2)

What is the name of your school? *This information will only be used to match responses to school-level demographics. Individual responses and data will never be reported.

What is the name of your school district? ${ }^{*}$ This information will only be used to match responses to district-level demographics. Individual responses and data will never be reported. 
How many total years of experience do you have in this current role?
O $1(5)$
O $2(6)$
O $3(7)$
O $4(8)$
O $5(9)$
O $6(10)$
O $7(11)$
O $8(12)$
O $9(13)$
O $10(14)$
O $11(15)$
O $12(16)$
O $13(17)$
O $14(18)$
O $15(19)$
O $16(20)$
O 17 (21)
○ 18 (22)
O 19 (23)
O 20 (24)
○ 21 (25)
○ 22 (26)
○ 23 (27)
○ 24 (28)
○ 25 (29)
O 26 (30)
○ 27 (31)
○ 28 (32)
O 29 (33)
O 30 (34)
O 31 (36)
○ 32 (37)
○ 33 (38)
O 34 (39)
○ 35 (40)
O 36 (41)
○ 37 (42) 


$$
\begin{array}{ll}
\text { O } & 38(43) \\
\text { ○ } & 39(44) \\
\text { O } & 40(45)
\end{array}
$$


How many total years of professional experience in education do you have?
O $1(5)$
O $2(6)$
O $3(7)$
O $4(8)$
O $5(9)$
O $6(10)$
O $7(11)$
O $8(12)$
O $9(13)$
O $10(14)$
O $11(15)$
O $12(16)$
O $13(17)$
O $14(18)$
O 15 (19)
O $16(20)$
O 17 (21)
○ 18 (22)
O 19 (23)
○ 20 (24)
○ 21 (25)
○ 22 (26)
○ 23 (27)
○ 24 (28)
○ 25 (29)
O 26 (30)
○ 27 (31)
○ 28 (32)
O 29 (33)
O 30 (34)
O 31 (36)
○ 32 (37)
○ 33 (38)
O 34 (39)
○ 35 (40)
O 36 (41)
O 37 (42) 

O $38(43)$
O 39 (44)
O $40(45)$

What is your gender?

O Male (1)

O Female (2)

I currently work in $\mathrm{a}(\mathrm{n}) \ldots$

O Elementary School (1)

O Middle School (2)

O High School (3)

O Vocational/Technical School (4)

O School District's Central Office (5)

O Alternative School (6)

O K-12 School (7)

C Combined Secondary School (e.g., middle and high school) (8)

What is your highest level of education?

O Bachelor's degree (3)

O Master's degree (4)

O Specialist's degree (2)

O Doctoral degree (5)

What is your race/ethnicity?

O Asian/Pacific Islander (1)

O Black/African-American (2)

O Hispanic/Latino (4)

O Mixed Ethnicity (7)

O Native-American (3)

O White (8)

O Multi-racial (9) 


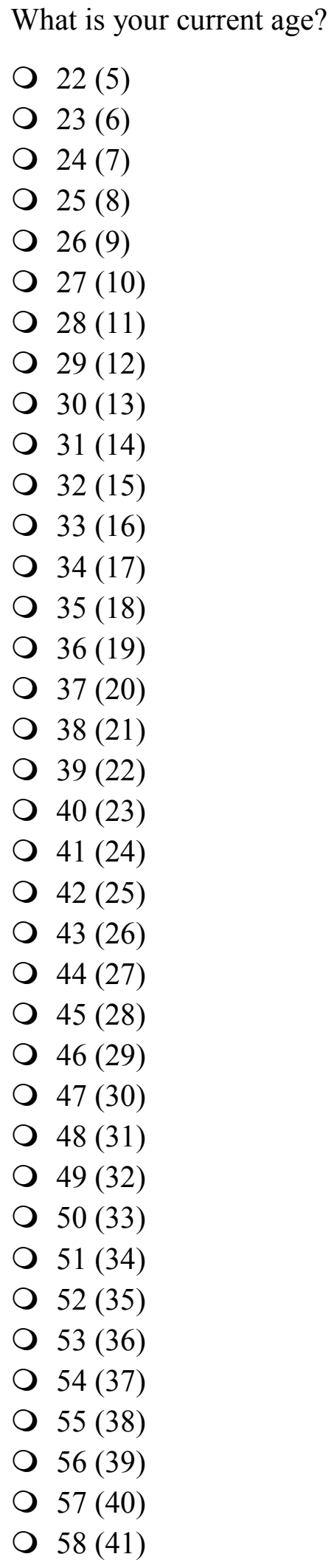




\begin{tabular}{|c|}
\hline ○ 59 (42) \\
\hline O $60(43)$ \\
\hline O 61 (44) \\
\hline $62(45)$ \\
\hline O $63(46)$ \\
\hline ○ 64 (47) \\
\hline O 65 (48) \\
\hline O 66 (49) \\
\hline O $67(50)$ \\
\hline O 68 (51) \\
\hline O $69(52)$ \\
\hline O $70(53)$ \\
\hline O $71(54)$ \\
\hline O $72(55)$ \\
\hline O $73(56)$ \\
\hline ○ 74 (57) \\
\hline O $75(58)$ \\
\hline О $76(59)$ \\
\hline ○ $77(60)$ \\
\hline O 78 (61) \\
\hline $79(62)$ \\
\hline O $80(63)$ \\
\hline $81(64)$ \\
\hline $82(65)$ \\
\hline O $83(66)$ \\
\hline O 84 (67) \\
\hline O $85(68)$ \\
\hline
\end{tabular}


On a scale of 1-5, how important do you consider each of the following characteristics in hiring a teacher? 


\begin{tabular}{|c|c|c|c|c|c|}
\hline & $\begin{array}{l}\text { Not at all } \\
\text { Important } \\
=1(1)\end{array}$ & $\begin{array}{l}\text { Very } \\
\text { Unimportant } \\
=2(2)\end{array}$ & $\begin{array}{l}\text { Moderately } \\
\text { Important } \\
=3(3)\end{array}$ & $\begin{array}{l}\text { Very } \\
\text { Important } \\
=4(4)\end{array}$ & $\begin{array}{l}\text { Extremely } \\
\text { Important } \\
=5(5)\end{array}$ \\
\hline Applicant's Motivation (1) & O & O & o & 0 & O \\
\hline Applicant's Creativity (2) & $\mathrm{O}$ & $\mathrm{O}$ & O & $\mathrm{O}$ & O \\
\hline Applicant's Intelligence (3) & $\mathrm{O}$ & $\mathrm{O}$ & $\mathrm{O}$ & $\mathrm{O}$ & $\mathrm{O}$ \\
\hline $\begin{array}{c}\text { Applicant's } \\
\text { Thoughtfulness/Reflectiveness } \\
\text { (4) }\end{array}$ & $\mathrm{O}$ & $\mathrm{O}$ & $\mathrm{O}$ & O & $\mathrm{O}$ \\
\hline $\begin{array}{l}\text { Applicant's Cooperativeness } \\
\text { (5) }\end{array}$ & $\mathrm{O}$ & $\mathrm{O}$ & O & $\mathrm{O}$ & $\mathrm{O}$ \\
\hline $\begin{array}{c}\text { Applicant's Organizational } \\
\text { Skills (6) }\end{array}$ & $\mathrm{O}$ & $\mathrm{O}$ & O & $\mathrm{O}$ & O \\
\hline $\begin{array}{c}\text { Applicant's Certification } \\
\text { Status (7) }\end{array}$ & $\mathrm{O}$ & $\mathrm{O}$ & $\mathrm{O}$ & $\mathrm{O}$ & O \\
\hline $\begin{array}{c}\text { Applicant's Fluency in } \\
\text { Languages other than English } \\
\text { (8) }\end{array}$ & $\mathrm{O}$ & $\mathrm{O}$ & $\mathrm{O}$ & $\mathrm{O}$ & $\mathrm{O}$ \\
\hline $\begin{array}{l}\text { Applicant's Postsecondary } \\
\text { Education Institution Attended } \\
\text { (9) }\end{array}$ & $\mathrm{O}$ & $\mathrm{O}$ & $\mathrm{O}$ & O & $\mathrm{O}$ \\
\hline Applicant's Caring (10) & $\mathrm{O}$ & $\mathrm{O}$ & $\mathrm{O}$ & O & $\mathrm{O}$ \\
\hline $\begin{array}{l}\text { Applicant's Content } \\
\text { Knowledge (11) }\end{array}$ & $\mathrm{O}$ & $\mathrm{O}$ & O & O & $\mathrm{O}$ \\
\hline Applicant's Enthusiasm (12) & $\mathrm{O}$ & $\mathrm{O}$ & $\mathrm{O}$ & $\mathrm{O}$ & $\mathrm{O}$ \\
\hline $\begin{array}{c}\text { Applicant's Communication } \\
\text { Skills (13) }\end{array}$ & $\mathrm{O}$ & $\mathrm{O}$ & $\mathrm{O}$ & O & $\mathrm{O}$ \\
\hline $\begin{array}{l}\text { Applicant's Ability to Works } \\
\text { Well with Others (14) }\end{array}$ & $\mathrm{O}$ & $\mathrm{O}$ & O & $\mathrm{O}$ & O \\
\hline $\begin{array}{c}\text { Applicant's Level of } \\
\text { Education/Degrees Earned } \\
(15)\end{array}$ & 0 & 0 & 0 & 0 & 0 \\
\hline $\begin{array}{c}\text { Applicant's Prior Experience } \\
\text { (16) }\end{array}$ & 0 & 0 & 0 & $O$ & 0 \\
\hline $\begin{array}{c}\text { Applicant's Teaching Skills } \\
\text { (17) }\end{array}$ & 0 & 0 & 0 & 0 & 0 \\
\hline $\begin{array}{l}\text { Applicant's Willingness to } \\
\text { Give Extra Effort/Go Above } \\
\text { and Beyond (18) }\end{array}$ & 0 & 0 & 0 & 0 & 0 \\
\hline
\end{tabular}




\begin{tabular}{|c|c|c|c|c|c|}
\hline $\begin{array}{l}\text { Applicant's Commitment to } \\
\text { Professional Development } \\
\text { (19) }\end{array}$ & 0 & 0 & O & O & $\mathrm{O}$ \\
\hline $\begin{array}{l}\text { Applicant's High Expectation } \\
\text { of Students (20) }\end{array}$ & $\mathrm{O}$ & 0 & O & $\mathrm{O}$ & $\mathrm{O}$ \\
\hline $\begin{array}{l}\text { Applicant's Previous Exposure } \\
\text { to Diversity (21) }\end{array}$ & O & O & O & O & 0 \\
\hline $\begin{array}{l}\text { Applicant's Technological } \\
\text { Proficiency (22) }\end{array}$ & $\mathrm{O}$ & O & $\mathrm{O}$ & $\mathrm{O}$ & $\mathrm{O}$ \\
\hline Applicant's Flexibility (23) & $\mathrm{O}$ & $\mathrm{O}$ & $\mathrm{O}$ & $\mathrm{O}$ & $\mathrm{O}$ \\
\hline $\begin{array}{l}\text { Applicant's Classroom } \\
\text { Management Skills (24) }\end{array}$ & 0 & 0 & 0 & 0 & 0 \\
\hline $\begin{array}{l}\text { Applicant is a Positive Role } \\
\text { Model for Students (25) }\end{array}$ & $\mathrm{O}$ & 0 & O & $\mathrm{O}$ & $\mathrm{O}$ \\
\hline $\begin{array}{l}\text { Applicant's Teaching } \\
\text { Philosophy (26) }\end{array}$ & $\mathrm{O}$ & O & O & $\mathrm{O}$ & $\mathrm{O}$ \\
\hline $\begin{array}{l}\text { Applicant's Ability to Raise } \\
\text { Student Test Scores (27) }\end{array}$ & 0 & O & O & $\mathrm{O}$ & $\mathrm{O}$ \\
\hline $\begin{array}{l}\text { Applicant's Ability to Increase } \\
\text { Student Achievement Beyond } \\
\text { Standardized Tests (28) }\end{array}$ & $\mathrm{O}$ & $\mathrm{O}$ & O & $\mathrm{O}$ & $\mathrm{O}$ \\
\hline Applicant's Race (29) & $\mathrm{O}$ & $\mathrm{O}$ & $\mathrm{O}$ & $\mathrm{O}$ & $\mathrm{O}$ \\
\hline Applicant's Gender (31) & $\mathrm{O}$ & O & O & O & 0 \\
\hline $\begin{array}{c}\text { Applicant's Place of Resident } \\
\text { (Distance from School with a } \\
\text { Vacancy) (32) }\end{array}$ & 0 & 0 & 0 & O & $\mathrm{O}$ \\
\hline
\end{tabular}




\section{APPENDIX B}

\section{Data Collection Communications}

\section{Initial phone call to Superintendent of target district:}

Greeting and Introduction -- background (10 years as BCPS supt., working to finish doctorate, need the help of fellow supt.) Purpose of Research -- There is little research looking at the preferences that principals look for when selecting teachers, or if what they do look for are the things that make a difference in student achievement. The study I am doing will help narrow down those preferences of principals and assistant principals working in districts surrounding Kentucky urban areas and determine if there are differences in preferences based on the school demographic and background of the principal.

I Need your help -- We know that administrators are more likely to find something important if the superintendent finds it important. In order to get enough responses to have valid results, I need your help and it won't take much of your time. I am asking you to copy some text I will provide into an email to all your principals and your assistant principals. Coming from you will make it more likely that they will respond, especially since it will take very little of their time. After five days, I'll send you some more text to copy into a second email to send to those who haven't already completed it. That will be all I ask of you.

Time it will take -- The entire survey will take less than 7 minutes to complete. It asks for some demographic data, including school number to gather performance and demographic information.

Share results -- Once this is finished, I will share the overall results with you, and you can share with the principals and assistant principals if you wish. There will be no personally identifiable information, so administrators are free to be completely honest in their responses.

If possible -- Can you ask your assistant to email me a list of your schools, along with the names of the principals and assistant principals at each school? It will help me cross check my data.

Follow-up -- I'll follow this call up with an email shortly going over what we discussed and including the text and link that you can copy and paste into an email to your school administrators. 


\section{Written follow up with the Superintendent of target district:}

Dear

It was great talking to you today and I appreciate your willingness to assist me in gathering data for my dissertation study. Here is a recap of our conversation and below that in red bold type is the text to copy and paste in an email to your school administrators:

Purpose of Research -- There is little research looking at the preferences that principals look for when selecting teachers, or if what they do look for are the things that make a difference in student achievement. The study I am doing will help narrow down those preferences of principals and assistant principals working in districts surrounding Kentucky urban areas and determine if there are differences in preferences based on the school demographic and background of the principal.

Your Role -- Encourage your administrators to complete the short survey at the link enclosed by copying the text provided below into an email to all your principals and your assistant principals. In five days, I'll send you some more text to copy into a second email to send to those who haven't already completed it. Finally, please ask your administrative assistant to email me a list of your schools, along with the principals and assistant principals of each one..

Time it will take -- The entire survey will take less than 7 minutes to complete. It asks for some demographic data, including school number to gather performance and demographic information.

Share results -- Once this is finished, I will share the overall results with you, and you can share with the principals and assistant principals if you wish. There will be no personally identifiable information, so administrators are free to be completely honest in their responses.

Dear Principal or Assistant Principal,

One of our colleagues, Keith Davis, who is superintendent of Bullitt County Schools, is conducting a study for his dissertation regarding the school leaders' preferences for teacher applicant characteristics. He selected our district, along with 11 other districts, because our district lies adjacent to an urban district. With so few districts, it is important to get as high a response rate as possible. The link below is to a survey that will take 5-7 minutes and asks for some demographic information along with your preferences regarding personal and professional attributes you seek when hiring teachers. Please take the time now to complete this survey, either at your computer or on your phone. Once the research is complete, Keith will share the results with all of us, though none of the results will contain any identifying data. Thanks you for your help on this.

\section{$\underline{\text { LINK TO SURVEY }}$}

Sincerely, 
Your Name Here

\section{Email direct to participants the next day, repeating request and expressing appreciation for those already completed:}

Dear Colleague,

I am following up on the email that your superintendent sent you yesterday regarding the survey research I am conducting for my dissertation. I want to thank those of you who have already completed it, and beg the rest of you to take 5-7 minutes to complete it now. Aside from the importance to me personally, I do believe that this area of research is one that is rich with opportunities to help us better identify teachers who are more able to effectively help students learn. I realize this time of year is busy (when isn't it?), but there is no better time to consider your personal preferences regarding teacher applicant characteristics than now, when most of you are in the thick of staffing vacancies in your schools.

Here is the link again, and I assure you that any personally identifiable information will never be divulged. The results, which I am happy to share with you when the study is complete, will be reported only in aggregate with neither the school nor district identified.

Thanks again for your help. I really appreciate it, and thank you for all you do for your school and students.

\section{LINK TO SURVEY}

Keith

\section{Second email through superintendent five days later}

Dear Principals and Assistant Principals,

A few days ago, I sent you a note regarding a survey related to some research being conducted by our colleague Keith Davis, who is superintendent of Bullitt County Schools. As of this morning, you haven't yet completed the survey. I know you are busy and may have been on vacation, but I urge you to take 5-7 minutes to complete the survey now. Thanks very much.

\section{$\underline{\text { LINK TO SURVEY }}$}

Sincerely,

Superintendent 


\section{Ten days later - a final direct email follow-up}

Dear Colleague,

Good morning. I haven't yet received your response to the survey regarding school

leaders' preferences for teacher applicant characteristics. Your response is vital to having enough data to meet the statistical requirement of the data analysis. I humbly request that you now take 5-7 minutes to complete the survey that you will find at the link below. Thank you so much for your help.

\section{LINK TO SURVEY}

Sincerely,

Keith 


\section{APPENDIX C}

\section{Principal Components \& Random Normal Data Generation}

Raw Data Eigenvalues, \& Mean \& Percentile Random Data Eigenvalues

$\begin{array}{crrr}\text { Root } & \text { Raw Data } & \text { Means } & \text { Prentyle } \\ & & & \\ 1.000000 & 6.225998 & 1.801832 & 1.911468 \\ 2.000000 & 2.893961 & 1.688158 & 1.768329 \\ 3.000000 & 2.589180 & 1.601086 & 1.666583 \\ 4.000000 & 1.607244 & 1.529494 & 1.590731 \\ 5.000000 & 1.259695 & 1.464620 & 1.520728 \\ 6.000000 & 1.177306 & 1.404567 & 1.454663 \\ 7.000000 & 1.168192 & 1.349047 & 1.393958 \\ 8.000000 & 1.081901 & 1.297307 & 1.341141 \\ 9.000000 & 1.035615 & 1.248963 & 1.289598 \\ 10.000000 & .954355 & 1.202799 & 1.242053 \\ 11.000000 & .933137 & 1.158090 & 1.198407 \\ 12.000000 & .871998 & 1.116148 & 1.154444 \\ 13.000000 & .826337 & 1.072978 & 1.109038 \\ 14.000000 & .768129 & 1.032137 & 1.068298 \\ 15.000000 & .756429 & .992146 & 1.026569 \\ 16.000000 & .663055 & .954623 & .988414 \\ 17.000000 & .639541 & .917819 & .952461 \\ 18.000000 & .605583 & .881653 & .916513 \\ 19.000000 & .557151 & .845302 & .878753 \\ 20.000000 & .523594 & .810395 & .844562 \\ 21.000000 & .504943 & .775516 & .808102 \\ 22.000000 & .471495 & .741110 & .772833 \\ 23.000000 & .454932 & .706812 & .740393 \\ 24.000000 & .399220 & .673389 & .705112 \\ 25.000000 & .392017 & .640314 & .672285 \\ 26.000000 & .384749 & .606177 & .640464 \\ 27.000000 & .327662 & .571563 & .604732 \\ 28.000000 & .302414 & .536783 & .570689 \\ 29.000000 & .270626 & .501919 & .537659 \\ 30.000000 & .249457 & .462108 & .497586\end{array}$




\begin{tabular}{llll}
31.000000 & .104082 & .415147 & .456908 \\
\hline
\end{tabular}

Scree Plot for Parallel Analysis

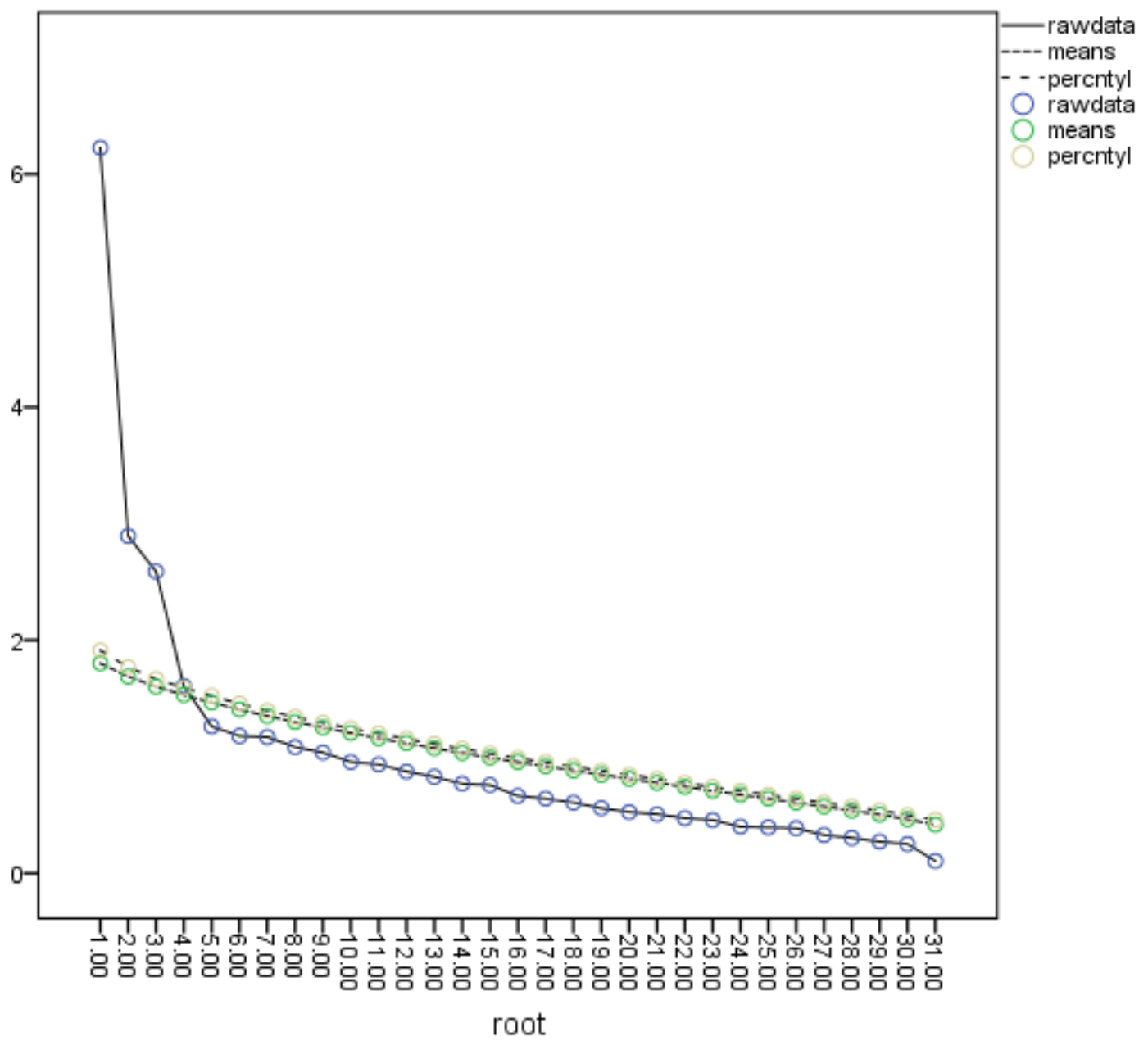




\section{APPENDIX D}

Assessment of four factors derived from Exploratory Factor Analysis

Tests of Normality using Shapiro-Wilk

\begin{tabular}{lccc} 
& Statistic & df & Sig \\
\hline Personal Characteristics & .940 & 209 & .000 \\
Professional Characteristics & .979 & 209 & .003 \\
Ancillary Characteristics & .978 & 209 & .003 \\
Demographic Characteristics & .807 & 209 & .000 \\
\hline
\end{tabular}

\section{Frequency Histograms}

Personal Characteristics

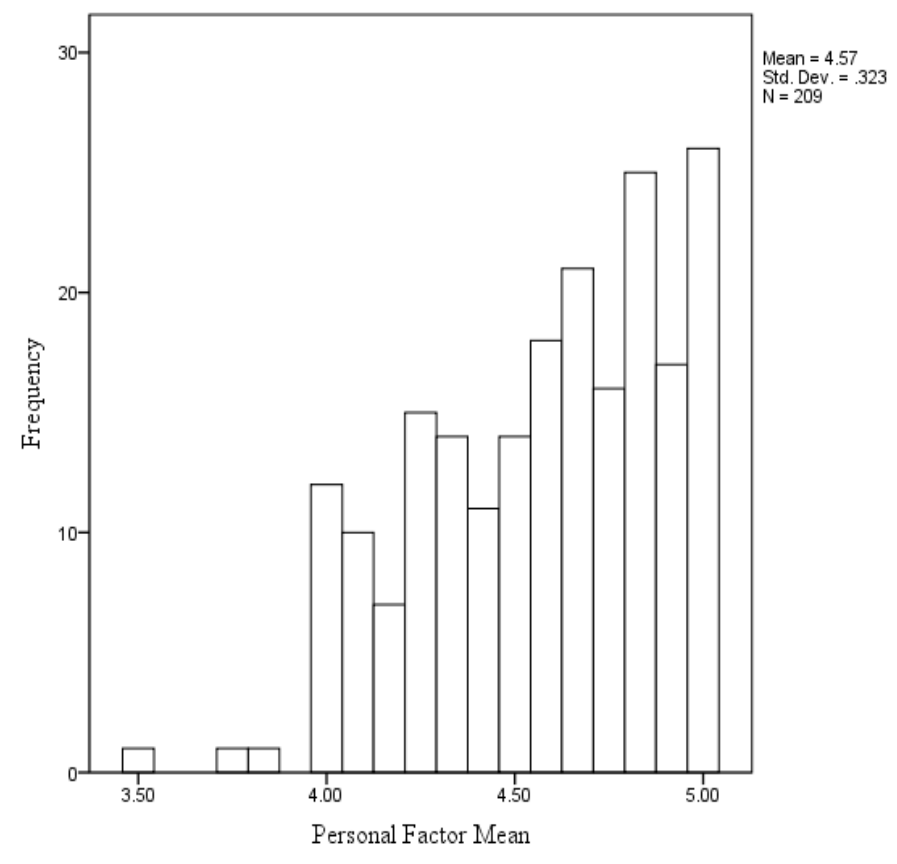




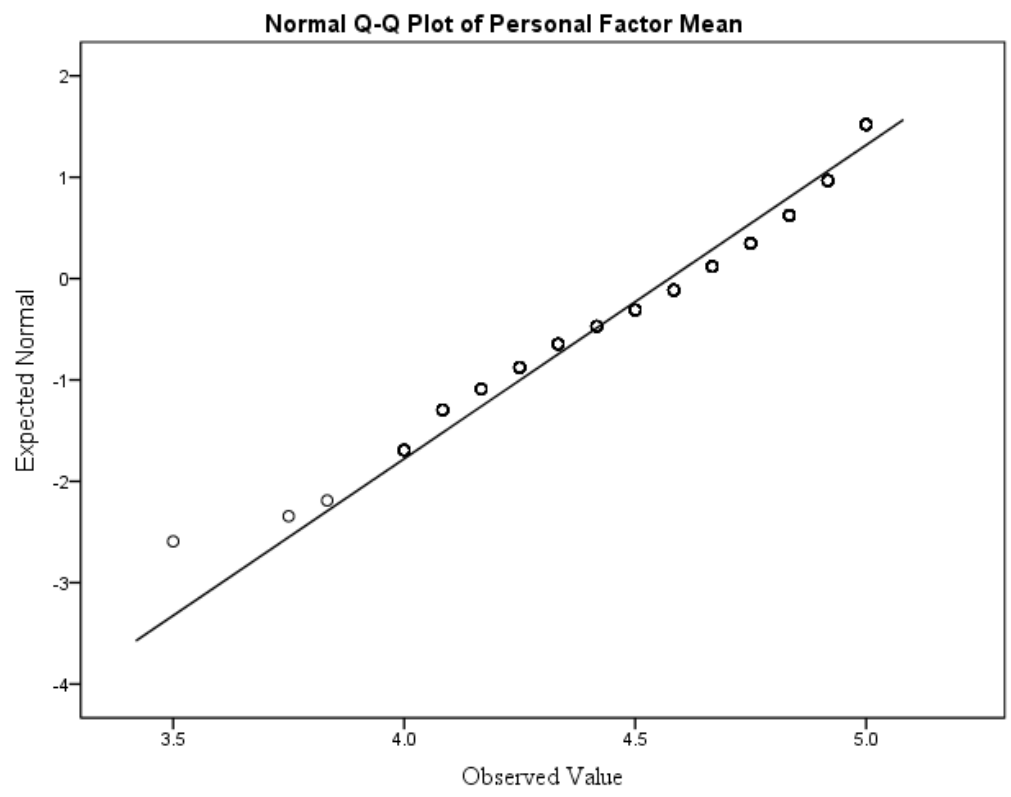

Professional Characteristics

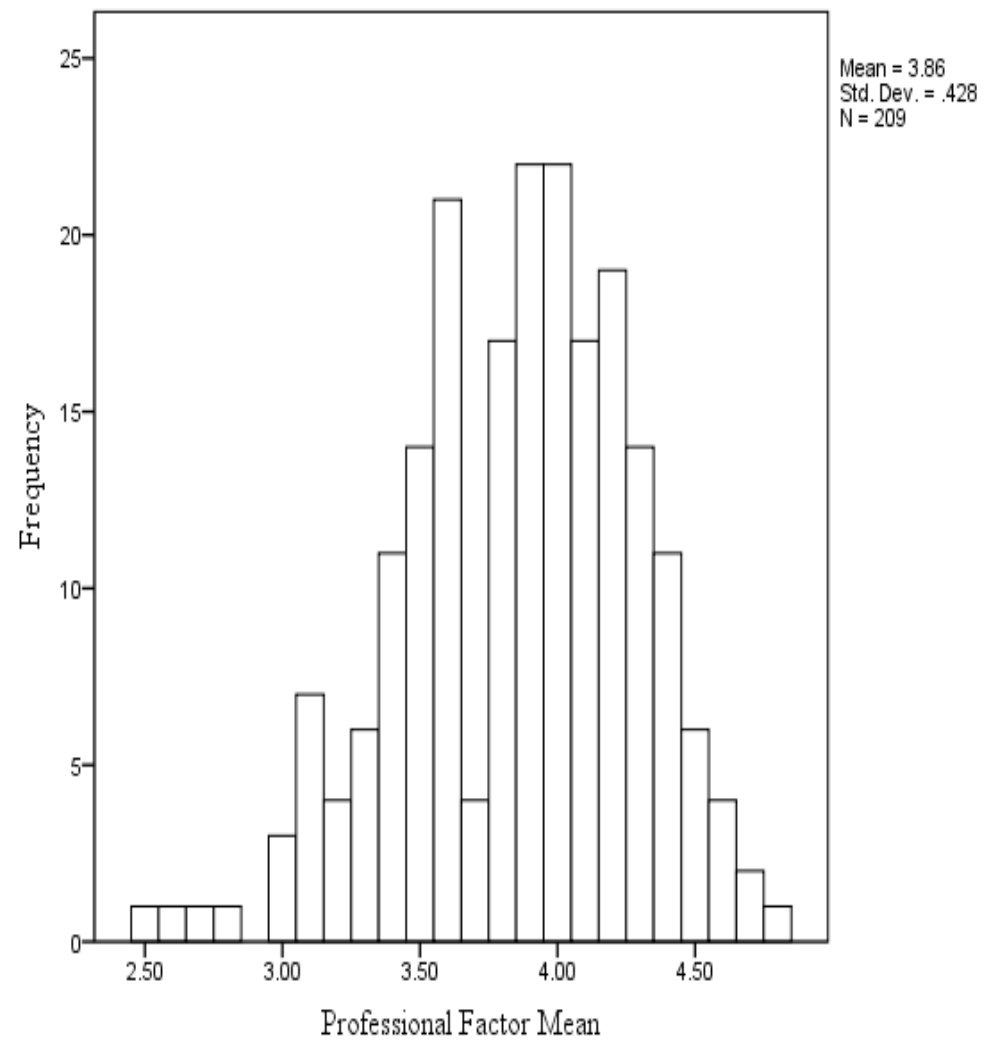




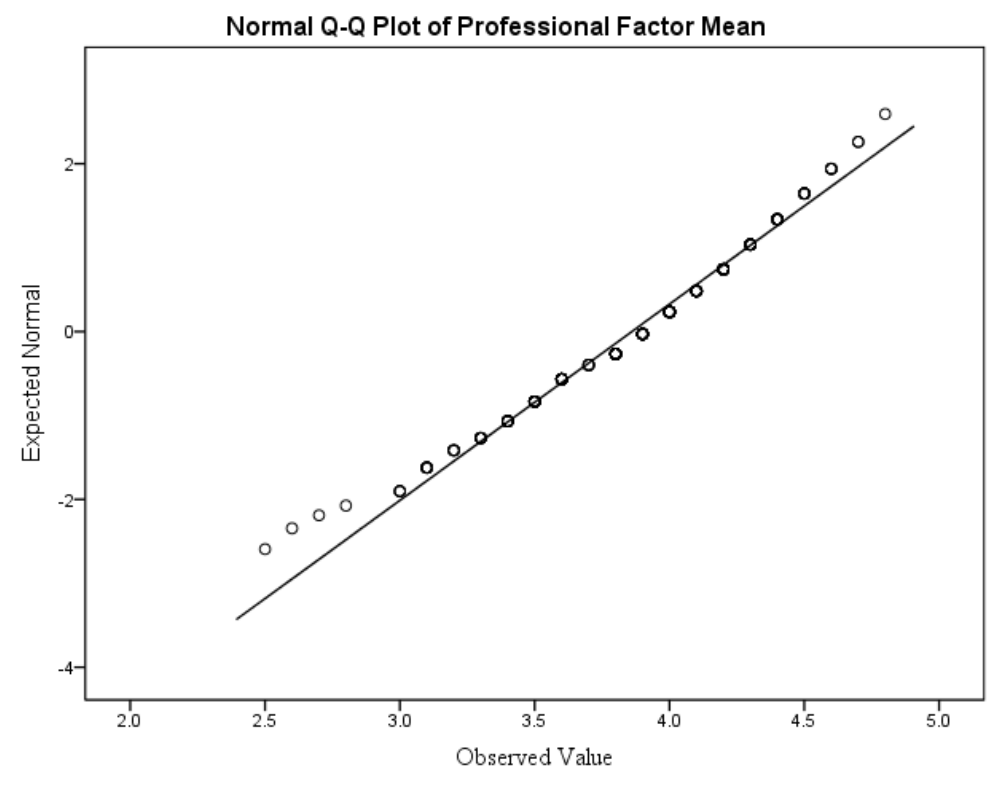

Ancillary Characteristics

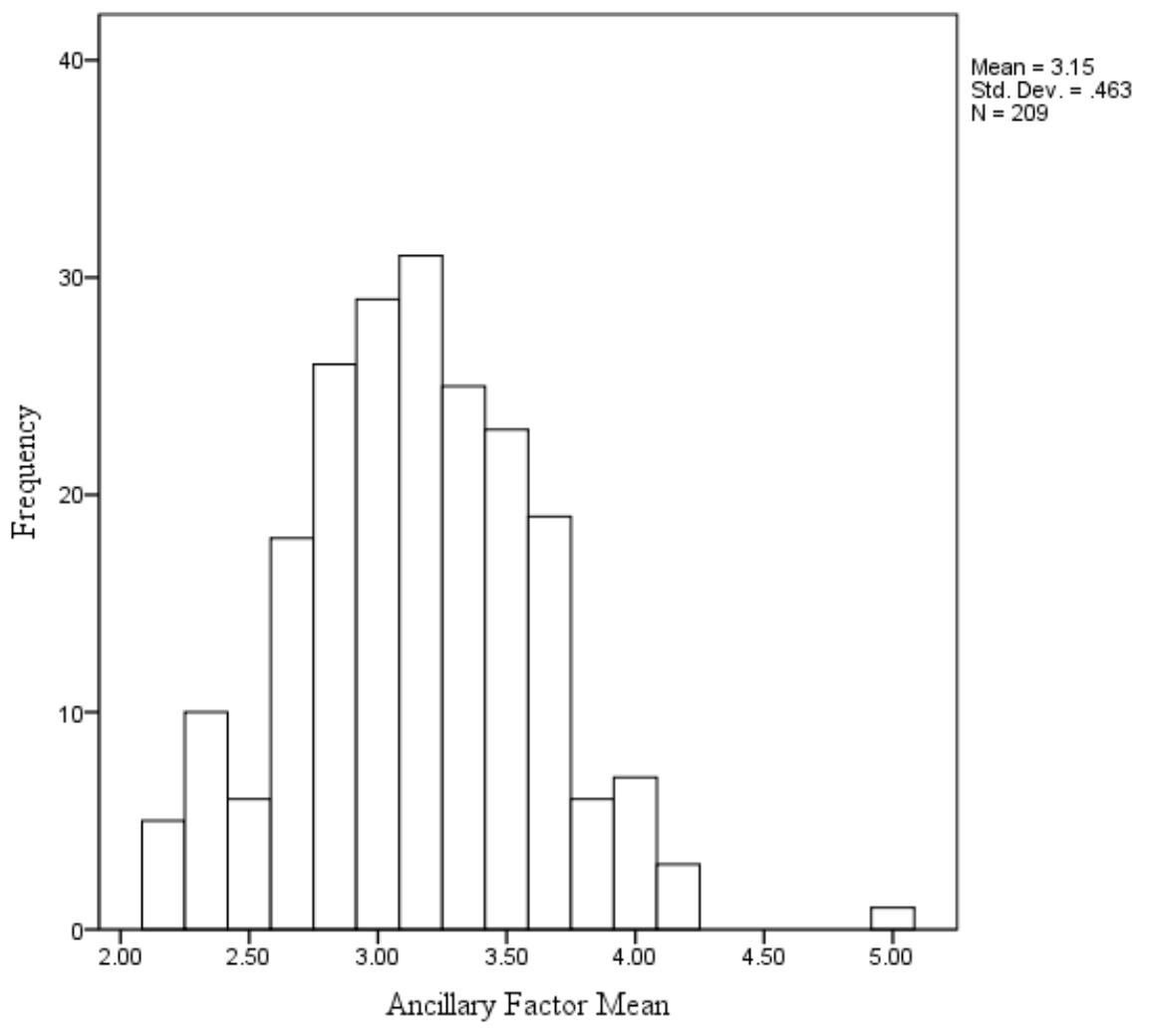




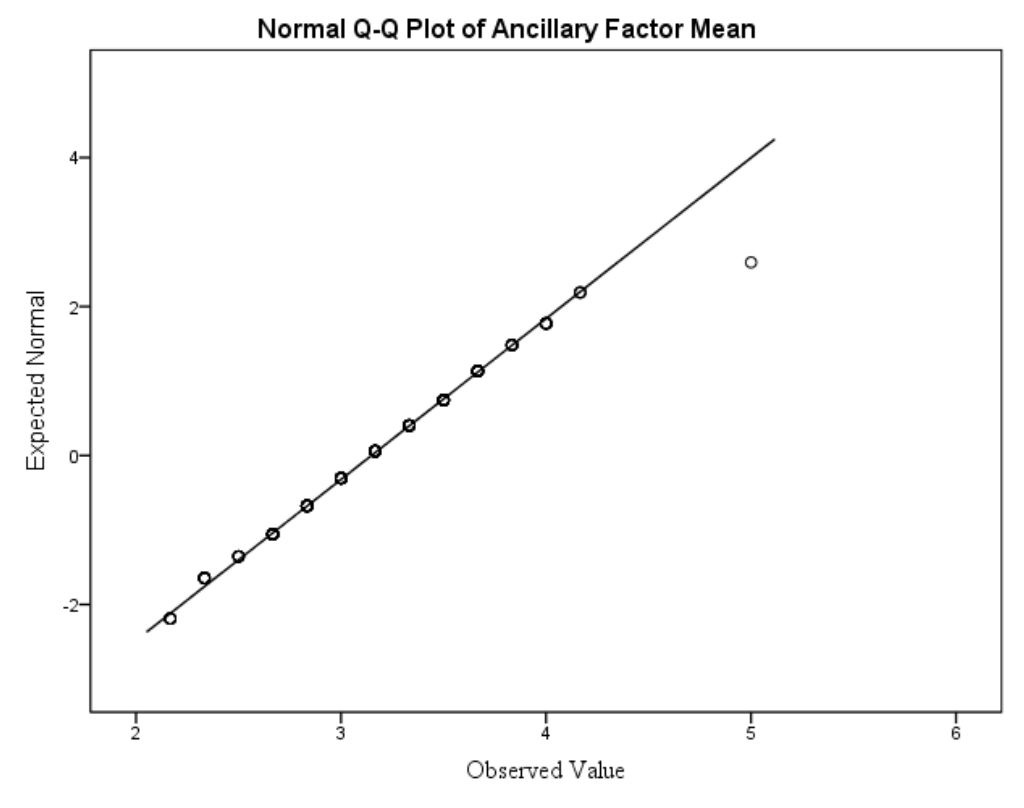

Demographic Characteristics

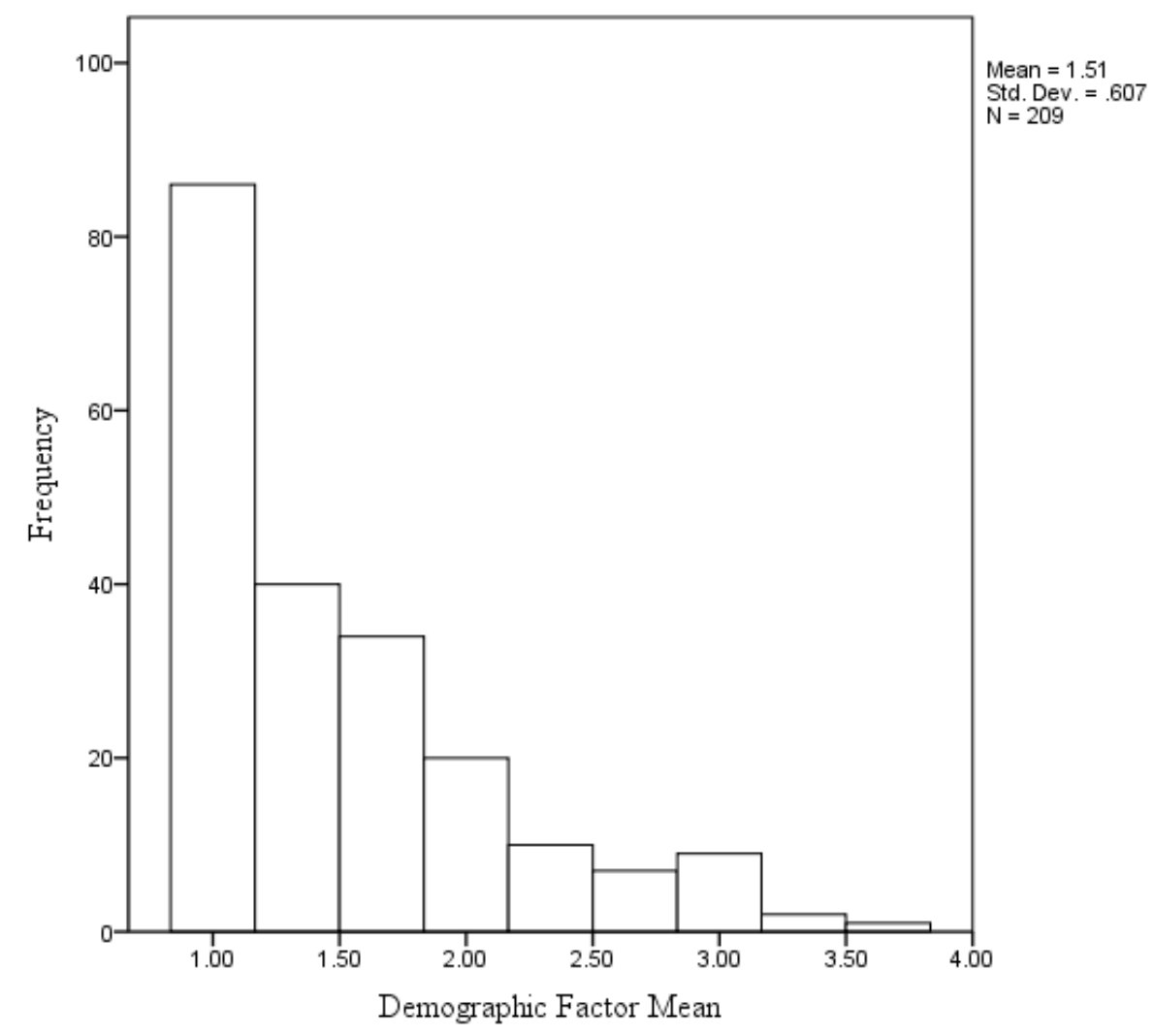




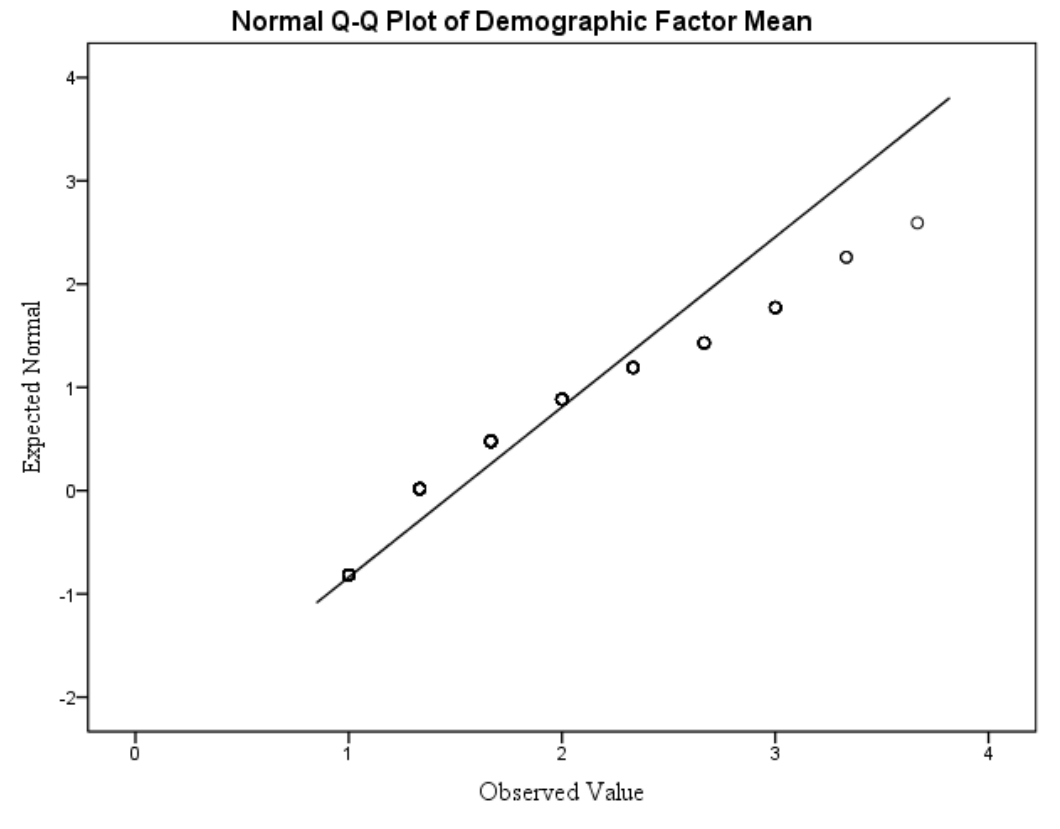




\section{Boxplots with outliers}

\section{Personal Characteristics}

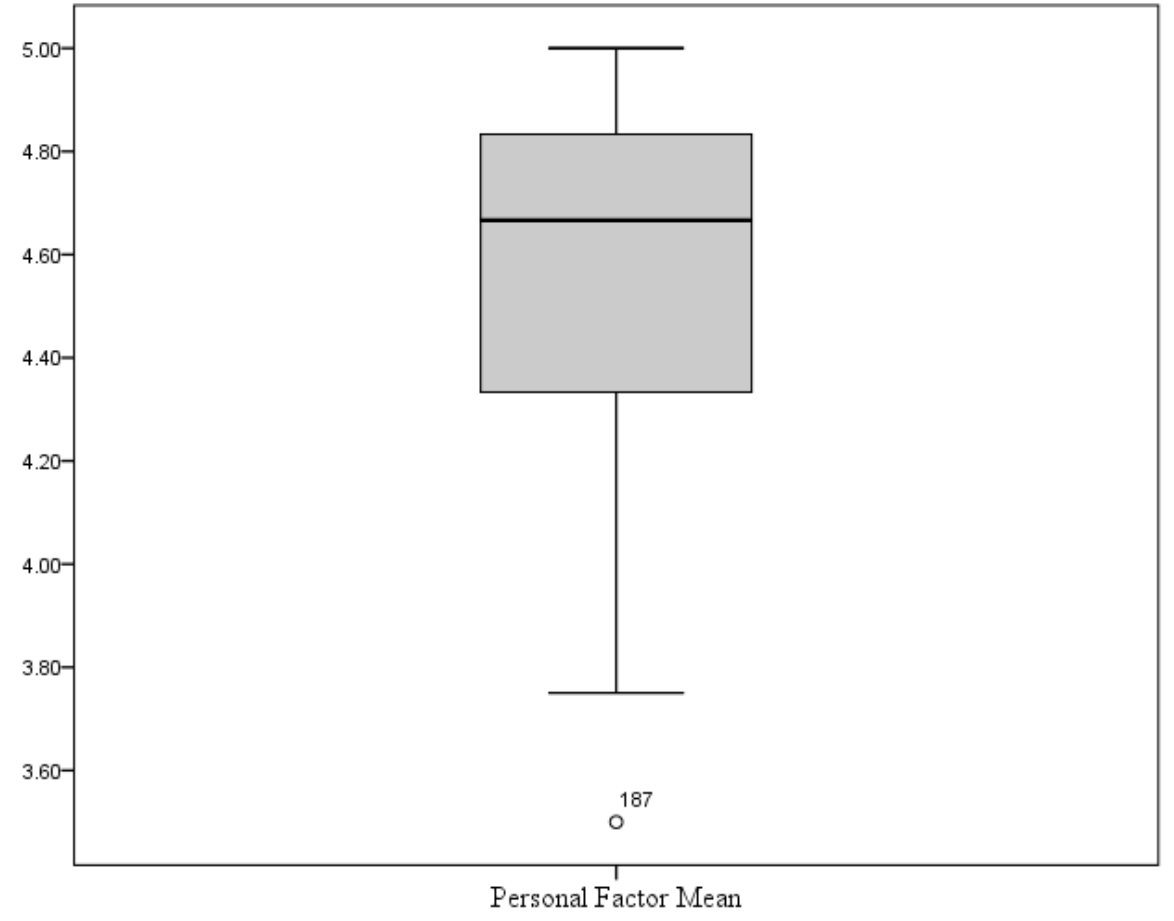

Professional Characteristics

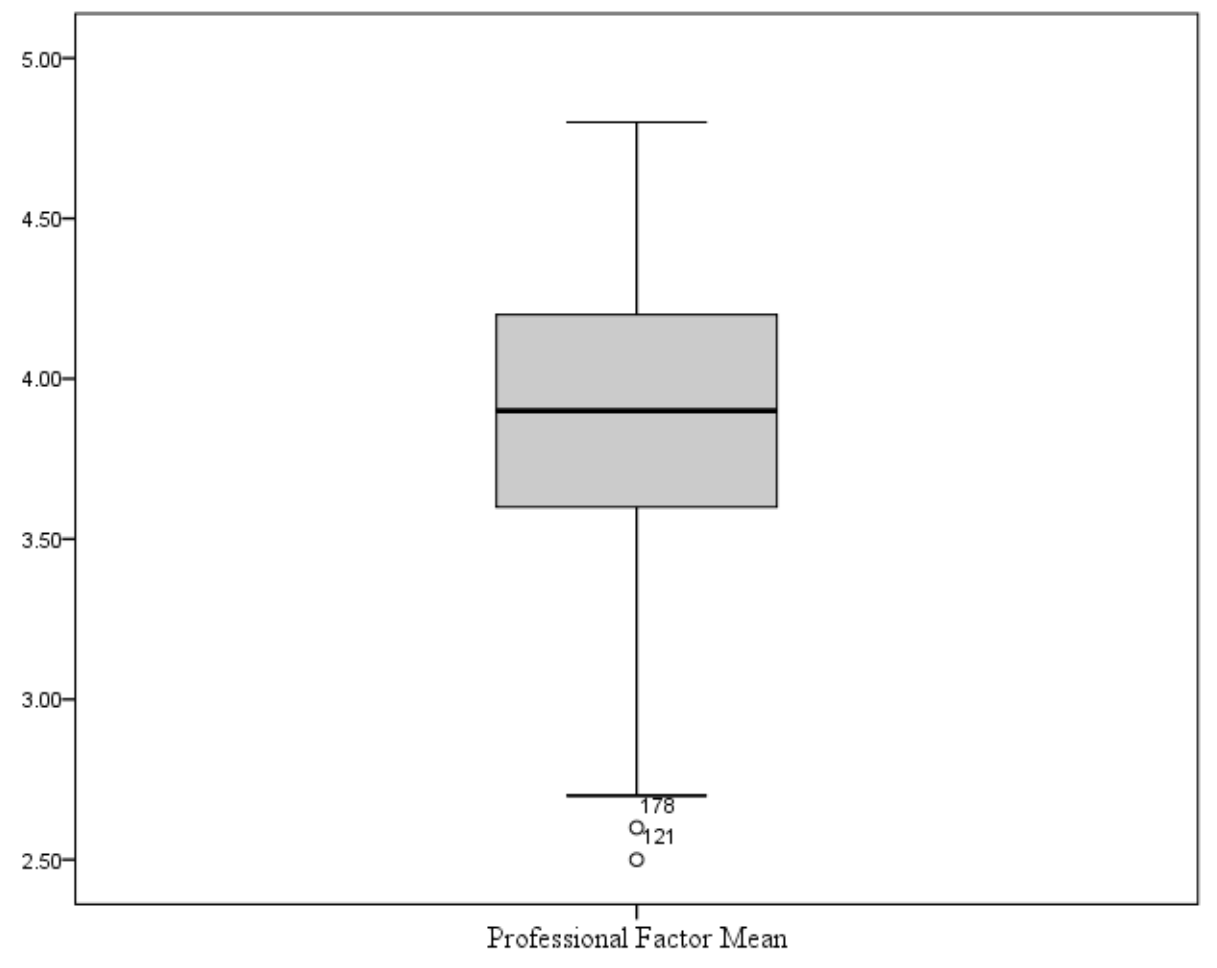


Ancillary Characteristics

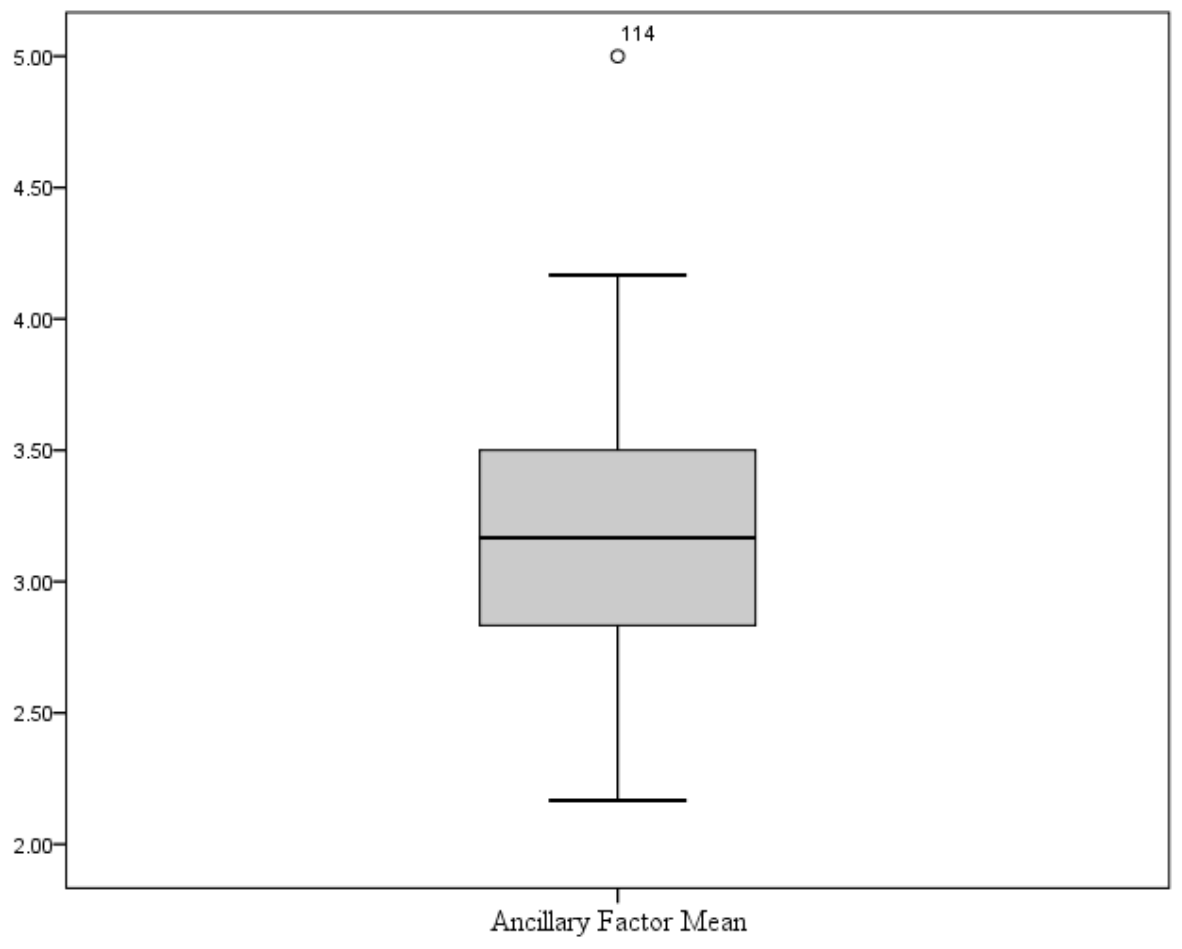

Demographic Characteristics

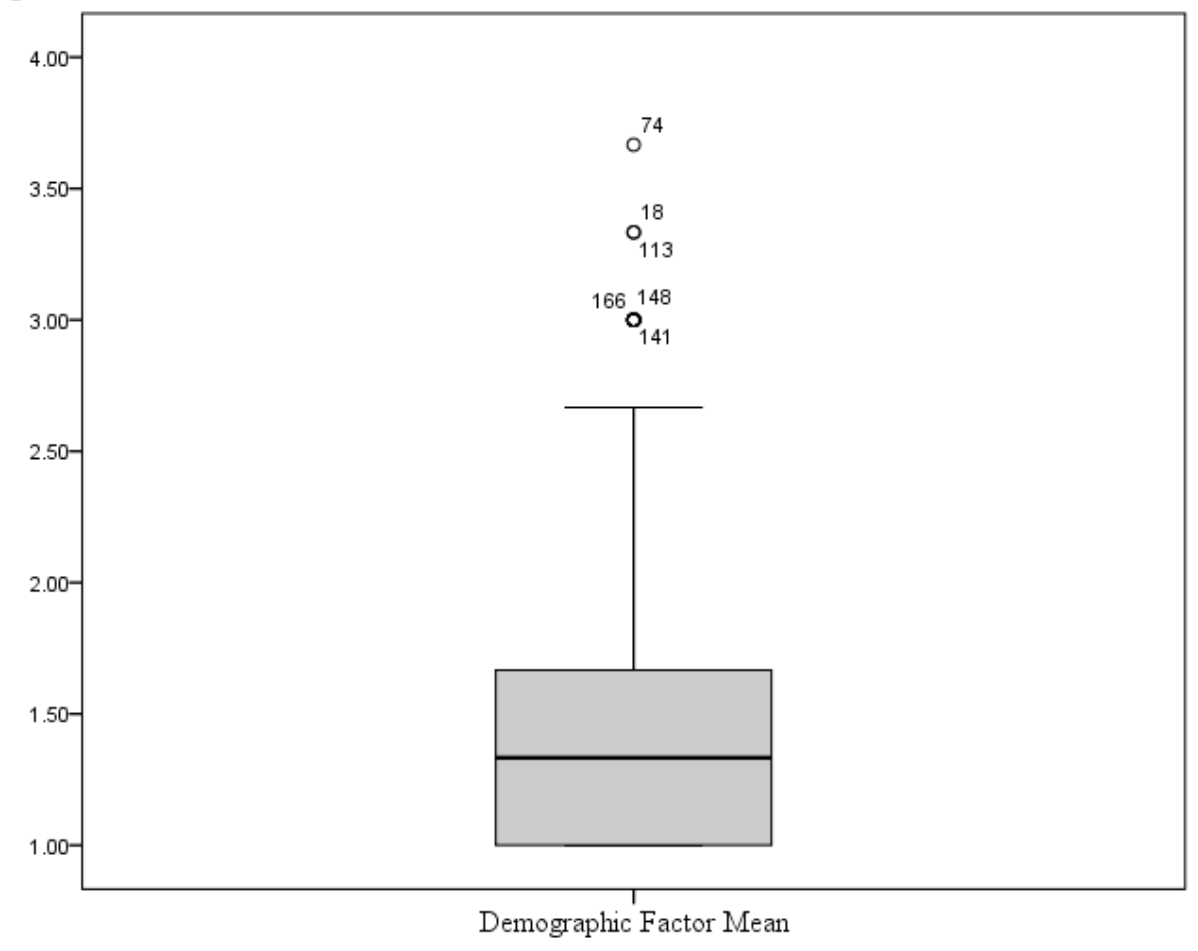


CURRICULUM VITA

\section{Keith Davis}

346 River Edge Drive

Shepherdsville, Kentucky 40165

Keithdavis1000@gmail.com

502-744-7500

\section{AREA OF SPECIALIZATION}

I am an effective, experienced, and dynamic school district leader, well versed in administration of the entire school district program. Major responsibilities include personnel supervision and evaluation, curricular leadership, student safety, budget development and administration, Board and community communication, development and implementation of various district improvement initiatives, and facility construction and maintenance.

\section{EDUCATION}

Doctor of Education

December, 2017

- Educational Leadership and Organizational Development University of Louisville Louisville, Kentucky

School Financial Management May, 2003

- Certificate - Gatton College of Business and Economics University of Kentucky

Lexington, Kentucky

Superintendent Certification

May, 2000

- Educational Leadership University of Louisville

Louisville, Kentucky

Rank I and Certification August, 1994

- Middle School Principalship. Western Kentucky University

Bowling Green, Kentucky

Master of Arts in Education August, 1991

- Middle Grades Education. Western Kentucky University

Bowling Green, Kentucky 
Bachelor of Science

May, 1990

- Middle Grades Education (Mathematics and Social Studies)

Western Kentucky University Bowling Green, Kentucky

\section{LICENSURE \& ENDORSEMENTS}

- Professional Certificate for Instructional Leadership - School Superintendent

- Professional Certificate for Instructional Leadership - Middle Grade School Principal

- Middle School Teaching Field: Mathematics

- Middle School Teaching Field: Social Studies

\section{EMPLOYMENT}

\section{Superintendent}

Bullitt County Public Schools
July, 2007 to July, 2018

Shepherdsville, Kentucky

- Fully responsible for the operational success of the $7^{\text {th }}$ largest school district in Kentucky

- From 2007 to present, our scores on state assessment system moved from the $21^{\text {st }}$ percentile to Proficient the last four cycles. College/Career Readiness percentage will top $90 \%$ for 2017 . We have accomplished similar results on other metrics of academic achievement

- Implemented a successful communication program including a weekly Board Update, district web presence, Infinite Campus parent portal and messenger, e-newsletters, monthly editorial columns, District Assembly, teacher web pages, Facebook, \& physical and virtual suggestion boxes

- Focused district work around student learning by implementing Leadership Team Meetings, Professional Learning Communities, Teacher Work Days, Leadership Training week, and focus on student learning data

- Focused attention on high ability learners by creating Bullitt Advanced Math \& Science Program, the 12X12 dual credit program, the College Credit Advanced Placement program, a STEM-focused middle school Discovery School program, strongly promoted Gatton Academy and Craft Academy for Math and Science, and reformed the Gifted \& Talented Program

- Revamped the Bullitt Alternative Center, created the Career Readiness Center, increased career pathways and alignment at the high schools, and made college or career readiness a requirement for graduation

- Instituted a coordinated response to intervention program using longitudinal district-wide student data, including norm referenced assessments and school administered common assessments

- Successfully completed construction of 3 new elementary schools and complete renovations at 8 other schools, major additions at 3 high schools, as well as the state's largest-to-date single contract Energy Performance Contract, cosmetic renovations at the Area Technical Center, and complete reconstruction of 3 track and field facilities 
Assistant Superintendent

Business Administration \& Finance

Bullitt County Public Schools
July, 2000 to July, 2007

Shepherdsville, Kentucky

- Strictly managed a budget in excess of $\$ 90$ million, increasing reserves from emergency levels to satisfactory levels in four years

- Ensured timely payment of salaries and outstanding invoices

- Responsible to Superintendent for financial position of the school district

- Compliance with statutes and regulations

- Evaluation of Directors, Principals, and classified Support Staff

- Advised Superintendent and Board on a wide range of issues as requested

- Served on District Improvement Planning Committee, Energy Committee, Facilities Planning Committee, Contract Negotiating Committee

\section{Principal}

Hebron Middle School
August, 1999 to July, 2000

Shepherdsville, Kentucky

- Personnel supervision and evaluation - Observe and evaluate over 60 certified and classified staff members

- Budget development and administration - Develop and administer school SBDM budget, internal accounts, funds for textbooks, extended school services, professional development, title VI, and vocational funds

- Scheduling and management of school activities - Develop master school schedule and schedules for lunch, athletics, programs, field trips, and innumerable day to day activities

- Curricular leadership - Review and provide feedback on all lesson plans, provide leadership in the implementations of Accelerated Reader program, the "Hebron Canon," and the Advisory Program, and provide information on research-based practices to aid teachers in curricular improvement

- School improvement planning - Provide for the completion of the consolidated school improvement plan, lead review and analysis of assessment results, provide structure and guidance to the school's current improvement efforts, and developing a structure and forum for on-going content area improvement

- Addressing concerns - Constantly consulting and assisting in the solution of every imaginable problem that arises from the day-to-day operation of a school serving over 700 early adolescents, their parents, and community

Assistant Principal

Hebron Middle School
April, 1996 to August, 1999

Shepherdsville, Kentucky

- Special Education - SBARC Chairman, scheduling, and administration

- School supervision and discipline - Maintenance of school environment conducive to proper learning. Management of office referrals, In School Alternative Program, detention, and juvenile court interventions

- Textbooks - Assembling textbook committee, completing textbook purchasing plan, budgeting, inventory, distribution, and fine collection 
- Attendance - Formulation and implementation of attendance plan, attendance incentive program, and truancy referrals

- School Technology - School Technology Committee Chairman, preparation of school technology plan, and assembly and maintenance of computers and printers

Teacher

Butler County Middle School
December, 1991 to March, 1996

Morgantown, Kentucky

- Teacher of 8 in grade Mathematics and U.S. History

- Team Leader - Scheduling, discipline, and management of team

- Girls Basketball Coach

- Chess Team Coach

- Academic Team Coach

- Member, Site-Based Decision Making Council

\section{SERVICE}

- Bullitt County Court Appointed Special Advocates (CASA) - Board of Directors 2017Present

- Kentucky Association of School Superintendents - Legislative Committee 2016- Present

- National Air \& Space Education Institute - Board of Directors 2015 - 2016

- Ohio Valley Educational Cooperative Chairman 2012-2014

- Local Superintendents Advisory Council 2012-Present

- Bullitt County Chamber of Commerce - Board of Directors 2008-Present

- Kentucky Association of School Administrators Legislative affairs committee 2009-2011 \& 2014-2016

- Bullitt County YMCA - Steering Committee 2013-15

- Local Candidate Forum Committee - 2014-15

- Work Ready Communities Co-Chair - 2013-Present

- Advisory Committee - Bullitt County Metro United Way

- Kentucky Educational Professional Standards Board Task Force to Review Superintendent Preparation Programs 2012

- Kentucky School Boards Association Policy Committee 2009-Present

- University Medical Center Board of Directors 2008-2012

- Bullitt County Parks \& Recreation - Volunteer

- Jewish Hospital Community Advisory Board 2008-12

- Arla Education Foundation 2008-12

\section{PROFESSIONAL ASSOCIATIONS}

- Kentucky Association of School Administrators

- Kentucky Association of School Superintendents

- American Association of School Superintendents 


\section{HONORS}

- Community Change Agent Award, December 2017 - University of Louisville Department of Educational Leadership, Evaluation, and Organizational Development

- Barbara Cahoe Memorial Award 2017 - Bullitt County Chamber of Commerce

- Sergeant Darin Potter Leadership \& Citizenship Award 2017 - NBHS Army JROTC

- NAGC/Ball State Administrator Award 2015 - National Association for Gifted Children

- Service \& Advocacy Award 2013 - Kentucky Association for Gifted Education

- Dean's Award 2003 - Gatton College of Business and Economics

- Scottish Rite Fellowship for Doctoral Study

- Treasurer - Kentucky Middle School Association

- Summer Scholarship for School Administrators - Kentucky Association of School Administrators

- Historian \& Secretary - Phi Delta Kappa, Epsilon Kappa Chapter

\section{COURSES TAUGHT}

Bellarmine University

EDAD 711: Financial, Legal, and Ethical Responsibilities of the Principal - Summer 2016:

\section{PUBLICATIONS \& PRESENTATIONS}

- Bullitt County Public Schools' New Teacher Recruitment and Induction Program. Kentucky School Leader - Spring/Summer 2017

- Education Professional Standards Board -Testimony to Amend Regulation on Career \& Technical Education Certification (with Education Commissioner and Secretary of Workforce Development - April 12, 2017

- Kentucky Association of Gifted Education - Panel Presentation on Gifted Programs February 27, 2017

- KentuckianaWorks Board Presentation - College/Career Readiness in Bullitt County Schools - November 17, 2016

- LEAD Greater Louisville Inc. - October 12, 2015 - Vision, Progress, and Challenges for Bullitt County Schools

- Bullitt East High School - November 24, 2015 -- School of Distinction Ceremony Remarks to Student Body

- Institute of School Finance - March 2013 -- Top 10 Things a New Superintendent Should know about School Finance 